\title{
Capsaicin Exerts Therapeutic Effects by targeting tNOX-SIRT1 Axis and Augmenting ROS-Dependent Cytotoxic Autophagy in Melanoma Cancer Cells
}

\author{
Atikul Islam \\ National Chung Hsing University \\ Pei-Fang Hsieh \\ National Chung Hsing University \\ Jou-Chun Chou \\ National Chung Hsing University \\ Jiunn-Wang Liao \\ National Chung Hsing University \\ Ming-Kun Hsieh \\ National Chung Hsing University \\ Pin Ju Chueh ( $\square$ pjchueh@dragon.nchu.edu.tw) \\ National Chung Hsing University https://orcid.org/0000-0002-3200-7552
}

\section{Research}

Keywords: Autophagy, Melanoma, p53, Tumor-associated NADH oxidase (tNOX or ENOX2), Sirtuin 1 (SIRT1), c-Myc, Protein acetylation, Reactive oxygen species (ROS)

Posted Date: December 9th, 2020

DOl: https://doi.org/10.21203/rs.3.rs-117713/v1

License: (c) (i) This work is licensed under a Creative Commons Attribution 4.0 International License. Read Full License 


\section{Abstract}

Background: Although considered a rare form of skin cancer, malignant melanoma has steadily increased internationally and is a main cause of cancer-associated death worldwide. The treatment options for malignant melanoma are very limited. Accumulating data suggest that the natural compound, capsaicin, exhibits preferential anticancer properties to act as a nutraceutical agent. Here, we explored the underlying molecular events involved in the inhibitory effects of capsaicin on the growth of melanoma cells.

Methods: The cellular thermal shift assay (CETSA) and isothermal dose response fingerprint (ITDRF $\left.{ }_{\text {CETSA }}\right)$ were utilized to validate the binding of capsaicin with the tumor-associated NADH oxidase, tNOX (ENOX2) in melanoma cells. We also assessed the cellular impact of capsaicin-targeting of tNOX on A375 cells by flow cytometry and protein analysis. The essential role of tNOX in tumor- and melanoma-growth limiting abilities of capsaicin was evaluated in C57BL/6 mice.

Results: Our data show that capsaicin directly targets cellular tNOX to inhibit its enzymatic activity and enhance protein degradation capacity. The inhibition of tNOX by capsaicin is accompanied by the attenuation of SIRT1, a NAD ${ }^{+}$-dependent deacetylase that enhances ULK1 acetylation to induce ROSdependent autophagy in melanoma cells. Capsaicin treatment of mice implanted with melanoma cancer cells suppressed tumor growth by down-regulating INOX and SIRT1, which was also seen in an in vivo xenograft study with tNOX-depleted melanoma cells.

Conclusions: Together, our findings suggest that tNOX expression is important for the growth of melanoma cancer cells both in vitro and in vivo, and that inhibition of the INOX-SIRT1 axis contributes to inducting cytotoxic ROS-dependent autophagy in melanoma cells.

\section{Background}

Malignant melanoma accounts for approximately $5 \%$ of skin cancers; however, its high metastatic potential means that it accounts for $>75 \%$ of all skin cancer deaths in the United States, with particularly high mortality seen in those diagnosed at a later stage [1, 2]. Unfortunately, acquired drug resistance largely restricts the efficacy of chemotherapy in melanoma, resulting in disease progression and a poor long-term survival rate [3-5]. Accumulated evidence demonstrates that phytochemicals, such as capsaicin (8-methyl-N-vanillyl-6-nonenamide; the active component in chili peppers), can exhibit superior toxicity toward cancer cells over non-cancerous cells and may offer benefits as nutraceutical agents [611]. Indeed, capsaicin has long been known to suppress the growth of human and mouse melanoma cells [12-17]. However, we current lack direct and physical evidence linking the specific target(s) of capsaicin to its superior cytotoxicity. Thus, it is worth investigating novel cellular target(s) for capsaicin that have therapeutic potential, and assessing the relevant mechanism(s) of action in melanoma.

In previous work, we explored the distinct cellular impacts of capsaicin in different systems and identified a tumor-associated NADH oxidase (tNOX; ENOX2) that is hormone- and growth factor-stimulated in non- 
cancerous cells but constitutively activated in transformed/cancer cells $[6,18]$. Given that tNOX is commonly expressed in cancer/transformed but not non-cancerous cells, its downregulation has become an important premise to explain the preferential cytotoxicity of capsaicin toward cancerous cells, including those of human and mouse melanoma, breast, stomach, colon, lung, and bladder cancer [6, 12 , 19-23]. Importantly, by utilizing cell lines from human lung tissues, we learned that capsaicin suppresses tNOX activity/expression to reduce intracellular $\mathrm{NAD}^{+}$concentration and a NAD ${ }^{+}$-dependent SIRT1 deacetylase activity, leading to augmented p53 acetylation and apoptosis in lung cancer cells [22]. We also showed that, conversely, capsaicin increased the intracellular NAD ${ }^{+} / \mathrm{NADH}$ ratio and SIRT1 deacetylase activity, decreasing Atg 5 acetylation to trigger protective autophagy in MRC- 5 cells lacking tNOX expression [22]. In addition to programmed cell death, it appears that capsaicin also acts on cell migration, epithelial-mesenchymal transition (EMT), and cell cycle progression through inhibition of the tNOX-SIRT1 axis $[23,24]$.

In this present study, to demonstrate that capsaicin directly targets tNOX in melanoma cancer cells, we performed a cellular thermal shift assay (CETSA) and obtained isothermal dose-response fingerprint (ITDRFCETSA) curves. The basis for such techniques relies on the concept that a target protein will be heat-stable in the presence of its ligand compound [25-30]. We show that the interaction between capsaicin and tNOX resulted in tNOX degradation, which in turn triggered cytotoxic ROS-dependent autophagy in melanoma cells through enhanced ULK1 acetylation.

\section{Materials And Methods}

\section{Cell culture and reagents}

Capsaicin (purity $>95 \%$ ) was purchased from Sigma-Aldrich Corporation (St. Louis, MO, USA). The antiSIRT1, anti-Atg5, anti-p53, anti-acetyl-p53, anti-phosphorylated-p53, anti-phsophorylated Akt, anti-mTOR, anti-phosphorylated mTOR, anti-ULK1, anti-PARP, anti-Bak, anti-Bax, anti-caspase 8, anti-caspase 9, anticaspase 3, and anti-acetylated Lysine antibodies were purchased from Cell Signaling Technology, Inc. (Beverly, MA, USA). The anti-b-actin antibody was from Millipore Corp. (Temecula, CA, USA). The anti-Akt antibody was purchased from Santa Cruz Biotechnology, Inc. (Santa Cruz, CA, USA). The anti-p62 antibody was from BD Biosciences (San Jose, CA, USA). The anti-Beclin 1, anti-Atg7, and anti-LC3 antibodies were obtained from Novus biologicals (Centennial, CO, USA). The commercially available antiCOVA1 (a.k.a. tNOX, ENOX2) antibody from Proteintech (Rosemont, IL, USA) was used for immunoprecipitation. The antisera to tNOX used for immunoblotting were generated as described previously [31]. The anti-mouse and anti-rabbit IgG antibodies and other chemicals were purchased from the Sigma Chemical Company (St. Louis, MO, USA), unless otherwise specified.

B16F10 (mouse melanoma) and A375 (human melanoma) cells grown in Dulbecco's Modified Eagle Medium (DMEM), were purchased from the Bioresource Collection and Research Center (BCRC, Hsinchu, Taiwan). Media were supplemented with $10 \% \mathrm{FBS}, 100 \mathrm{units} / \mathrm{ml}$ penicillin and $50 \mu \mathrm{g} / \mathrm{ml}$ streptomycin. Cells were maintained at $37^{\circ} \mathrm{C}$ in a humidified atmosphere of $5 \% \mathrm{CO}_{2}$ in air, and the media were replaced 
every 2-3 days. Cells were treated with different concentrations of capsaicin (dissolved in ethanol), as described in the text, or with the same volume of ethanol (vehicle control).

tNOX short hairpin RNA was constructed in the pCDNA-HU6, kindly provided by Dr. J. T. Chang (Chung Shan Medical University) [32]. Two oligonucleotides (shRNA-F:

GATCCGAGGAAATTCGCAACATTCATTTCAAGAGAA and shRNA-R:

AGCTTAAAAAGAGGAAATTCGCAACATTCATTCTCTTGAAA) were synthesized, treated with T4 polynucleotide kinase (New England BioLabs, Ipswich, MA) and ligated to a pCDNA-HU6 vector. A set of scrambled oligonucleotides was used as negative control. Briefly, cells were seeded in 10-cm dishes, allowed to attach overnight, and then transfected with tNOX shRNA or control shRNA using the jet PEI transfection reagent (Polyplus-transfection SA, Illkirch Cedex, France), according to the manufacturer's instructions.

Continuous monitoring of cell growth by cell impedance measurements

For continuous monitoring of changes in cell growth, cells $\left(10^{4}\right.$ cells/well) were seeded onto E-plates and incubated for $30 \mathrm{~min}$ at room temperature, after which E-plates were placed onto the xCELLigence System (Roche, Mannhein, Germany). Cells were grown overnight before exposed to capsaicin or ethanol and impedance was measured every hour, as previously described [22]. Cell impedance is defined by the cell index $(\mathrm{Cl})=\left(\mathrm{Z}_{\mathrm{i}}-\mathrm{Z}_{0}\right)[\mathrm{Ohm}] / 15[\mathrm{Ohm}]$, where $\mathrm{Z}_{0}$ is background resistance and $\mathrm{Z}_{\mathrm{i}}$ is the resistance at an individual time point. A normalized cell index was determined as the cell index at a certain time point $\left(\mathrm{Cl}_{\mathrm{ti}}\right)$ divided by the cell index at the normalization time point $\left(\mathrm{Cl}_{\text {nml_time }}\right)$.

\section{Cell viability assay}

Cells $\left(5 \times 10^{3}\right)$ were seeded in 96 -well culture plates and permitted to adhere overnight at $37^{\circ} \mathrm{C}$ in medium containing $10 \%$ serum. Cells were then treated with different concentrations of capsaicin for $24,48,72$ hours, and at the end of treatment, cell viability was determined using a rapid, MTS-based colorimetric assay (CellTiter 96 cell proliferation assay kit; Promega, Madison, WI, USA) as described by the manufacturer. All experiments were performed at least in triplicate on three separate occasions. Data are presented as means \pm SDs.

\section{Colony-formation assay}

Two hundred cells were seeded onto a 6-cm dish and incubated in culture medium with different concentrations of capsaicin for 10 days to allow colony formation. After incubation, colonies were fixed in $1.25 \%$ glutaraldehyde at room temperature for 30 minutes, rinsed with distilled water and stained with a $0.05 \%$ methylene blue solution. The number of colonies was counted and recorded.

\section{Apoptosis determination}


Apoptosis was measured using an Annexin V-FITC Apoptosis Detection Kit (BD Pharmingen, San Jose, CA, USA). Cells cultured in 6-cm dishes were trypsinized and collected by centrifugation. The cell pellet was washed, resuspended in $1 \mathrm{x}$ binding buffer and stained with annexin V-FITC (fluorescein isothiocyanate), as recommended by the manufacturer. Cells were also stained with propidium iodide (PI) to detect necrosis or late apoptosis. The distribution of viable (FITC/PI double-negative), early apoptotic (FITC-positive), late apoptotic (FITC/PI double-positive) and necrotic (PI-positive/FITC-negative) cells was analyzed using a Beckman Coulter FC500 flow cytometer. The results are expressed as a percentage of total cells.

\section{Autophagy determination}

Autophagosomes-acidic intracellular compartments that mediate the degradation of cytoplasmic materials during autophagy -were visualized by staining with Acridine Orange (AO; Sigma Chemical $\mathrm{Co}$.). After incubation, cells were washed with PBS and stained with $2 \mathrm{mg} / \mathrm{ml} \mathrm{AO}$ for $10 \mathrm{~min}$ at $37^{\circ} \mathrm{C}$. AOstained cells were then washed, trypsinized, and analyzed using a Beckman Coulter FC500. The results are expressed as a percentage of total cells.

\section{Reverse transcriptase-polymerase chain reaction (RT-PCR)}

Total RNA from melanoma cancer cells was isolated using the TRIzol reagent (Gibco, Carlsbad, CA, USA). First strand cDNA was synthesized from $1 \mu \mathrm{g}$ of total RNA using Superscript II (Life Technologies, Rockville, MD, USA). The following primers sets were used for PCR amplifications: tNOX, 5'GAAGTGTGATGCCGATAACAG -3" (sense) and 5'-AGTACTAGAGCCCAGGCGAA-3' (antisense); SIRT1, 5'TGATTGGCACAGATCCTCGAA-3" (sense) and 5'-AAGTCTACAGCAAGGCGAGC-3' (antisense); and b-actin, 5'-ACTCACCTTGGTGGTGCATA-3' (sense) and 5'-ACACCTTGATGGGAAAGGTGG-3' (antisense). The reaction conditions consisted of $30 \mathrm{cycles}$ of $95^{\circ} \mathrm{C}$ for $30 \mathrm{sec}, 55^{\circ} \mathrm{C}$ for $30 \mathrm{sec}$, and $72^{\circ} \mathrm{C}$ for $1 \mathrm{~min}$, followed by a final extension of $5 \mathrm{~min}$ at $72^{\circ} \mathrm{C}$. The obtained PCR products were resolved by $1.4 \%$ agarose gels electrophoresis and visualized by ethidium bromide staining.

\section{Measurement of reactive oxygen species (ROS)}

Oxidative stress was determined by measuring the level of hydrogen peroxide $\left(\mathrm{H}_{2} \mathrm{O}_{2}\right)$ generated in the cells, as assessed by 5-(6)-carboxy-2',7'-dichlorodihydrofluorescein diacetate (carboxy- $\mathrm{H}_{2} \mathrm{DCFDA}$ ) staining. The nonpolar, nonionic $\mathrm{H}_{2}$-DCFDA is cell permeable and is hydrolyzed to nonfluorescent $\mathrm{H}_{2}$-DCF by intracellular esterases. In the presence of peroxide, $\mathrm{H}_{2}$-DCF is rapidly oxidized to highly fluorescent DCF. In brief, at the end of test compound treatment, cells $\left(2 \times 10^{5}\right)$ were washed with PBS and incubated with $5 \mathrm{mM} \mathrm{H}_{2}$ DCFDA in binding buffer for $30 \mathrm{~min}$. The cells were then collected by trypsinization and centrifugation, washed with PBS, centrifuged at $200 \times \mathrm{g}$ for $5 \mathrm{~min}$ and analyzed immediately using a Beckman Coulter FC500 flow cytometer.

\section{SIRT1 activity measurement}


The cellular SIRT1 activity was measured using a SIRT1 Activity Assay Kit (Fluorometric)(Abcam Inc. Cambridge, MA, USA). Briefly, 1' $10^{5}$ cells (either untreated or capsaicin-treated for $24 \mathrm{~h}$ ) were washed, harvested and resuspended in $1 \mathrm{~mL}$ of lysis buffer $(10 \mathrm{mM}$ Tris- $\mathrm{HCl}$ pH 7.5, $10 \mathrm{mM} \mathrm{NaCl}, 15 \mathrm{mM} \mathrm{MgCl}$, $250 \mathrm{mM}$ sucrose, $0.5 \% \mathrm{NP}-40,0.1 \mathrm{mM}$ EGTA). Cell lysates were sonicated 4 times for 5 seconds each on ice, and were centrifuged for $10 \mathrm{~min}$ at $4^{\circ} \mathrm{C}$. The supernatant was then used for the determination of SIRT1 activity according to the manufacturer's instructions.

\section{Cellular target identification of capsaicin by cellular thermal shift assay (CETSA)}

Intracellular tNOX as cellular target of capsaicin was established by CETSA. Samples were prepared from control and capsaicin-exposed cells. For each set, $2 \times 10^{7}$ cells were seeded in a 10-cm cultured dish. After $24 \mathrm{~h}$ of culture, the cells were pretreated with $10 \mathrm{mM} \mathrm{MG} 132$ for $1 \mathrm{~h}$, washed with PBS, treated with trypsin, and collected. Samples were centrifuged at 12,000 rpm for $3 \mathrm{~min}$ at room temperature, the pellets were gently resuspended with $1 \mathrm{~mL}$ of PBS, and the samples were centrifuged at 7,500 rpm for $3 \mathrm{~min}$ at room temperature. The pellets were resuspended with $1 \mathrm{~mL}$ of PBS containing $20 \mathrm{mM} \mathrm{Tris-HCl} \mathrm{pH} \mathrm{7.4,}$ $100 \mathrm{mM} \mathrm{NaCl}, 5 \mathrm{mM}$ EDTA, $2 \mathrm{mM}$ phenylmethylsulfonyl fluoride (PMSF), $10 \mathrm{ng} / \mathrm{ml}$ leupeptin, and 10 $\mathrm{mg} / \mathrm{ml}$ aprotinin. The samples were transferred to Eppendorf tubes and subjected to three freeze-thaw cycles; for each cycle, they were exposed to liquid nitrogen for $3 \mathrm{~min}$, placed in a heating block at $37^{\circ} \mathrm{C}$ for $3 \mathrm{~min}$, and vortexed briefly. For the experimental sample set, capsaicin was added to a final concentration of $2 \mathrm{mM}$; for the control sample set, the same volume of vesicle solvent was added. The samples were heated at $37^{\circ} \mathrm{C}$ for $1 \mathrm{~h}$ and dispensed to $100 \mathrm{ml}$ aliquots. Pairs consisting of one control aliquot and one experimental aliquot were heated at $40^{\circ} \mathrm{C}, 43^{\circ} \mathrm{C}, 46^{\circ} \mathrm{C}, 49^{\circ} \mathrm{C}, 52^{\circ} \mathrm{C}, 55^{\circ} \mathrm{C}, 58^{\circ} \mathrm{C}$, or $61^{\circ} \mathrm{C}$ for $3 \mathrm{~min}$. Insoluble proteins were separated by centrifugation at $12,000 \mathrm{rpm}$ for $30 \mathrm{~min}$ at $4^{\circ} \mathrm{C}$, and the supernatants with soluble proteins were used for SDS-PAGE and Western blot analysis using antisera to tNOX [31, 33]. bactin was used as the control.

The procedure for establishing an isothermal dose-response fingerprint (ITDRF $\left.{ }_{\text {CETSA }}\right)$ was similar to that of the CETSA melting curve experiments as described above. Cells were seeded in $60 \mathrm{~mm}$ cultured dishes. After $24 \mathrm{~h}$ of culture, the cells were pretreated with $10 \mathrm{mM} \mathrm{MG} 132$ and exposed to different final concentrations of $0.001,0.01,0.05,0.25,0.5,1,10,100,200 \mathrm{mM}$ capsaicin for $1 \mathrm{~h}$, washed with PBS, treated with trypsin, and collected with centrifugation at 12,000 rpm for $2 \mathrm{~min}$ at room temperature. The pellets were gently resuspended with $1 \mathrm{~mL}$ of PBS, and then centrifuged at 7,500 rpm for $3 \mathrm{~min}$ at room temperature, and resuspended with PBS containing $20 \mathrm{mM}$ Tris-HCl pH 7.4, $100 \mathrm{mM} \mathrm{NaCl}, 5 \mathrm{mM}$ EDTA, 2 $\mathrm{mM}$ phenylmethylsulfonyl fluoride (PMSF), $10 \mathrm{ng} / \mathrm{ml}$ leupeptin, and $10 \mathrm{mg} / \mathrm{ml}$ aprotinin, and then subjected to three freeze-thaw cycles; for each cycle, they were exposed to liquid nitrogen for $3 \mathrm{~min}$, placed in a heating block at $25^{\circ} \mathrm{C}$ for $3 \mathrm{~min}$, and vortexed briefly. The samples were then heated at $54^{\circ} \mathrm{C}$ for $3 \mathrm{~min}$ and cooled for $3 \mathrm{~min}$ at room temperature. Insoluble proteins were separated by centrifugation at $12,000 \mathrm{rpm}$ for $30 \mathrm{~min}$ at $4^{\circ} \mathrm{C}$, and the supernatants with soluble proteins were used for SDS-PAGE and Western blot analysis using antisera to tNOX. b-actin was used as the control.

\section{Immunoblotting and immunoprecipitation}


Cell extracts were prepared in lysis buffer (20 mM Tris- $\mathrm{HCl} \mathrm{pH} \mathrm{7.4,} 100 \mathrm{mM} \mathrm{NaCl}, 5 \mathrm{mM}$ EDTA, $2 \mathrm{mM}$ phenylmethylsulfonyl fluoride (PMSF), $10 \mathrm{ng} / \mathrm{ml}$ leupeptin, $10 \mathrm{mg} / \mathrm{ml}$ aprotinin). Volumes of extract containing equal amounts of proteins $(40 \mu \mathrm{g})$ were applied to SDS-PAGE gels, and resolved proteins were transferred to PVDF membranes (Schleicher \& Schuell, Keene, NH, USA). The membranes were blocked, washed, and probed with primary antibody. After washing to remove unbound primary antibody, membranes were incubated with horseradish peroxidase-conjugated secondary antibody for 2 hours. The blots were washed again and developed using enhanced chemiluminescence (ECL) reagents, according to the manufacturer's protocol (Amersham Biosciences, Piscataway, NJ, USA).

For immunoprecipitation, protein extracts from $100 \mathrm{~mm}$ dishes were incubated with $60 \mathrm{ml}$ of Protein $\mathrm{G}$ Agarose Beads (for rabbit antibodies) for $1 \mathrm{~h}$ at $4^{\circ} \mathrm{C}$ in rotation for pre-clearing. The ULK1 antibody or control IgG were incubated onto beads in $500 \mathrm{ml}$ of PBS-Tween $201 \%$ for overnight in rotation at $4^{\circ} \mathrm{C}$. Beads were precipitated by centrifugation at $3000 \mathrm{rpm}, 2 \mathrm{~min}$ at $4^{\circ} \mathrm{C}$ and $80 \mathrm{ml}$ of supernatants were collected for input total lysates. Beads were washed three times with lysis buffer and samples were prepared for Western blotting analysis.

\section{In vivo xenograft studies}

Specific pathogen free (SPF) female C57BL/ 6 mice were purchased from the National Laboratory Animal Center (Taipei, Taiwan). The animal use protocols were approved by the Institutional Animal Care and Use Committee of National Chung Hsing University (Taichung, Taiwan). Mice were subcutaneously inoculated with $100 \mathrm{ml}$ of a B16F10 cell mixture containing $2 \times 10^{5}$ live cells in PBS. The tumor-bearing mice were randomly divided into two groups ( $\mathrm{n}=4$ per group) when the tumor mass reached an average diameter of 0.5-1 cm. Group 1 mice were intratumorally injected with vehicle buffer (1.12\% ethanol in 1X PBS) as untreated control (VC group). Group 2 mice were intratumorally treated with $200 \mathrm{mg}$ capsaicin in vehicle buffer (Cap group). Intratumoral therapy was performed two times at an interval of one week. The tumor size was recorded every 2-3 days and the tumor volume was calculated using the formula: length $x$ width $^{2} \times 0.5$ ). Mice were euthanized at 4 days after the final treatment. The significance of differences in tumor size was determined by one-tailed Student's $t$ test.

To confirm the contribution of tNOX to tumor growth, $1^{\prime} 10^{6}$ B16F10 mouse melanoma cells transfected with either synthesized scramble (control-i) or tNOX (tNOX-i) shRNA were used for inoculation. Eightweek-old female C57BL/ 6 mice were randomly divided into two groups and subcutaneously inoculated with tumor cells at the right flank: Group-1 mice $(n=3)$ were injected with control-i cells as a control group and group-2 mice $(n=3)$ were injected with tNOX-i cells. Fourteen days after tumor cell injection, mice were euthanized, the tumor mass was quickly removed, and the mass was weighed.

\section{Statistical analyses}

All in vitro experiments were performed at least three times and all in vivo experiments were conducted with at least three animals. The results of each experiment are expressed as the means \pm SEs. Betweengroup comparisons were performed using one-way analysis of variance (ANOVA) followed by an 
appropriate post-hoc test. A value of $\mathrm{p}<0.05$ was considered to indicate a statistically significant difference.

\section{Results}

\section{Capsaicin suppresses the growth of mouse and human melanoma cells}

We first set out to determine the effect of capsaicin on the growth of melanoma cells, utilizing both mouse (B16F10) and human (A375) cells by dynamically monitoring cell impedance, and displayed the results as cell index $(\mathrm{Cl})$ values $[34,35]$. Our results suggested that capsaicin attenuated the growth of these two cell lines with comparable degrees of cytotoxicity at concentrations above $10 \mu \mathrm{M}(\mathrm{Fig}$. 1A). We observed a slight rise in the proliferation of these cancer cell lines when exposed to $10 \mu \mathrm{M}$ capsaicin, which was similar to a previous reported finding [21]. Consistent results were also obtained with a cell viability assay, which indicated that capsaicin induced dose- and time-dependent decreases in melanoma cell viability, except at $10 \mu \mathrm{M}$ for the A375 cells (Fig. 1B). However, when we used a colony-forming assay to examine the longer-term effect, we found that capsaicin markedly diminished A375 cell proliferation at 10 and $50 \mu \mathrm{M}$, and completely blocked cell proliferation at 100 and $200 \mu \mathrm{M}$ (Fig. 1C).

\section{Capsaicin Induces Ros-dependent Autophagy But Not Apoptosis}

Given that capsaicin has long been recognized as a nutraceutical agent for its apoptotic activity, we next validated the cellular outcomes in melanoma cells exposed to capsaicin. However, our results suggested that capsaicin was unable to induce apoptosis in A375 cells even at $200 \mu \mathrm{M}$ (Fig. 2A). Instead, it appeared to induce autophagy in a concentration- and time-dependent fashion (Fig. 2B). Pretreatment with the autophagy inhibitor 3-methyladenine (3-MA), significantly increased capsaicin-induced apoptosis at 100 and $200 \mu \mathrm{M}$ (Fig. 2C), suggesting that capsaicin-induced autophagy was inhibitory to apoptosis in our system. Protein analysis showed that capsaicin-induced autophagy involved the up-regulation of the autophagy-related proteins Beclin 1, Atg5, Atg7, and p62, and the level of cleaved LC-3 II, and that this was accompanied by a decrease in the activation/phosphorylation of mTOR and Akt (Fig. 2D). On the contrary, apoptosis markers were unchanged by capsaicin exposure, including cleaved/activated caspases, the levels of the pro-apoptotic proteins Bak, Bax, p53, and the cleavage of PARP (Fig. 2E).

Using the fluorescent dye, $\mathrm{H}_{2}$ DCFDA, we found that capsaicin markedly triggered the generation of reactive oxygen species (ROS) at 100 and $200 \mu \mathrm{M}$ (Fig. 3A), as proposed by many other studies [36-38]. Pretreatment with the ROS scavenger, N-acetyl-L-cysteine (NAC), effectively attenuated capsaicinmediated autophagy at $200 \mu \mathrm{M}$ (Fig. 3B). Furthermore, our protein analysis validated that the capsaicinmediated changes in autophagy-related proteins were reversed by pretreatment with NAC, suggesting that capsaicin induced autophagy was dependent of ROS signaling (Fig. 3C). 


\section{Capsaicin directly binds to tNOX, as indicated by cellular thermal shift assay (CETSA)}

Capsaicin has long been known to suppress plasma membrane NADH oxidase (a.k.a tNOX; ENOX2) and the growth of human and mouse melanoma cells [12]. The previous study mainly correlated the inhibition of NADH oxidase activity with attenuation of cancer cell growth, but did not reveal the molecular events contributing to this capsaicin-mediated suppression. To shed light on the action mechanism of capsaicin, we next examined whether there is a direct interaction between capsaicin and tNOX to regulate autophagy in melanoma cells. Given that the interaction between a ligand and its target protein enhances its heat resistance, a cellular thermal shift assay (CETSA) was conducted to examine the direct targeting between capsaicin and target proteins. Interestingly, in the presence of capsaicin, tNOX apparently precipitated at higher temperatures compared with that seen in control A375 cells (Fig. 4A). The relative tNOX intensity observed at all temperatures tested was significantly higher in capsaicin-exposed cell compared to controls (Fig. 4B). Moreover, the melting temperature values ( $T_{\mathrm{m}}$; the temperature at which $50 \%$ of proteins are unfolded and rapidly precipitated by heat) derived from the plot of thermal melting curves showed that the addition of capsaicin increased the parameter by 6.1 degrees, from $46.5^{\circ} \mathrm{C}$ (control) to $52.6^{\circ} \mathrm{C}$ (exposed to capsaicin) (Fig. 4C), suggesting that there is direct binding between capsaicin and tNOX. We also examined the dose-response relationship between capsaicin and the heat stability of tNOX; this experiment was performed at $54{ }^{\circ} \mathrm{C}$, as most tNOX proteins would be denatured and precipitated unless they were thermally stabilized by binding to the ligand, capsaicin. Indeed, capsaicin dose-dependently increased the stability of tNOX, with an $\mathrm{OC}_{50}$ value of $30 \mu \mathrm{M}$ for $\mathrm{A} 375$ melanoma cells (Fig. 4D).

\section{Capsaicin reduces tNOX and SIRT1 expression at the translational and transcriptional levels}

Based on our finding that capsaicin can directly bind to cellular tNOX protein in melanoma cells, we next examined the cellular impact of this interaction. We found that capsaicin concentration-dependently downregulated tNOX in A375 cells, and that this was seen at both transcriptional and translational levels (Fig. 5A). Pretreatment with the protein-synthesis inhibitor, revealed that the half-life of tNOX in A375 cells was significantly reduced by $200 \mu \mathrm{M}$ capsaicin starting at $6 \mathrm{~h}$ (Fig. 5B). ROS signaling seemed to play a key role in capsaicin-mediated tNOX downregulation as evidenced by the marked enhancement of tNOX stability seen in cultures pretreated with NAC (Fig. 5C). Treatment with the lysosome inhibitor, chloroquine (CQ), profoundly enhanced tNOX expression in A375 cells exposed to capsaicin (Fig. 5D), indicating that lysosomal degradation might be involved in capsaicin-induced tNOX downregulation. Pretreatment with the proteasome inhibitor, MG132, markedly reversed tNOX expression in A375 cells exposed to capsaicin (Fig. 5E), indicating that capsaicin-induced tNOX downregulation might also be through proteasomal degradation. We further examined the effect of tNOX depletion in A375 cells subjected to RNA interference, and found that tNOX knockdown significantly enhanced the autophagy induced by 100 and $200 \mu \mathrm{M}$ capsaicin, but did not induce spontaneous autophagy in the absence of capsaicin (Fig. 5F).

Capsaicin induces autophagy by suppressing tNOX-SIRT1 deacetylase activity to enhance ULK1 acetylation 
Previous studies linked the inhibition of tNOX activity with the cancer cell growth-attenuating activity of capsaicin [6, 12], and inhibition of tNOX activity was reported to decrease the intracellular NAD ${ }^{+}$ concentration [22]. Thus, we next questioned whether a NAD+-dependent SIRT1 deacetylase could act as a tNOX-mediated $\mathrm{NAD}^{+}$generation-regulated switch for autophagy. We found that capsaicin attenuated SIRT1 expression at both transcriptional and translational levels in A375 cells (Fig. 6A). Furthermore, 100 and $200 \mu \mathrm{M}$ capsaicin significantly inhibited cellular SIRT1 deacetylase activity in A375 cells, as assessed using a fluorometric SIRT1 activity assay (Fig. 6B). We next focused on the autophagy-related pathway, using immunoprecipitation to reveal that ULK1 acetylation was augmented in our system, possibly through capsaicin-inhibited SIRT1 activity/expression (Fig. 6C). Interestingly, our data suggested that the capsaicin-induced suppression of tNOX expression was accompanied by a decrease in SIRT1 expression in A375 cells (Fig. 6D), as reported previously in other cancer cell types [22, 23]. Other cell death regulation-related downstream targets of SIRT1 were also examined: We found that p53 acetylation was increased, providing further evidence that capsaicin induced autophagy, not apoptosis, in our system (Fig. 6D).

\section{Capsaicin-induced inhibition of tNOX or depletion of tNOX limit tumor growth in vivo}

To determine whether capsaicin exerts an inhibitory activity on melanoma cancer in vivo, mice were inoculated with B16F10 cells. Tumor-bearing mice with average tumor diameters of around 0.5-1 cm were randomly divided into two groups and intratumorally injected with either $200 \mu \mathrm{g}$ capsaicin in vehicle buffer or buffer only. Mice were terminated at Day 10 and we found that capsaicin effectively lessened the tumor size (Fig. 7A). Furthermore, protein analysis of the tumor tissues from the control and capsaicin-treated groups revealed that capsaicin treatment effectively reduced the expression of tNOX/SIRT1 expression (Fig. 7B). We next explored the involvement of tNOX in melanoma xenograft experiments utilizing RNA interference (RNAi) technology in B16F10 cells. tNOX-specific shRNA effectively attenuated tNOX expression in B16F10 cells compared to the controls (Fig. 7C). The siRNAtransfected melanoma cells were injected into randomized C57BL/6 mice for an in vivo study. At the end of experiments, we found that average tumor mass grown in mice with tNOX-specific shRNA-transfected cells was marked reduced compared to that of the control group, suggesting that tNOX depletion decreased the ability of melanoma cells to induce tumor growth in vivo (Fig. 7C). Together, our findings suggest that capsaicin exerts its anticancer properties by directly targeting and enhancing the degradation of tNOX to inhibit NADH oxidation and SIRT1 deacetylase activity. In melanoma cells, through enhancement of ULK acetylation, capsaicin triggers cytotoxic autophagy dependent of ROS signaling.

\section{Discussion}

Capsaicin can be considered a nutraceutical, which is defined as any food component that has medical benefit, such as in the prevention and treatment of disease $[39,40]$. An emerging body of evidence suggests that capsaicin suppresses the growth of melanoma cells. This has been reported to act through induction of both apoptosis and autophagy [10], downregulation of Bcl-2 with enhanced apoptosis [15], 
downregulation of IL-8 with reduced cell proliferation [13], and suppression of B16F10 cell migration via $\mathrm{PI3K} /$ Akt/Rac1 pathway [16]. Unsurprisingly, capsaicin has been used as a prototype for the design and synthesis of analogs aimed at inducing selective apoptosis in melanoma cells [41]. Capsaicin has also been shown to have a synergistic effect when combined with other drugs: It has been shown to further delay tumor growth in a dose-dependent fashion in mice with lung (LLC), bladder (MBT-2), and melanoma (B16F10) cancers [42]. Consistent with the previous reports, we herein demonstrate that capsaicin reduces the growth of melanoma cells in vitro and in vivo and further show for the first time that this occur via inhibition of the INOX-SIRT1 axis and the subsequent induction of cytotoxic autophagy. The therapeutic efficiency of capsaicin was not ideal in our animal studies, but our further experiments revealed that a $\mathrm{NAD}^{+}$-dependent SIRT1 deacetylase activity appears to act as an orchestrated switch under regulation of tNOX-mediated $\mathrm{NAD}^{+}$generation to trigger cytotoxic autophagy via enhanced ULK1 acetylation. Thus, capsaicin may be considered as a novel candidate drug with specific intercellular protein targets (tNOX and SIRT1) for melanoma treatment.

Recent efforts to quantify the engagement between an unlabeled drug and a cellular protein target have shed lights on the action mechanisms of drugs. An example of such a technique is CETSA, which relies on the observation that ligand binding enhances the thermal stability of a target protein [26, 27]. The preferential cytotoxicity of capsaicin had been long linked with tNOX in melanoma cells [12], but we previously lacked any direct physical evidence supporting their undeviating engagement. Here, we used CETSA to reveal that capsaicin enhanced the thermal stabilization of tNOX through direct binding in melanoma cells. In other studies, we have used this approach to show that intracellular tNOX engages directly with capsaicin in other cell types, including T24 bladder cancer cells [24] and oral cancer cells [43]. Here, we show that this direct binding in melanoma cells influenced the degradation of tNOX and its function as a NADH oxidase to suppress SIRT1 deacetylase, which increased the acetylation of ULK1 to activate autophagy. Similar to our findings, other studies have reported that capsaicin exhibits autophagic activity that coexists or cooperates with apoptosis to enhance cell death $[44,45]$.

An array of diverse signaling pathways have been linked to the apoptotic/autophagic activity of capsaicin. Among them, oxidative stress signaling has often being highlighted. Given that ROS are generated mainly through the electron transport chain in mitochondria, many reports have emphasized the correlation between mitochondrial disruption and capsaicin-induced apoptosis in cancer cells [4649]. Compared to the ROS-dependent apoptotic activity of capsaicin, however, the ability of capsaicin to induce autophagy is relatively less common in the literature. Mostly, capsaicin-mediated has been proposed to promote survival and/or inhibit apoptosis under stressful conditions, regardless of the cancer status of the cells $[22,36,50,51]$. Very recently, we investigated the interplay between apoptosis and autophagy in capsaicin-treated oral cancer cells with either functional or mutant p53 and found that capsaicin induced significant cytotoxicity via autophagy but not apoptosis in p53-functional oral cancer cells [43]. Similarly, in this present study, we demonstrated that capsaicin triggers cytotoxic autophagy in A375 cells, which bears wild-type p53 gene status. Interestingly, capsaicin treatment of p53-mutated cells triggered both autophagy and apoptosis, with autophagy occurring first. In that case, capsaicin-induced

Page $11 / 58$ 
autophagy suppressed apoptosis in the early stage, but thereafter facilitated apoptosis at a later stage, suggesting a complicated crosstalk between these two pathways mediated by capsaicin [43].

In sum, we herein used CETSA to show that tNOX directly engages with capsaicin to mediate a pathway that leads to cytotoxic autophagy of melanoma cells through enhanced ULK1 acetylation. Our experimental findings and the results of our animal studies collectively suggest that tNOX could be a useful therapeutic drug target, and that capsaicin could be further developed as an anticancer therapeutic.

\section{Abbreviations}

AO: Acridine orange, CETSA: Cellular thermal shift assay, ITDRF: Isothermal dose response fingerprint, NAC: N-acetyl-L-cysteine, ROS: Reactive oxygen species, RNAi: RNA interference, tNOX or ENOX2: Tumorassociated NADH oxidase, SIRT1: Sirtuin 1

\section{Declarations}

- Ethics Approval and Consent to Participate: Not applicable.

- Consent for publication: Not applicable.

- Availability of data and supporting materials section: The datasets used and analyzed during the present study are available from the corresponding author on reasonable request.

- Competing interests: The authors declare that they have no competing interests.

- Funding: Financial support was provided by the Ministry of Sciences and Technology, Taiwan (Grant no. NSC 102-2320-B-005-008).

- Acknowledgements: This work was supported by the Ministry of Sciences and Technology, Taiwan (Grant no. NSC 102-2320-B-005-008).

- Authors' contributions: Conception and design: JCC, PJC. Wrote the manuscript: Al, PFH, PJC. Acquisition of data: Al, PFH, JCC. Analysis and interpretation of data: Al, PFH, JWL, MKH, PJC. Writing, review and/or revision of the manuscript: Al, PFH, PJC. Administrative, technical, or material support: WL, MKH, PJC.

\section{References}

1. Gershenwald JE, Guy GP. Stemming the Rising Incidence of Melanoma: Calling Prevention to Action. Jnci-J Natl Cancer I 2016, 108(1).

2. Garbe C, Eigentler TK, Keilholz U, Hauschild A, Kirkwood JM. Systematic Review of Medical Treatment in Melanoma: Current Status and Future Prospects. Oncologist. 2011;16(1):5-24.

3. Shi HB, Hugo W, Kong XJ, Hong A, Koya RC, Moriceau G, Chodon T, Guo RQ, Johnson DB, Dahlman $\mathrm{KB}$, et al. Acquired Resistance and Clonal Evolution in Melanoma during BRAF Inhibitor Therapy. Cancer Discov. 2014;4(1):80-93. 
4. Hauschild A, Grob JJ, Demidov LV, Jouary T, Gutzmer R, Millward M, Rutkowski P, Blank CU, Miller WH, Kaempgen E, et al: An update on BREAK-3, a phase III, randomized trial: Dabrafenib (DAB) versus dacarbazine (DTIC) in patients with BRAF V600E-positive mutation metastatic melanoma (MM). Journal of Clinical Oncology 2013, 31(15).

5. Chapman PB, Hauschild A, Robert C, Larkin JMG, Haanen JBAG, Ribas A, Hogg D, Hamid O, Ascierto $P A$, Testori A, et al: Updated overall survival (OS) results for BRIM-3, a phase III randomized, openlabel, multicenter trial comparing BRAF inhibitor vemurafenib (vem) with dacarbazine (DTIC) in previously untreated patients with BRAF(V600E)-mutated melanoma. Journal of Clinical Oncology 2012, 30(15).

6. Morre DJ, Chueh PJ, Morre DM. Capsaicin inhibits preferentially the NADH oxidase and growth of transformed cells in culture. Proc Natl Acad Sci U S A. 1995;92(6):1831-5.

7. Kim JD, Kim JM, Pyo JO, Kim SY, Kim BS, Yu R, Han IS. Capsaicin can alter the expression of tumor forming-related genes which might be followed by induction of apoptosis of a Korean stomach cancer cell line, SNU-1. Cancer Lett. 1997;120(2):235-41.

8. Gupta SC, Kim JH, Prasad S, Aggarwal BB. Regulation of survival, proliferation, invasion, angiogenesis, and metastasis of tumor cells through modulation of inflammatory pathways by nutraceuticals. Cancer Metast Rev. 2010;29(3):405-34.

9. Cho SC, Lee H, Choi BY. An updated review on molecular mechanisms underlying the anticancer effects of capsaicin. Food Sci Biotechnol. 2017;26(1):1-13.

10. Chu H, Li M, Wang X. Capsaicin induces apoptosis and autophagy in human melanoma cells. Oncology letters. 2019;17(6):4827-34.

11. Zhang SP, Wang DA, Huang JY, Hu YM, Xu YF. Application of capsaicin as a potential new therapeutic drug in human cancers. J Clin Pharm Ther. 2020;45(1):16-28.

12. Morre DJ, Sun E, Geilen C, Wu LY, de Cabo R, Krasagakis K, Orfanos CE, Morre DM. Capsaicin inhibits plasma membrane NADH oxidase and growth of human and mouse melanoma lines. Eur $\mathrm{J}$ Cancer. 1996;32A(11):1995-2003.

13. Patel PS, Varney ML, Dave BJ, Singh RK. Regulation of constitutive and induced NF-kappa B activation in malignant melanoma cells by capsaicin modulates interleukin-8 production and cell proliferation. J Interf Cytok Res. 2002;22(4):427-35.

14. Patel PS, Yang S, Li AH, Varney ML, Singh RK. Capsaicin regulates vascular endothelial cell growth factor expression by modulation of hypoxia inducing factor-l alpha in human malignant melanoma cells. J Cancer Res Clin. 2002;128(9):461-8.

15. Jun HS, Park T, Lee CK, Kang MK, Park MS, Kang HI, Surh YJ, Kim OH: Capsaicin induced apoptosis of B16-F10 melanoma cells through down-regulation of Bcl-2. Food and Chemical Toxicology 2007, 45(5):708-715.

16. Shin DH, Kim OH, Jun HS, Kang MK. Inhibitory effect of capsaicin on B16-F10 melanoma cell migration via the phosphatidylinositol 3-kinase/Akt/Rac1 signal pathway. Exp Mol Med. 2008;40(5):486-94. 
17. Pal HC, Hunt KM, Diamond A, Elmets CA, Afaq F. Phytochemicals for the Management of Melanoma. Mini-Rev Med Chem. 2016;16(12):953-79.

18. Morré DJ: NADH oxidase: A multifunctional ectoprotein of the eukaryotic cell surface. In: Asard $\mathrm{H}$, Bérczi A, Caubergs R, editors. Plasma membrane Redox Systems and their Role in Biological Stress and Disease. Kluwer Academic Publishers, Dordrecht, the Netherlands 1998:121-1561.

19. Wang HM, Chueh PJ, Chang SP, Yang CL, Shao KN. Effect of Ccapsaicin on tNOX (ENOX2) protein expression in stomach cancer cells. Biofactors. 2008;34(3):209-17.

20. Wang HM, Chuang SM, Su YC, Li YH, Chueh PJ. Down-regulation of tumor-associated NADH oxidase, tNOX (ENOX2), enhances capsaicin-induced inhibition of gastric cancer cell growth. Cell Biochem Biophys. 2011;61(2):355-66.

21. Liu NC, Hsieh PF, Hsieh MK, Zeng ZM, Cheng HL, Liao JW, Chueh PJ. Capsaicin-mediated tNOX (ENOX2) up-regulation enhances cell proliferation and migration in vitro and in vivo. J Agric Food Chem. 2012;60(10):2758-65.

22. Lee YH, Chen HY, Su LJ, Chueh PJ. Sirtuin 1 (SIRT1) Deacetylase Activity and NAD(+)/NADH Ratio Are Imperative for Capsaicin-Mediated Programmed Cell Death. J Agric Food Chem. 2015;63(33):7361-70.

23. Lin MH, Lee YH, Cheng HL, Chen HY, Jhuang FH, Chueh PJ: Capsaicin Inhibits Multiple Bladder Cancer Cell Phenotypes by Inhibiting Tumor-Associated NADH Oxidase (tNOX) and Sirtuin1 (SIRT1). Molecules 2016, 21(7).

24. Islam A, Su AJ, Zeng ZM, Chueh PJ, Lin MH. Capsaicin Targets tNOX (ENOX2) to Inhibit G1 Cyclin/CDK Complex, as Assessed by the Cellular Thermal Shift Assay (CETSA). Cells 2019, 8(10).

25. Dziekan JM, Wirjanata G, Dai L, Go KD, Yu H, Lim YT, Chen L, Wang LC, Puspita B, Prabhu N, et al: Cellular thermal shift assay for the identification of drug-target interactions in the Plasmodium falciparum proteome. Nat Protoc 2020.

26. Martinez Molina D, Jafari R, Ignatushchenko M, Seki T, Larsson EA, Dan C, Sreekumar L, Cao Y, Nordlund P. Monitoring drug target engagement in cells and tissues using the cellular thermal shift assay. Science. 2013;341(6141):84-7.

27. Martinez Molina D, Nordlund P. The Cellular Thermal Shift Assay: A Novel Biophysical Assay for In Situ Drug Target Engagement and Mechanistic Biomarker Studies. Annu Rev Pharmacol Toxicol. 2016;56:141-61.

28. Simon GM, Niphakis MJ, Cravatt BF. Determining target engagement in living systems. Nat Chem Biol. 2013;9(4):200-5.

29. Lim YT, Prabhu N, Dai L, Go KD, Chen D, Sreekumar L, Egeblad L, Eriksson S, Chen L, Veerappan S, et al. An efficient proteome-wide strategy for discovery and characterization of cellular nucleotideprotein interactions. PLoS One. 2018;13(12):e0208273.

30. Prabhu N, Dai L, Nordlund P. CETSA in integrated proteomics studies of cellular processes. Curr Opin Chem Biol. 2020;54:54-62. 
31. Chen CF, Huang S, Liu SC, Chueh PJ. Effect of polyclonal antisera to recombinant tNOX protein on the growth of transformed cells. Biofactors. 2006;28(2):119-33.

32. Chang JT. An economic and efficient method of RNAi vector constructions. Anal Biochem. 2004;334(1):199-200.

33. Liu SC, Yang JJ, Shao KN, Chueh PJ. RNA interference targeting tNOX attenuates cell migration via a mechanism that involves membrane association of Rac. Biochem Biophys Res Commun. 2008;365(4):672-7.

34. Ke N, Wang X, Xu X, Abassi YA. The XCELLigence system for real-time and label-free monitoring of cell viability. Methods Mol Biol. 2011;740:33-43.

35. Moela P, Choene MM, Motadi LR. Silencing RBBP6 (Retinoblastoma Binding Protein 6) sensitises breast cancer cells MCF7 to staurosporine and camptothecin-induced cell death. Immunobiology. 2014;219(8):593-601.

36. Chen X, Tan M, Xie Z, Feng B, Zhao Z, Yang K, Hu C, Liao N, Wang T, Chen D, et al. Inhibiting ROSSTAT3-dependent autophagy enhanced capsaicin-induced apoptosis in human hepatocellular carcinoma cells. Free Radic Res. 2016;50(7):744-55.

37. Bu HQ, Cai K, Shen F, Bao XD, Xu Y, Yu F, Pan HQ, Chen CH, Du ZJ, Cui JH. Induction of apoptosis by capsaicin in hepatocellular cancer cell line SMMC-7721 is mediated through ROS generation and activation of JNK and p38 MAPK pathways. Neoplasma. 2015;62(4):582-91.

38. Qian K, Wang G, Cao R, Liu T, Qian G, Guan X, Guo Z, Xiao Y, Wang X. Capsaicin Suppresses Cell Proliferation, Induces Cell Cycle Arrest and ROS Production in Bladder Cancer Cells through FOXO3aMediated Pathways. Molecules 2016, 21(10).

39. Kalra EK. Nutraceutical - Definition and introduction. Aaps Pharmsci 2003, 5(3).

40. Hardy G. Nutraceuticals and functional foods: Introduction and meaning. Nutrition. 2000;16(78):688-9.

41. Pereira GJV, Tavares MT, Azevedo RA, Martins BB, Cunha MR, Bhardwaj R, Cury Y, Zambelli VO, Barbosa EG, Hediger MA, et al. Capsaicin-like analogue induced selective apoptosis in A2058 melanoma cells: Design, synthesis and molecular modeling. Bioorg Med Chem. 2019;27(13):2893904.

42. Schwartz L, Guais A, Israel M, Junod B, Steyaert JM, Crespi E, Baronzio G, Abolhassani M. Tumor regression with a combination of drugs interfering with the tumor metabolism: efficacy of hydroxycitrate, lipoic acid and capsaicin. Investig New Drugs. 2013;31(2):256-64.

43. Chang CF, Islam A, Liu PF, Zhan JH, Chueh PJ. Capsaicin acts through tNOX (ENOX2) to induce autophagic apoptosis in p53-mutated HSC-3 cells but autophagy in p53-functional SAS oral cancer cells. Am J Cancer Res. 2020;10(10):3230-47.

44. Lin YT, Wang HC, Hsu YC, Cho CL, Yang MY, Chien CY. Capsaicin Induces Autophagy and Apoptosis in Human Nasopharyngeal Carcinoma Cells by Downregulating the PI3K/AKT/mTOR Pathway. Int J Mol Sci 2017, 18(7). 
45. Wang Y, Deng X, Yu C, Zhao G, Zhou J, Zhang G, Li M, Jiang D, Quan Z, Zhang Y. Synergistic inhibitory effects of capsaicin combined with cisplatin on human osteosarcoma in culture and in xenografts. J Exp Clin Cancer Res. 2018;37(1):251.

46. Xu SC, Cheng X, Wu LY, Zheng JX, Wang XW, Wu J, Yu HX, Bao JD, Zhang L. Capsaicin induces mitochondrial dysfunction and apoptosis in anaplastic thyroid carcinoma cells via TRPV1-mediated mitochondrial calcium overload. Cellular Signalling 2020, 75.

47. Xie L, Xiang GH, Tang T, Tang Y, Zhao LY, Liu D, Zhang YR, Tang JT, Zhou S, Wu DH. Capsaicin and dihydrocapsaicin induce apoptosis in human glioma cells via ROS and $\mathrm{Ca} 2+-$ mediated mitochondrial pathway. Mol Med Rep. 2016;14(5):4198-208.

48. Pramanik KC, Boreddy SR, Srivastava SK. Role of mitochondrial electron transport chain complexes in capsaicin mediated oxidative stress leading to apoptosis in pancreatic cancer cells. PLoS One. 2011;6(5):e20151.

49. Yang ZH, Wang XH, Wang HP, Hu LQ, Zheng XM, Li SW. Capsaicin Mediates Cell Death in Bladder Cancer T24 Cells Through Reactive Oxygen Species Production and Mitochondrial Depolarization. Urology. 2010;75(3):735-41.

50. Oh SH, Lim SC. Endoplasmic reticulum stress-mediated autophagy/apoptosis induced by capsaicin (8-methyl-N-vanillyl-6-nonenamide) and dihydrocapsaicin is regulated by the extent of c-Jun NH2terminal kinase/extracellular signal-regulated kinase activation in WI38 lung epithelial fibroblast cells. J Pharmacol Exp Ther. 2009;329(1):112-22.

51. Ramos-Torres A, Bort A, Morell C, Rodriguez-Henche N, Diaz-Laviada I. The pepper's natural ingredient capsaicin induces autophagy blockage in prostate cancer cells. Oncotarget. 2016;7(2):1569-83.

\section{Figures}



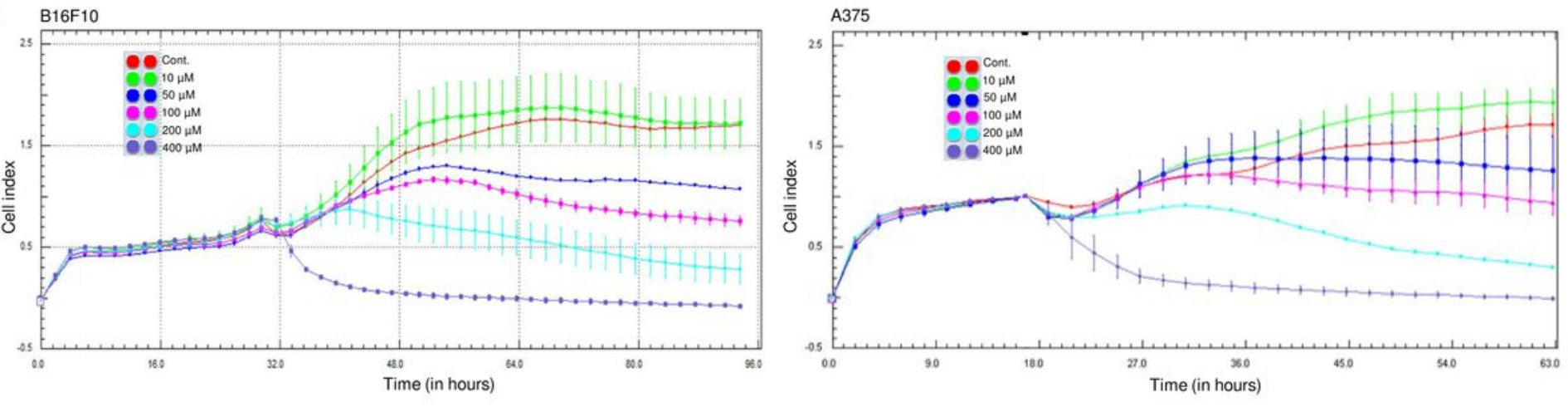

B

B16F10

A375
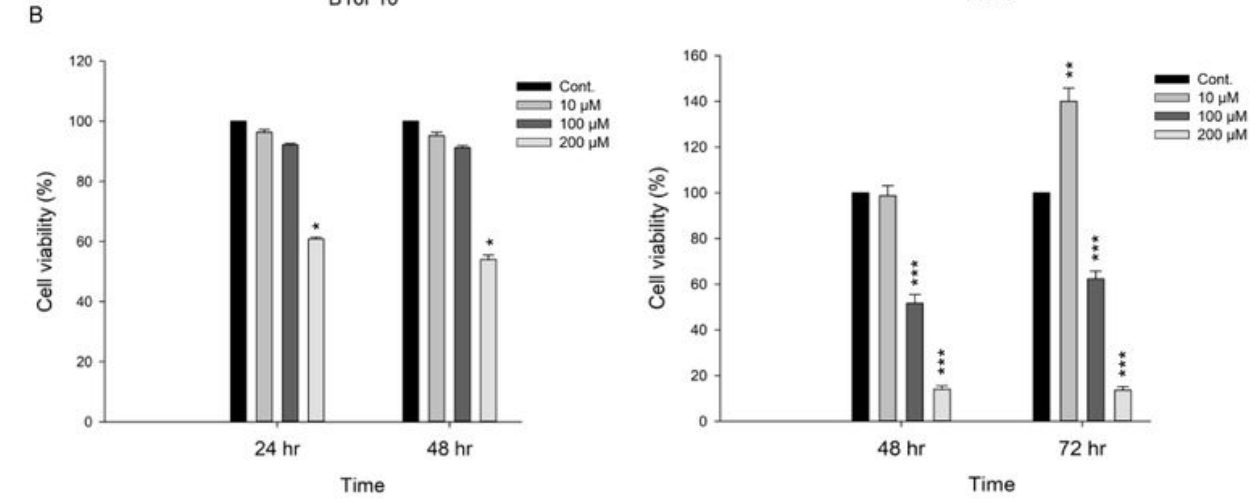

C

A375

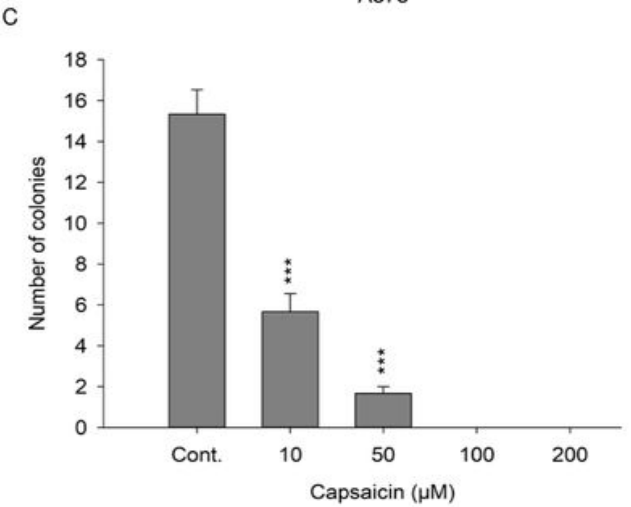

Figure 1

Capsaicin attenuates the growth of melanoma cells. (A) Capsaicin-mediated cell proliferation was dynamically monitoring by impedance measurements in B16F10 and A375 cells, as described in the Materials and Methods. Shown are normalized cell index values measured. (B) Cells were exposed to different concentrations of capsaicin for 24,48 , or $72 \mathrm{~h}$ and cell viability was measured using MTS-based assays. Values (means \pm SDs) are from three independent experiments. There was a significant difference observed in cell viability in cells treated with capsaicin compared to the controls $\left({ }^{*} p<0.05\right.$, ** $p$ $<0.01$, $\star \star \star ~ p ~<0.001)$. (C) A375 cells were exposed to different concentrations of capsaicin and allowed to form colonies. Colony numbers were counted and recorded. Values (means \pm SDs) are from three independent experiments. There was a significant reduction in cells treated with capsaicin compared to the controls ( $\left.{ }^{\star * \star} p<0.001\right)$. 

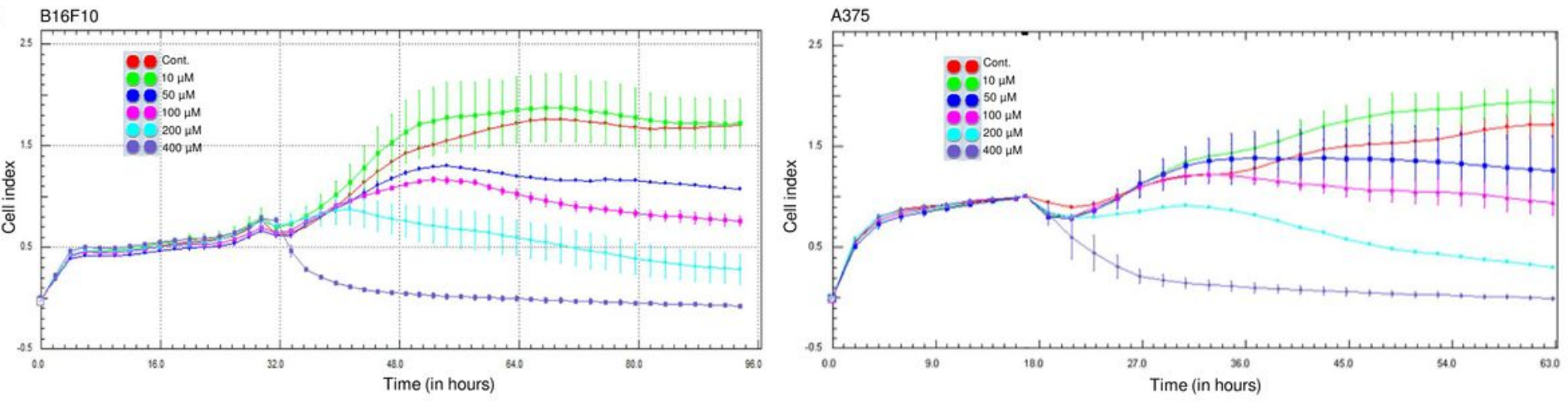

B

B16F10

A375
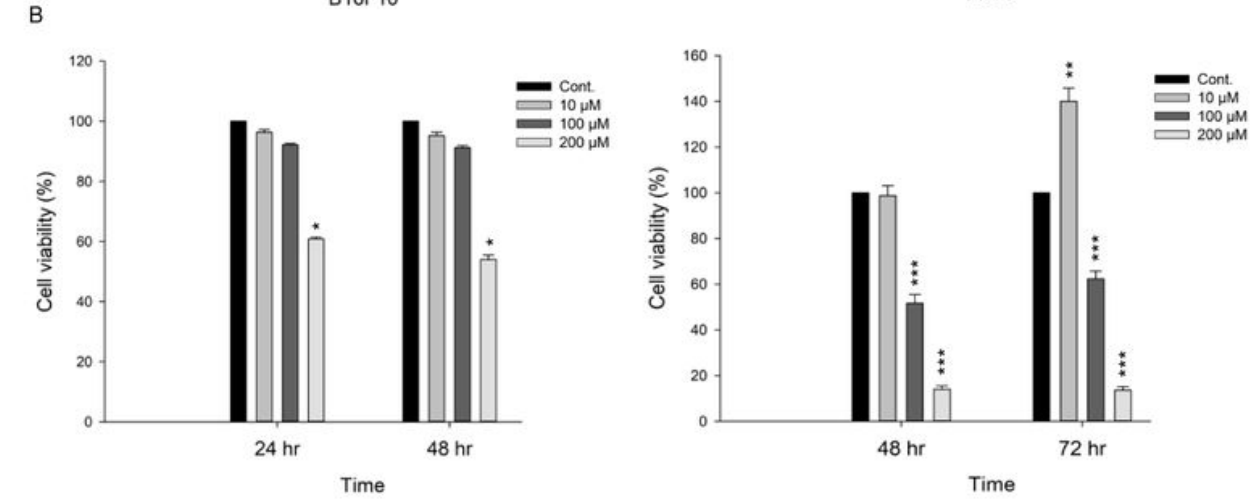

C

A375

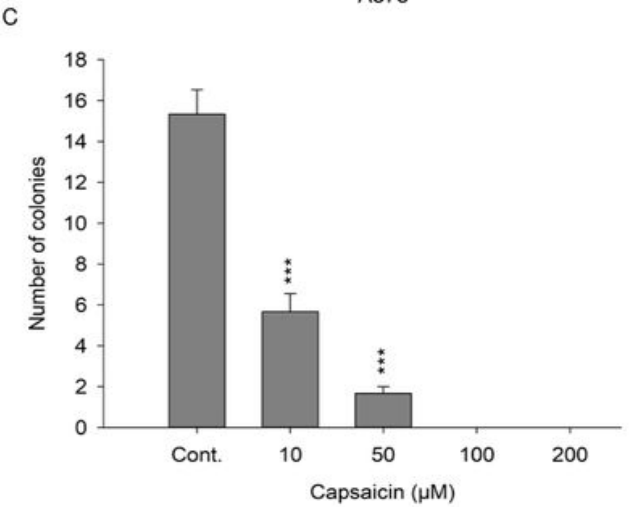

Figure 1

Capsaicin attenuates the growth of melanoma cells. (A) Capsaicin-mediated cell proliferation was dynamically monitoring by impedance measurements in B16F10 and A375 cells, as described in the Materials and Methods. Shown are normalized cell index values measured. (B) Cells were exposed to different concentrations of capsaicin for 24,48 , or $72 \mathrm{~h}$ and cell viability was measured using MTS-based assays. Values (means \pm SDs) are from three independent experiments. There was a significant difference observed in cell viability in cells treated with capsaicin compared to the controls $\left({ }^{*} p<0.05\right.$, ** $p$ $<0.01$, $\star \star \star ~ p ~<0.001)$. (C) A375 cells were exposed to different concentrations of capsaicin and allowed to form colonies. Colony numbers were counted and recorded. Values (means \pm SDs) are from three independent experiments. There was a significant reduction in cells treated with capsaicin compared to the controls ( $\left.{ }^{\star * \star} p<0.001\right)$. 


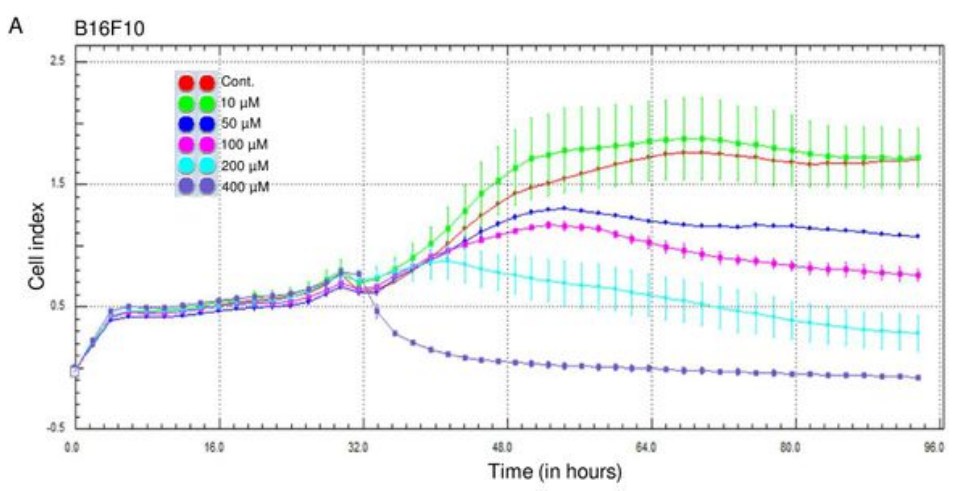

B

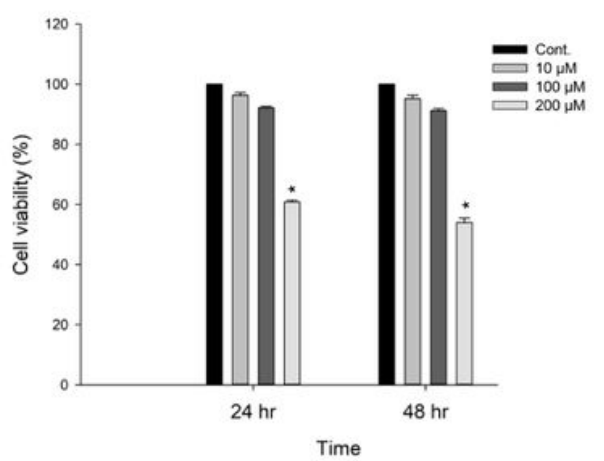

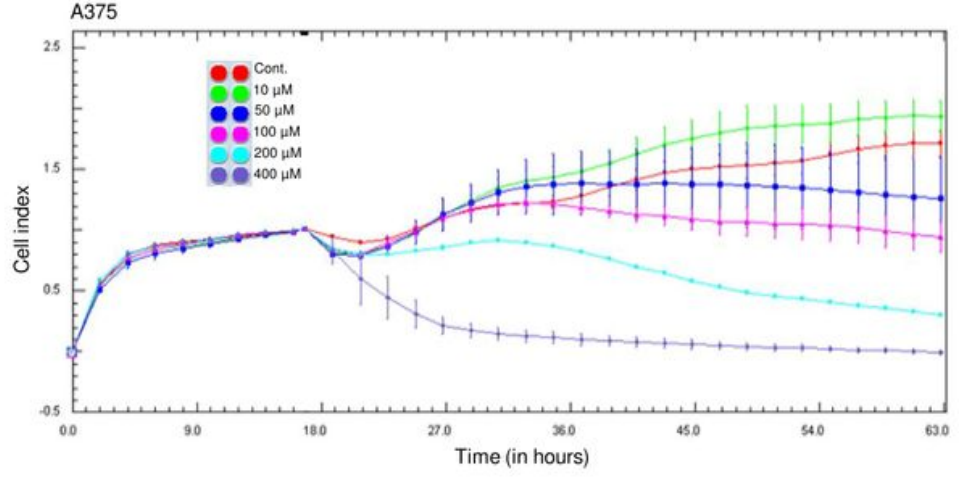

A375

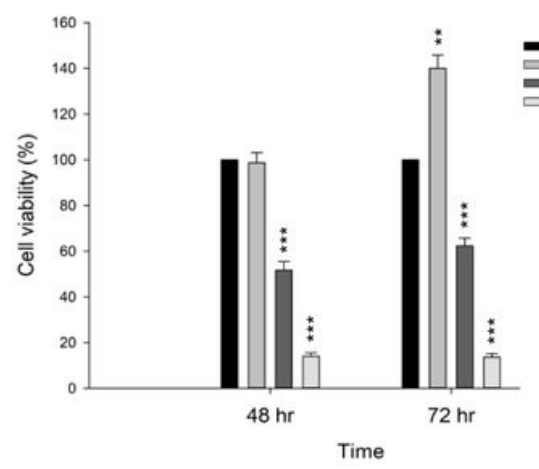

C

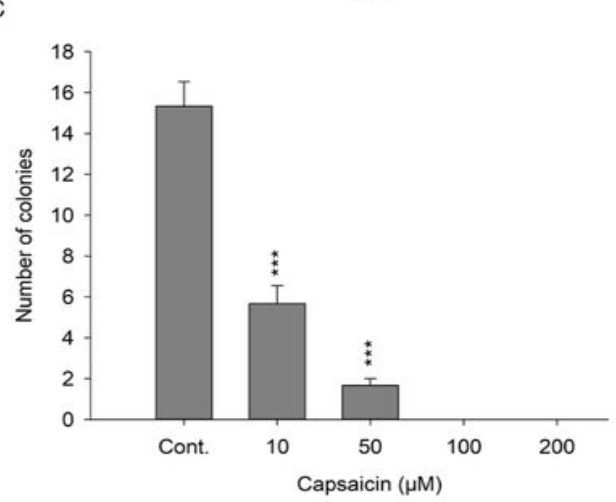

\section{Figure 1}

Capsaicin attenuates the growth of melanoma cells. (A) Capsaicin-mediated cell proliferation was dynamically monitoring by impedance measurements in B16F10 and A375 cells, as described in the Materials and Methods. Shown are normalized cell index values measured. (B) Cells were exposed to different concentrations of capsaicin for 24,48 , or $72 \mathrm{~h}$ and cell viability was measured using MTS-based assays. Values (means \pm SDs) are from three independent experiments. There was a significant difference observed in cell viability in cells treated with capsaicin compared to the controls $(* p<0.05$, ** $p$ $<0.01$, $\star \star \star ~ p ~<0.001)$. (C) A375 cells were exposed to different concentrations of capsaicin and allowed to form colonies. Colony numbers were counted and recorded. Values (means \pm SDs) are from three independent experiments. There was a significant reduction in cells treated with capsaicin compared to the controls ( $\left.{ }^{\star * \star} p<0.001\right)$. 


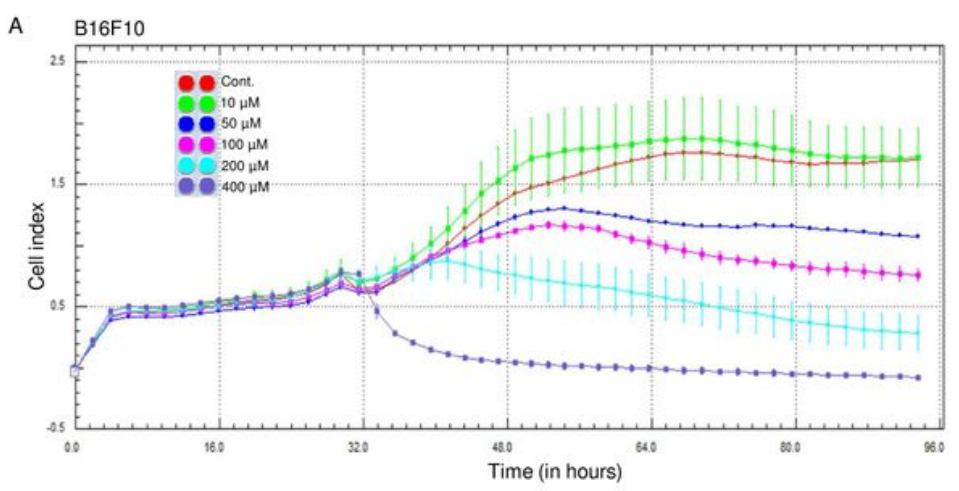

B

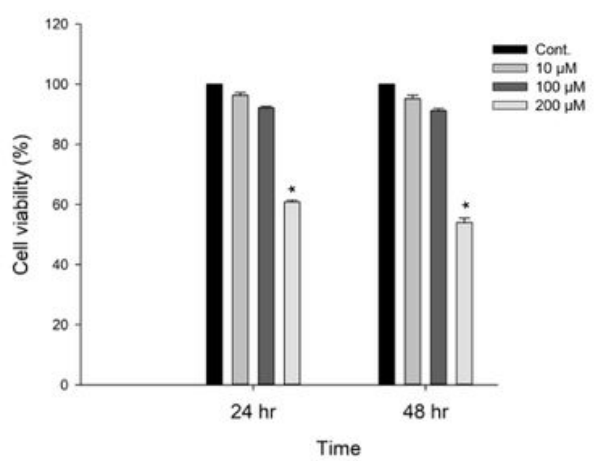

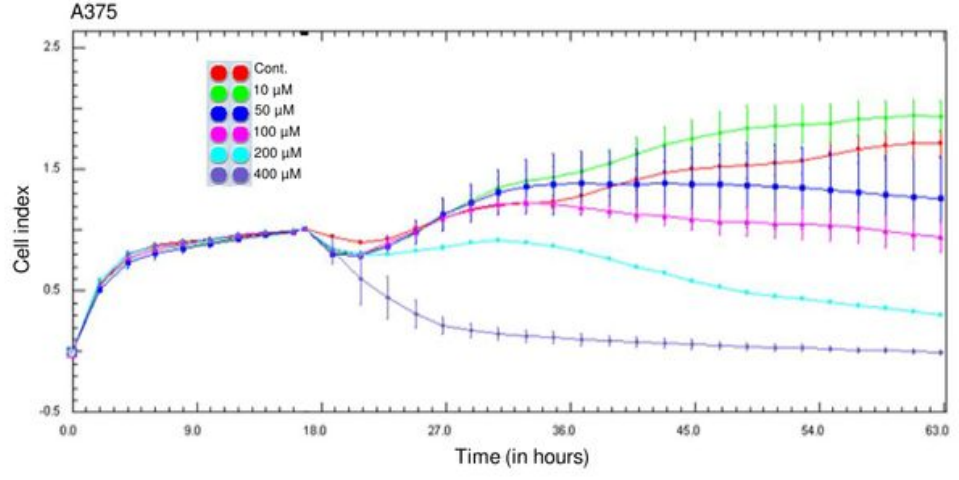

A375

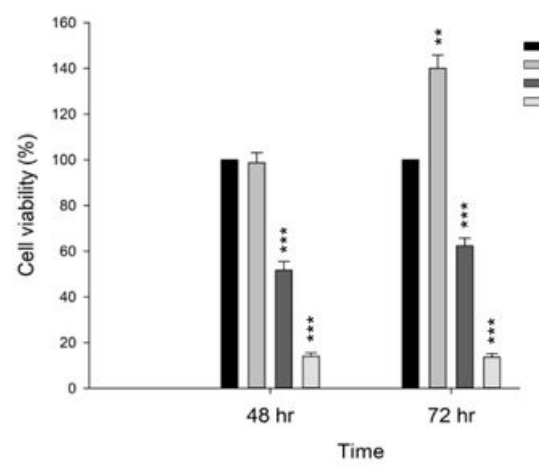

C

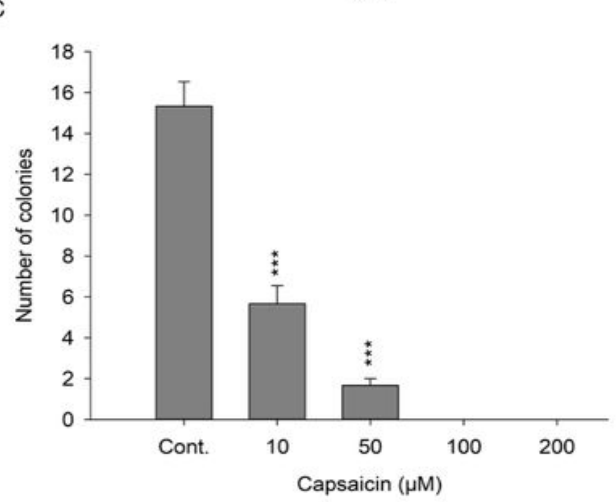

\section{Figure 1}

Capsaicin attenuates the growth of melanoma cells. (A) Capsaicin-mediated cell proliferation was dynamically monitoring by impedance measurements in B16F10 and A375 cells, as described in the Materials and Methods. Shown are normalized cell index values measured. (B) Cells were exposed to different concentrations of capsaicin for 24,48 , or $72 \mathrm{~h}$ and cell viability was measured using MTS-based assays. Values (means \pm SDs) are from three independent experiments. There was a significant difference observed in cell viability in cells treated with capsaicin compared to the controls $(* p<0.05$, ** $p$ $<0.01$, $\star \star \star ~ p ~<0.001)$. (C) A375 cells were exposed to different concentrations of capsaicin and allowed to form colonies. Colony numbers were counted and recorded. Values (means \pm SDs) are from three independent experiments. There was a significant reduction in cells treated with capsaicin compared to the controls ( $\left.{ }^{\star * \star} p<0.001\right)$. 


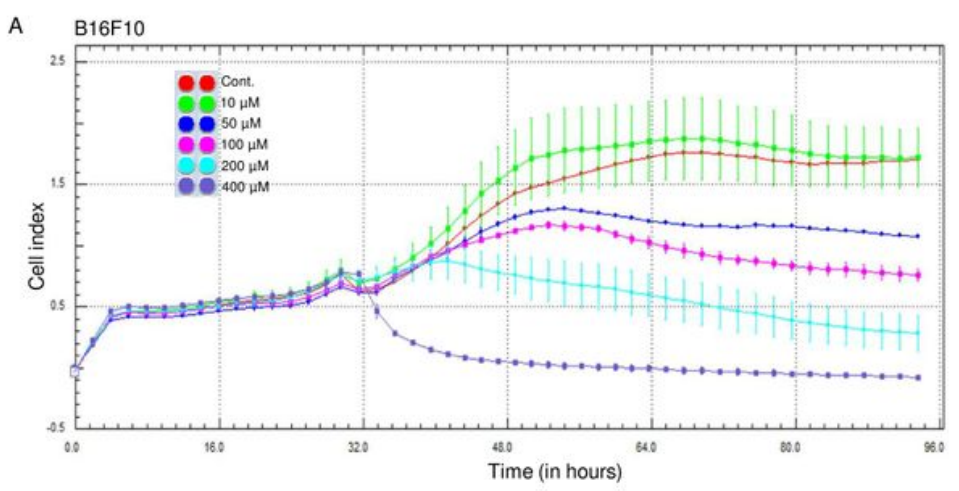

B

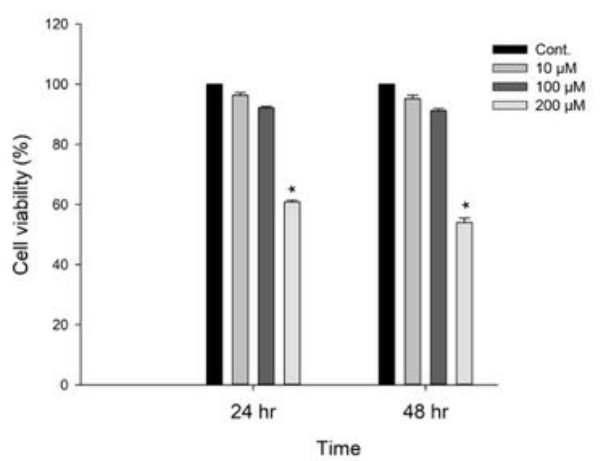

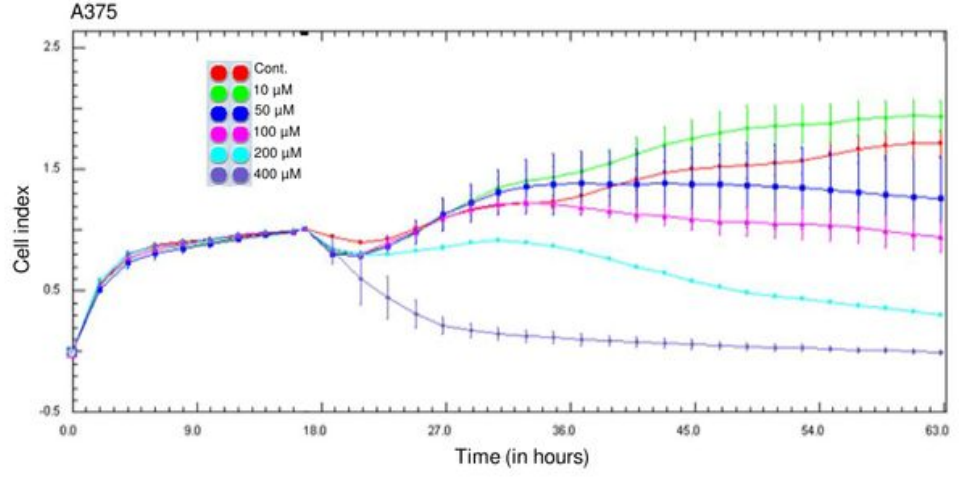

A375

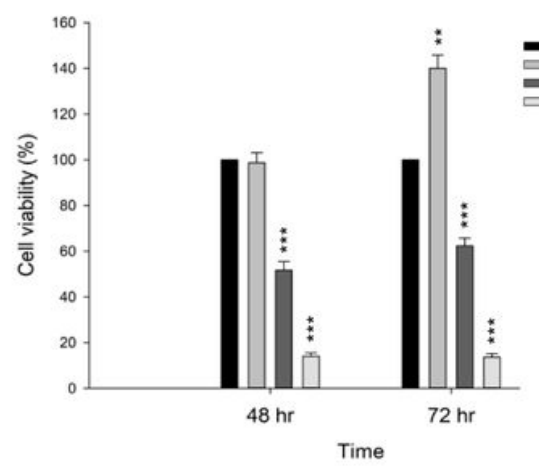

C

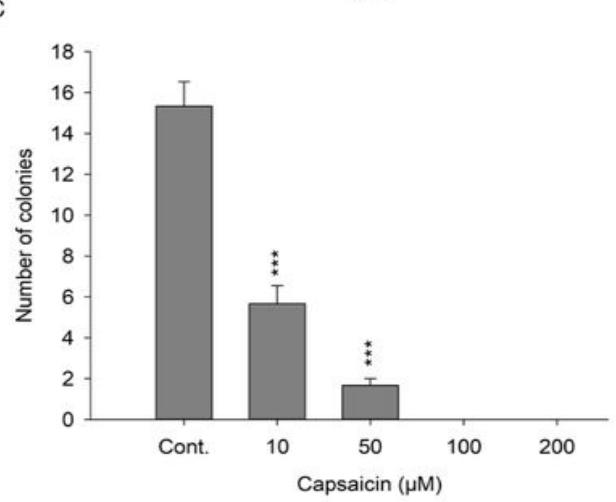

\section{Figure 1}

Capsaicin attenuates the growth of melanoma cells. (A) Capsaicin-mediated cell proliferation was dynamically monitoring by impedance measurements in B16F10 and A375 cells, as described in the Materials and Methods. Shown are normalized cell index values measured. (B) Cells were exposed to different concentrations of capsaicin for 24,48 , or $72 \mathrm{~h}$ and cell viability was measured using MTS-based assays. Values (means \pm SDs) are from three independent experiments. There was a significant difference observed in cell viability in cells treated with capsaicin compared to the controls $(* p<0.05$, ** $p$ $<0.01$, $\star \star \star ~ p ~<0.001)$. (C) A375 cells were exposed to different concentrations of capsaicin and allowed to form colonies. Colony numbers were counted and recorded. Values (means \pm SDs) are from three independent experiments. There was a significant reduction in cells treated with capsaicin compared to the controls ( $\left.{ }^{\star * \star} p<0.001\right)$. 

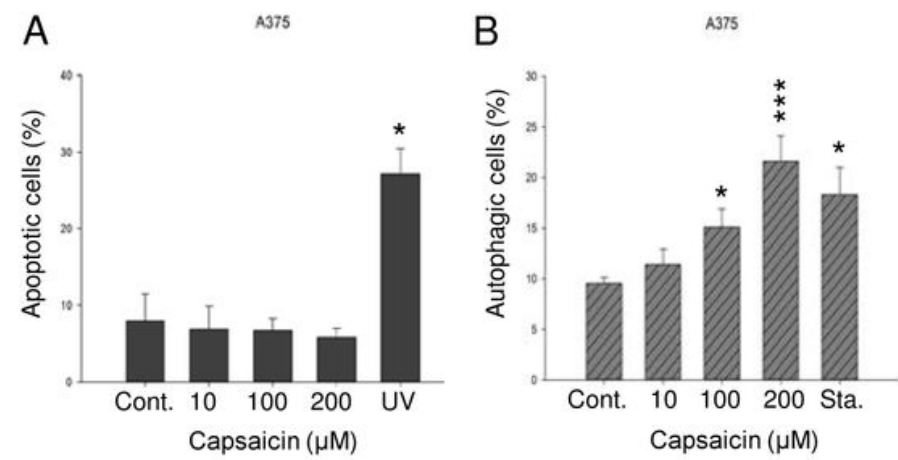

D

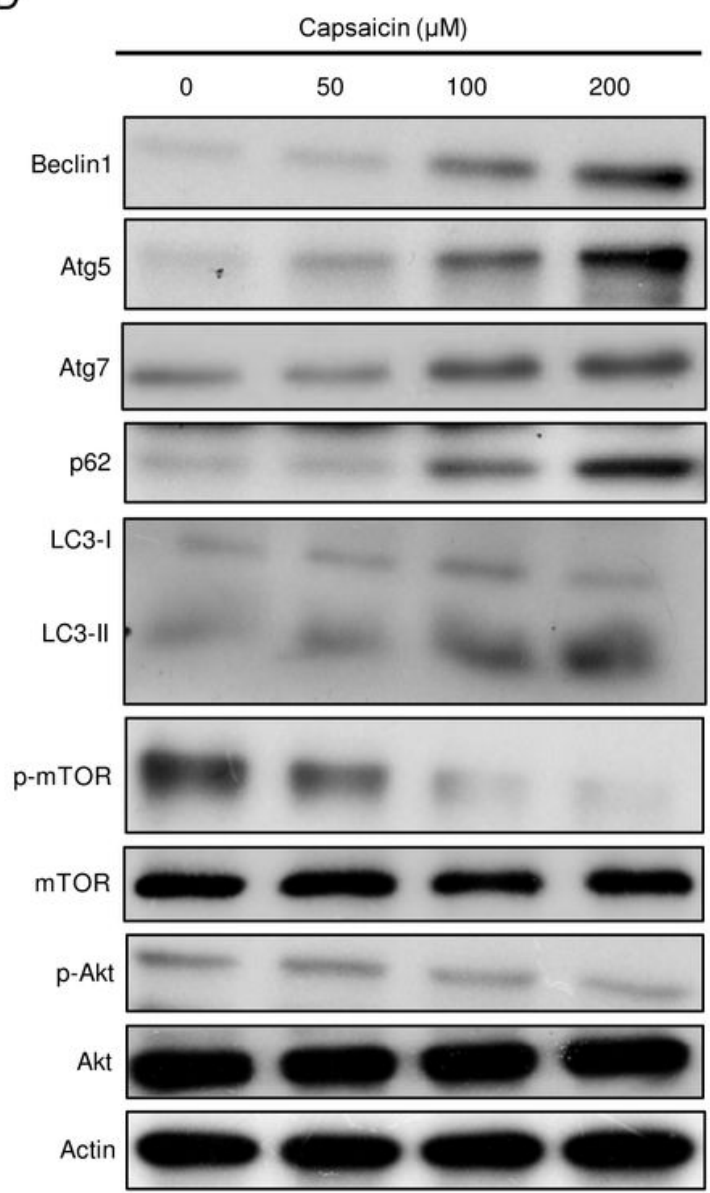

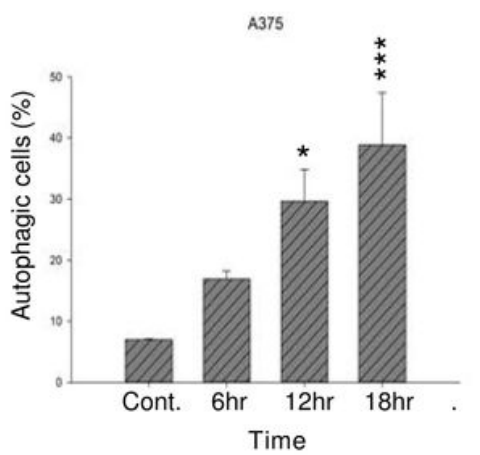

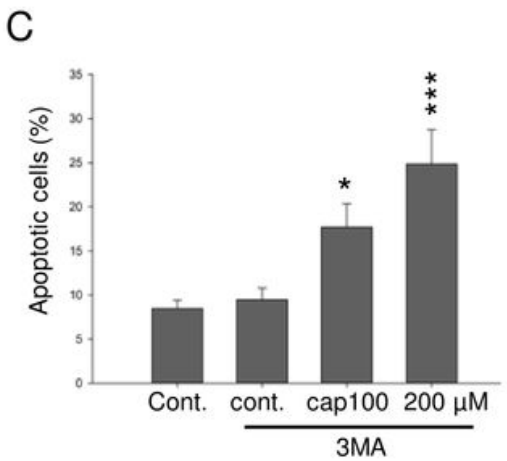

$\mathrm{E}$

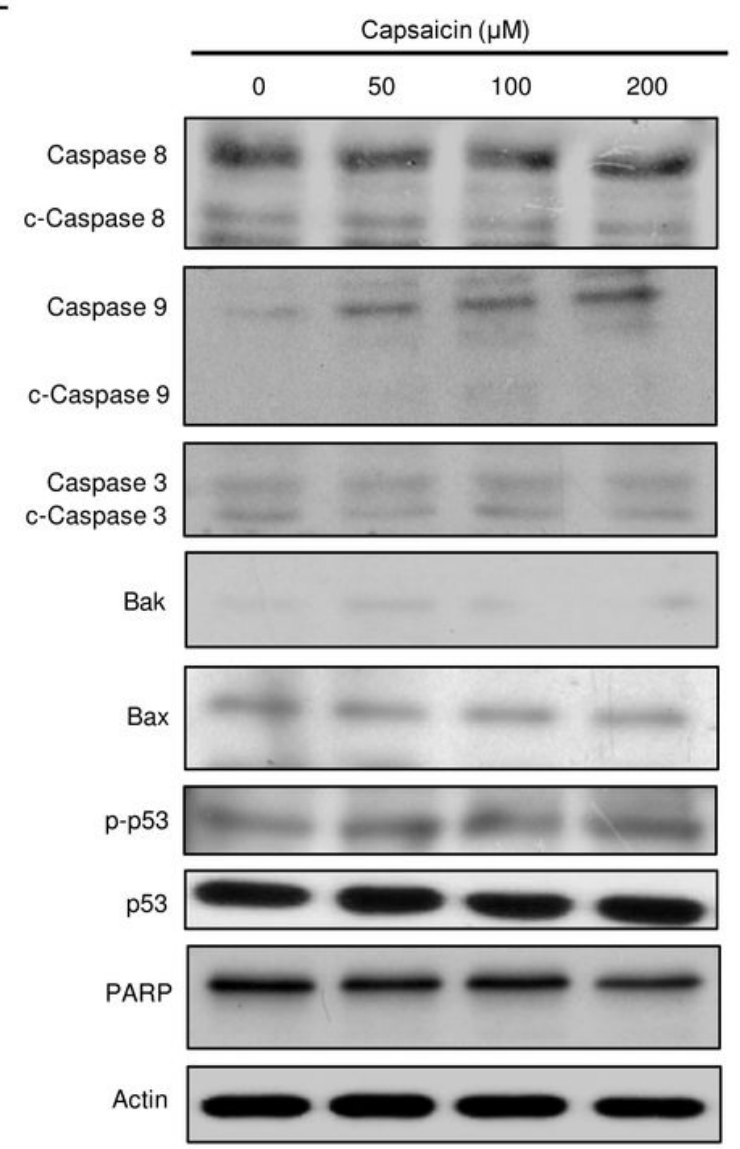

\section{Figure 2}

Capsaicin favorably triggers autophagy not apoptosis in A375 melanoma cells. (A) Cells were treated with capsaicin or ethanol for 24 hours. The percentage of apoptotic cells was determined by flowcytometry, and the results are presented as the percentage of apoptotic cells. Values (means \pm SDs) are from at least three independent experiments $(* p<0.05)$. (B) Cells were treated with different concentrations of capsaicin/ethanol for 15 hours or $200 \mu \mathrm{M}$ of capsaicin for different time length. Autophagy was determined by $\mathrm{AO}$ staining using flow cytometry, analysis and the results are expressed as a percentage of autophagic cells. Values (means \pm SDs) are from at least three independent experiments ( ${ }^{*}<<0.05$, ${ }^{\star \star *} \mathrm{p}<0.001$ ). (C) Cells were pretreated with $10 \mu \mathrm{M} 3-\mathrm{MA}$ for $1 \mathrm{~h}$ before exposure 
to capsaicin or ethanol for 24 hours. The percentage of apoptotic cells was assessed by flow cytometry, and the results are expressed as a percentage of apoptotic cells. Values (means \pm SDs) are from at least three independent experiments ( ${ }^{*} p<0.05,{ }^{* *} p<0.001$ ). (D, E) A375 cells were treated with capsaicin or ethanol for different concentrations and aliquots of cell lysates were separated by SDS-PAGE and analyzed for protein expression by Western blotting. $\beta$-actin was used as an internal control to monitor for equal loading. Representative images are shown from at least three independent experiments.

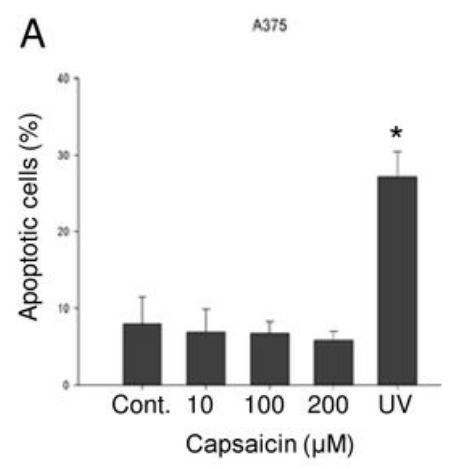

D

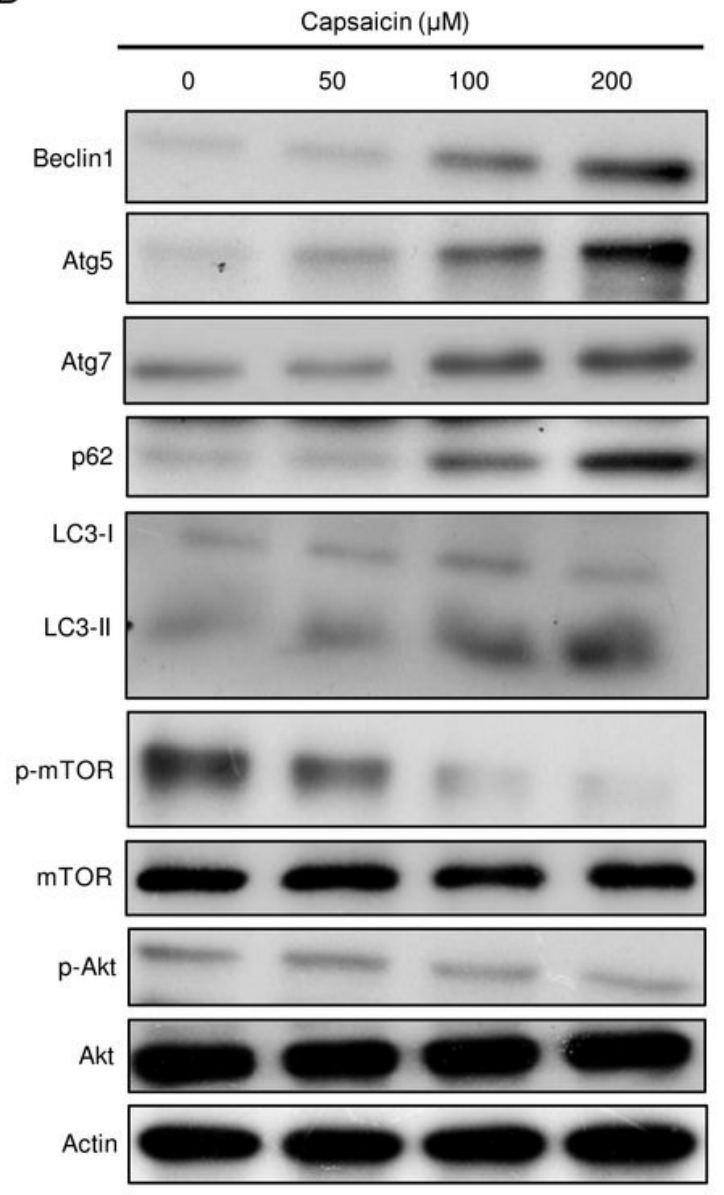

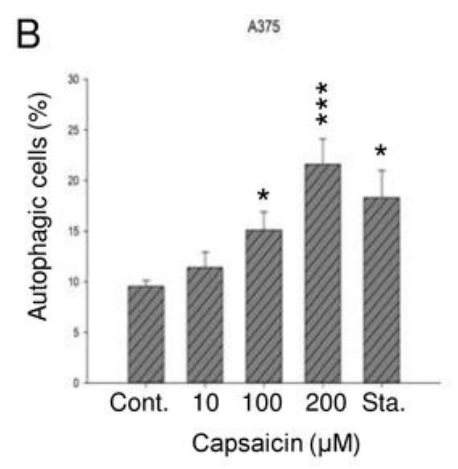
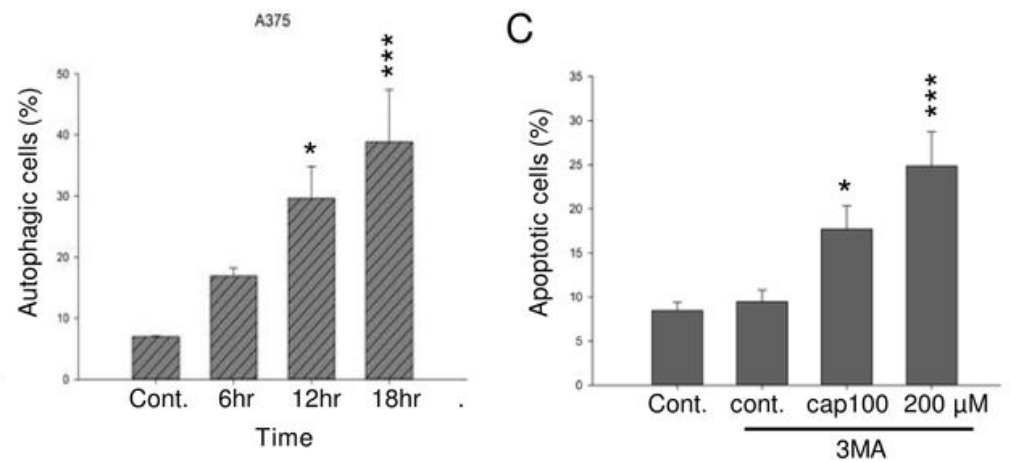

E

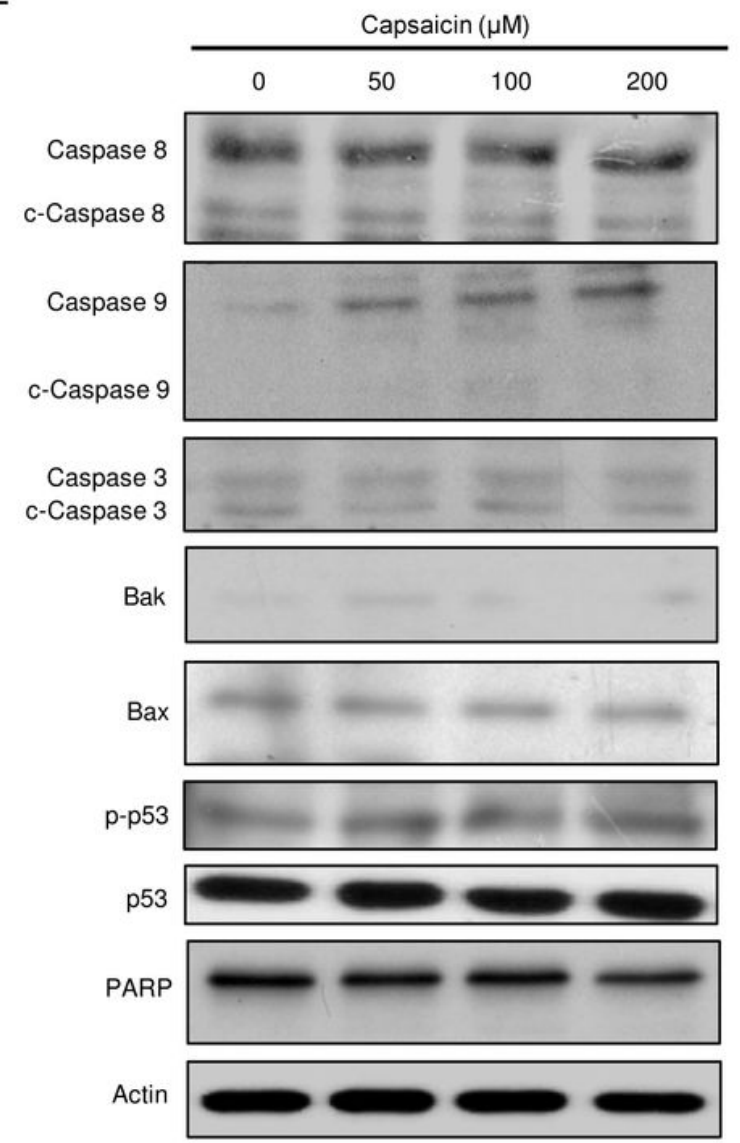

\section{Figure 2}

Capsaicin favorably triggers autophagy not apoptosis in A375 melanoma cells. (A) Cells were treated with capsaicin or ethanol for 24 hours. The percentage of apoptotic cells was determined by flow- 
cytometry, and the results are presented as the percentage of apoptotic cells. Values (means \pm SDs) are from at least three independent experiments $\left({ }^{*} p<0.05\right)$. (B) Cells were treated with different concentrations of capsaicin/ethanol for 15 hours or $200 \mu \mathrm{M}$ of capsaicin for different time length. Autophagy was determined by $\mathrm{AO}$ staining using flow cytometry, analysis and the results are expressed as a percentage of autophagic cells. Values (means \pm SDs) are from at least three independent experiments ( ${ }^{\mathrm{p}}<0.05$, $* \star \star \mathrm{p}<0.001$ ). (C) Cells were pretreated with $10 \mu \mathrm{M}$ 3-MA for $1 \mathrm{~h}$ before exposure to capsaicin or ethanol for 24 hours. The percentage of apoptotic cells was assessed by flow cytometry, and the results are expressed as a percentage of apoptotic cells. Values (means \pm SDs) are from at least three independent experiments ( ${ }^{*} p<0.05,{ }^{\star * *} p<0.001$ ). (D, E) A375 cells were treated with capsaicin or ethanol for different concentrations and aliquots of cell lysates were separated by SDS-PAGE and analyzed for protein expression by Western blotting. $\beta$-actin was used as an internal control to monitor for equal loading. Representative images are shown from at least three independent experiments. 

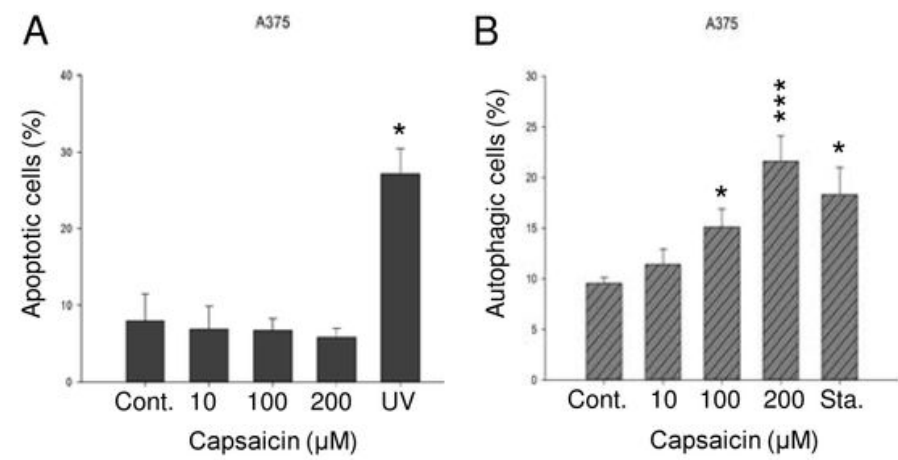

D

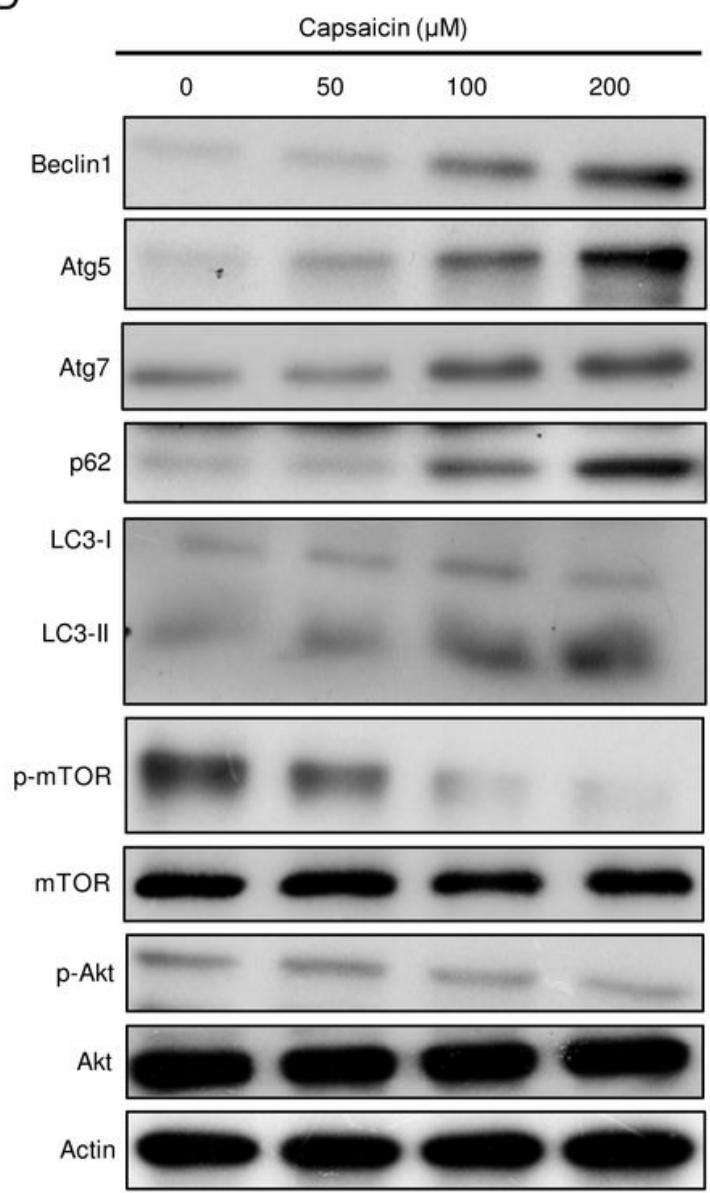

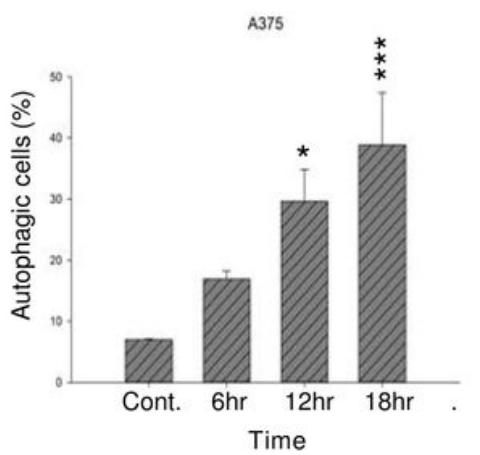

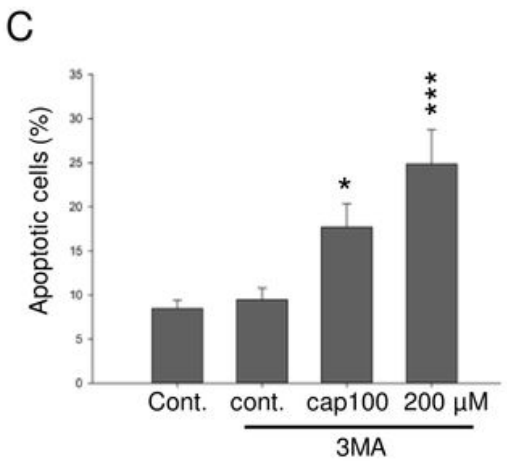

$\mathrm{E}$

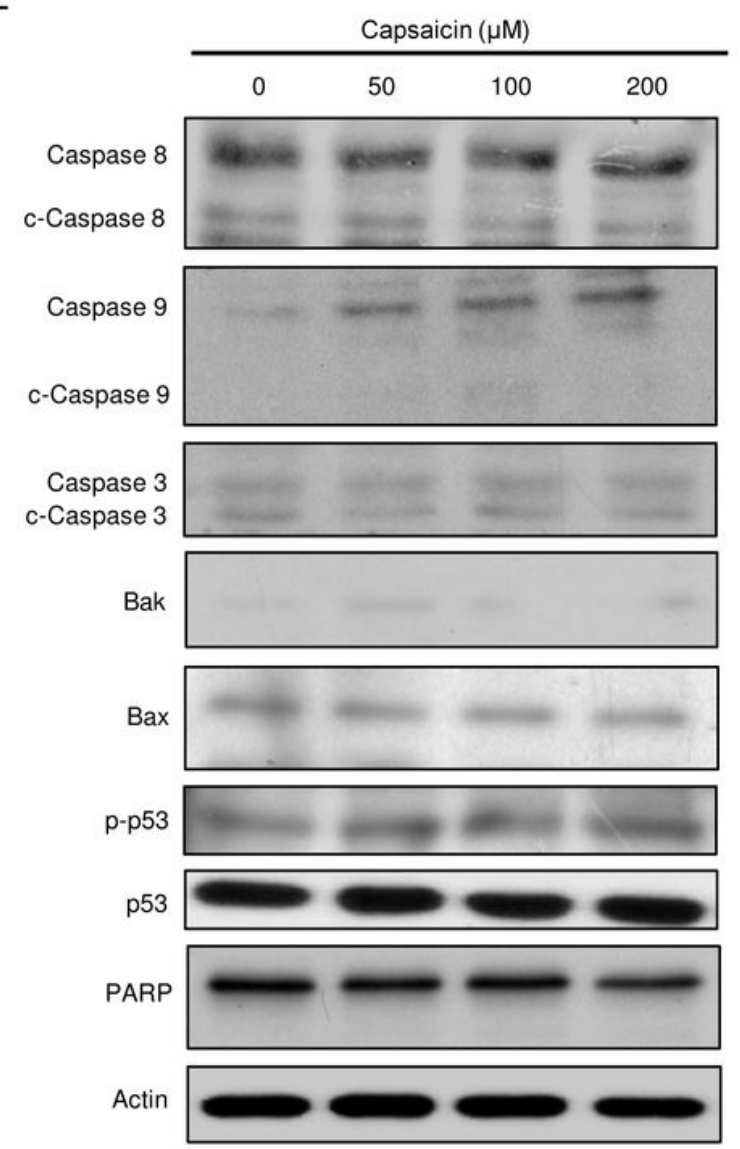

\section{Figure 2}

Capsaicin favorably triggers autophagy not apoptosis in A375 melanoma cells. (A) Cells were treated with capsaicin or ethanol for 24 hours. The percentage of apoptotic cells was determined by flowcytometry, and the results are presented as the percentage of apoptotic cells. Values (means \pm SDs) are from at least three independent experiments $(* p<0.05)$. (B) Cells were treated with different concentrations of capsaicin/ethanol for 15 hours or $200 \mu \mathrm{M}$ of capsaicin for different time length. Autophagy was determined by $\mathrm{AO}$ staining using flow cytometry, analysis and the results are expressed as a percentage of autophagic cells. Values (means \pm SDs) are from at least three independent experiments ( ${ }^{*}<<0.05$, ${ }^{\star \star *} \mathrm{p}<0.001$ ). (C) Cells were pretreated with $10 \mu \mathrm{M} 3-\mathrm{MA}$ for $1 \mathrm{~h}$ before exposure 
to capsaicin or ethanol for 24 hours. The percentage of apoptotic cells was assessed by flow cytometry, and the results are expressed as a percentage of apoptotic cells. Values (means \pm SDs) are from at least three independent experiments ( ${ }^{*} p<0.05,{ }^{* *} p<0.001$ ). (D, E) A375 cells were treated with capsaicin or ethanol for different concentrations and aliquots of cell lysates were separated by SDS-PAGE and analyzed for protein expression by Western blotting. $\beta$-actin was used as an internal control to monitor for equal loading. Representative images are shown from at least three independent experiments.

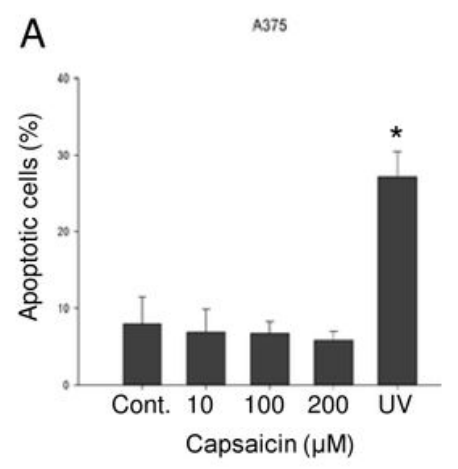

D

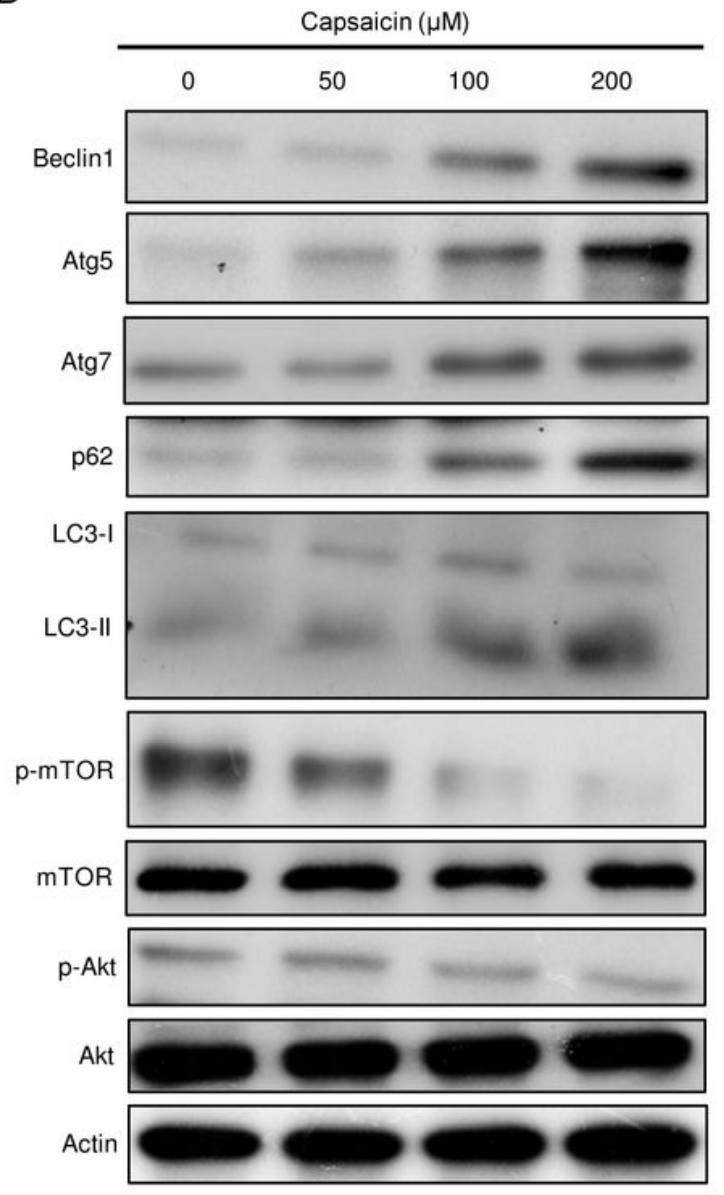

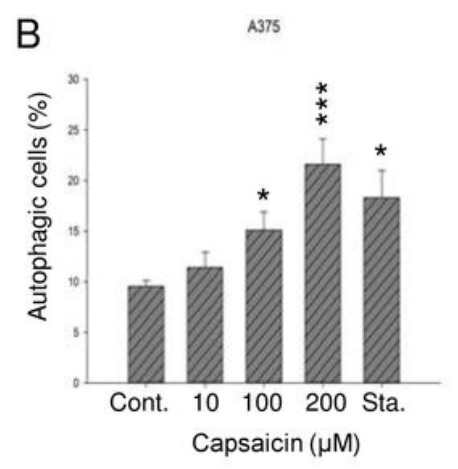
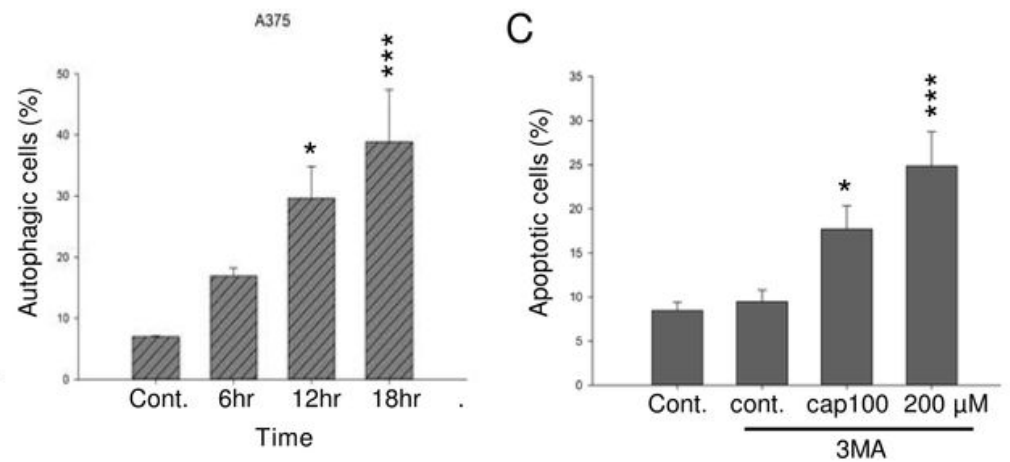

E

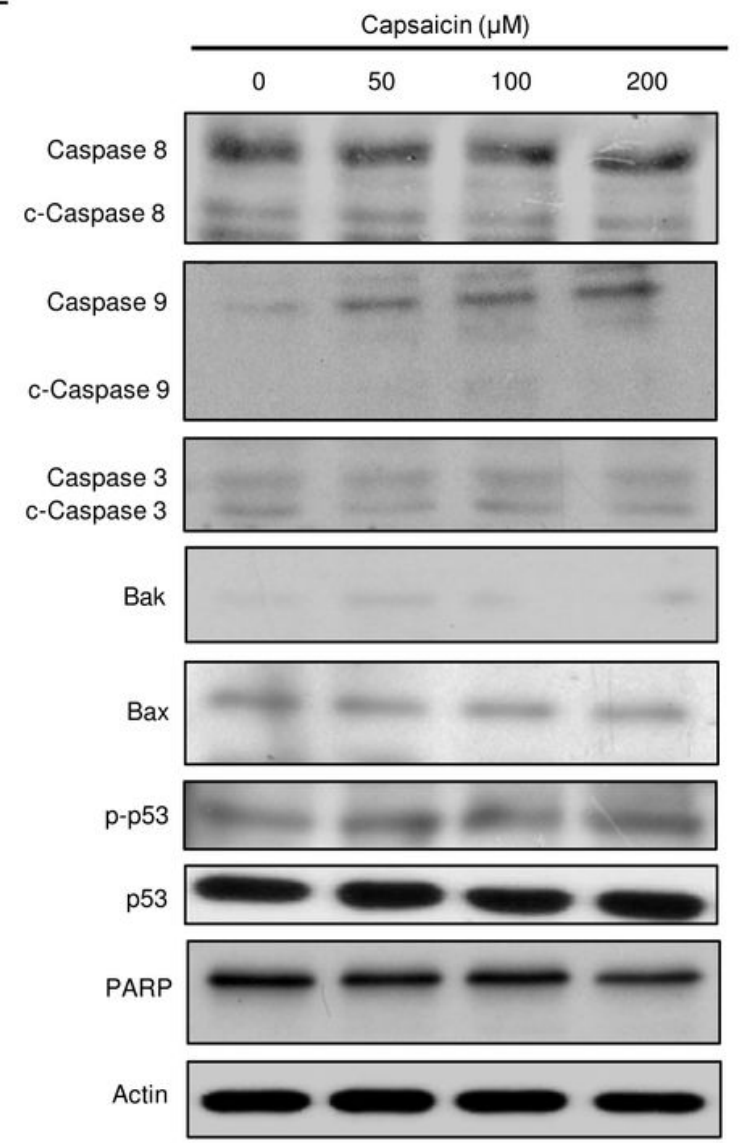

\section{Figure 2}

Capsaicin favorably triggers autophagy not apoptosis in A375 melanoma cells. (A) Cells were treated with capsaicin or ethanol for 24 hours. The percentage of apoptotic cells was determined by flow- 
cytometry, and the results are presented as the percentage of apoptotic cells. Values (means \pm SDs) are from at least three independent experiments $\left({ }^{*} p<0.05\right)$. (B) Cells were treated with different concentrations of capsaicin/ethanol for 15 hours or $200 \mu \mathrm{M}$ of capsaicin for different time length. Autophagy was determined by $\mathrm{AO}$ staining using flow cytometry, analysis and the results are expressed as a percentage of autophagic cells. Values (means \pm SDs) are from at least three independent experiments ( ${ }^{\mathrm{p}}<0.05$, $* \star \star \mathrm{p}<0.001$ ). (C) Cells were pretreated with $10 \mu \mathrm{M}$ 3-MA for $1 \mathrm{~h}$ before exposure to capsaicin or ethanol for 24 hours. The percentage of apoptotic cells was assessed by flow cytometry, and the results are expressed as a percentage of apoptotic cells. Values (means \pm SDs) are from at least three independent experiments ( ${ }^{*} p<0.05,{ }^{\star * *} p<0.001$ ). (D, E) A375 cells were treated with capsaicin or ethanol for different concentrations and aliquots of cell lysates were separated by SDS-PAGE and analyzed for protein expression by Western blotting. $\beta$-actin was used as an internal control to monitor for equal loading. Representative images are shown from at least three independent experiments. 

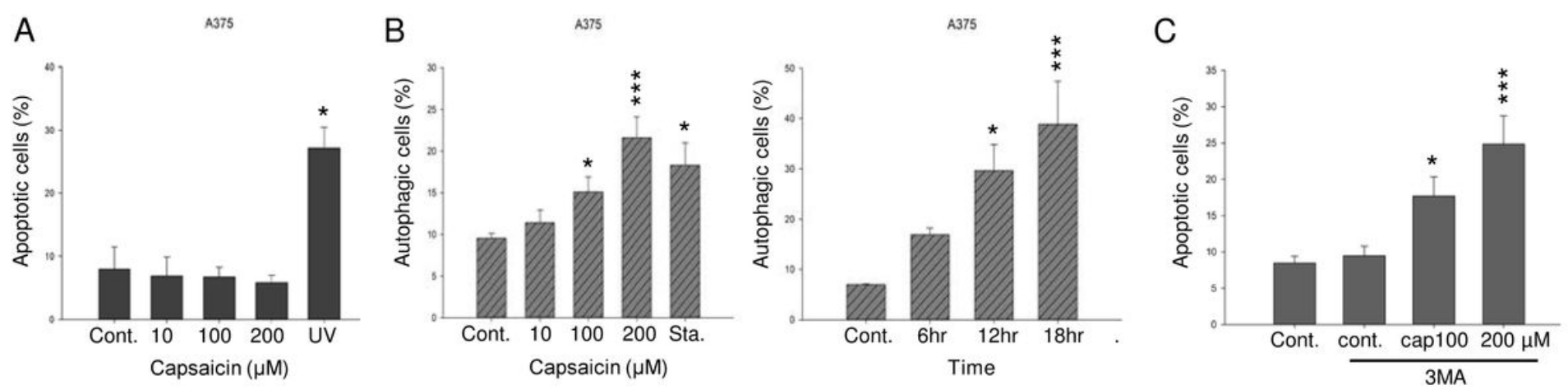

D

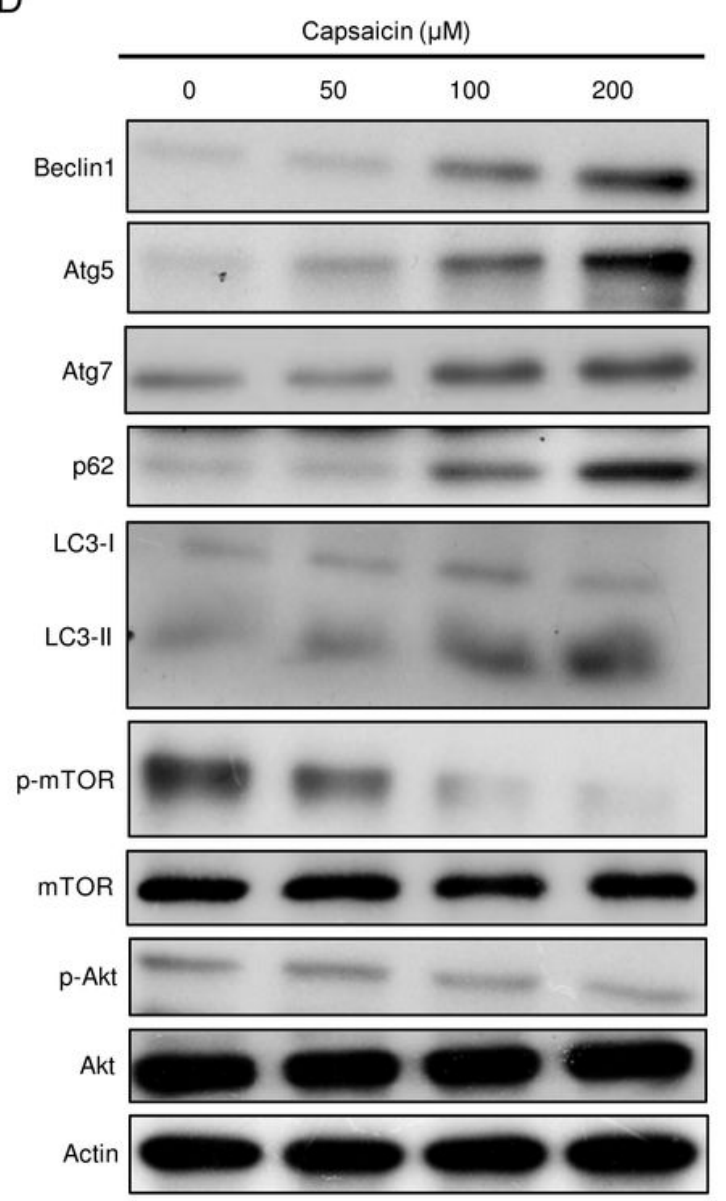

$\mathrm{E}$
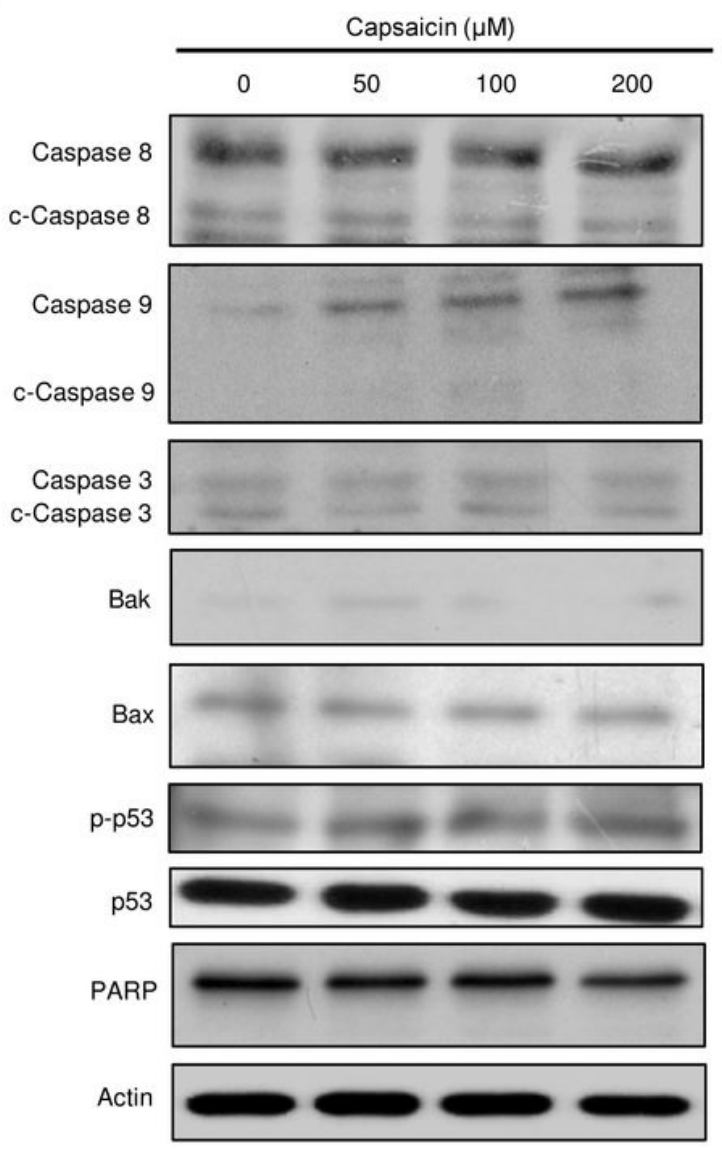

\section{Figure 2}

Capsaicin favorably triggers autophagy not apoptosis in A375 melanoma cells. (A) Cells were treated with capsaicin or ethanol for 24 hours. The percentage of apoptotic cells was determined by flowcytometry, and the results are presented as the percentage of apoptotic cells. Values (means \pm SDs) are from at least three independent experiments $(* p<0.05)$. (B) Cells were treated with different concentrations of capsaicin/ethanol for 15 hours or $200 \mu \mathrm{M}$ of capsaicin for different time length. Autophagy was determined by $\mathrm{AO}$ staining using flow cytometry, analysis and the results are expressed as a percentage of autophagic cells. Values (means \pm SDs) are from at least three independent experiments ( ${ }^{*}<0.05,{ }^{\star \star \star} \mathrm{p}<0.001$ ). (C) Cells were pretreated with $10 \mu \mathrm{M} 3$-MA for $1 \mathrm{~h}$ before exposure 
to capsaicin or ethanol for 24 hours. The percentage of apoptotic cells was assessed by flow cytometry, and the results are expressed as a percentage of apoptotic cells. Values (means \pm SDs) are from at least three independent experiments ( ${ }^{*} p<0.05,{ }^{* *} p<0.001$ ). (D, E) A375 cells were treated with capsaicin or ethanol for different concentrations and aliquots of cell lysates were separated by SDS-PAGE and analyzed for protein expression by Western blotting. $\beta$-actin was used as an internal control to monitor for equal loading. Representative images are shown from at least three independent experiments.

A

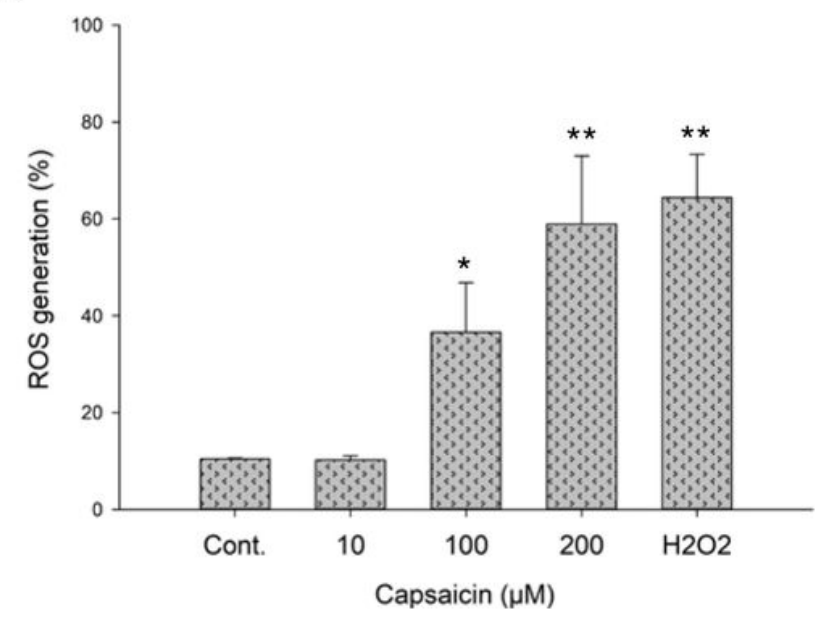

B

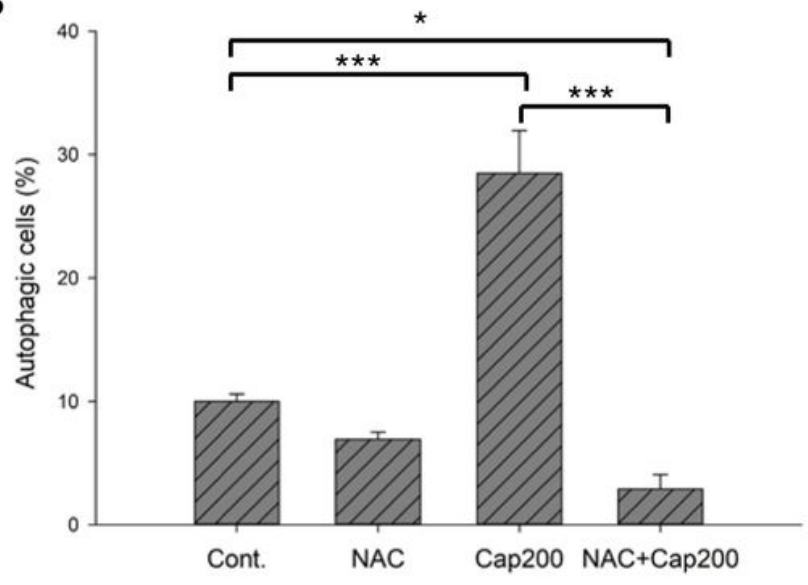

C

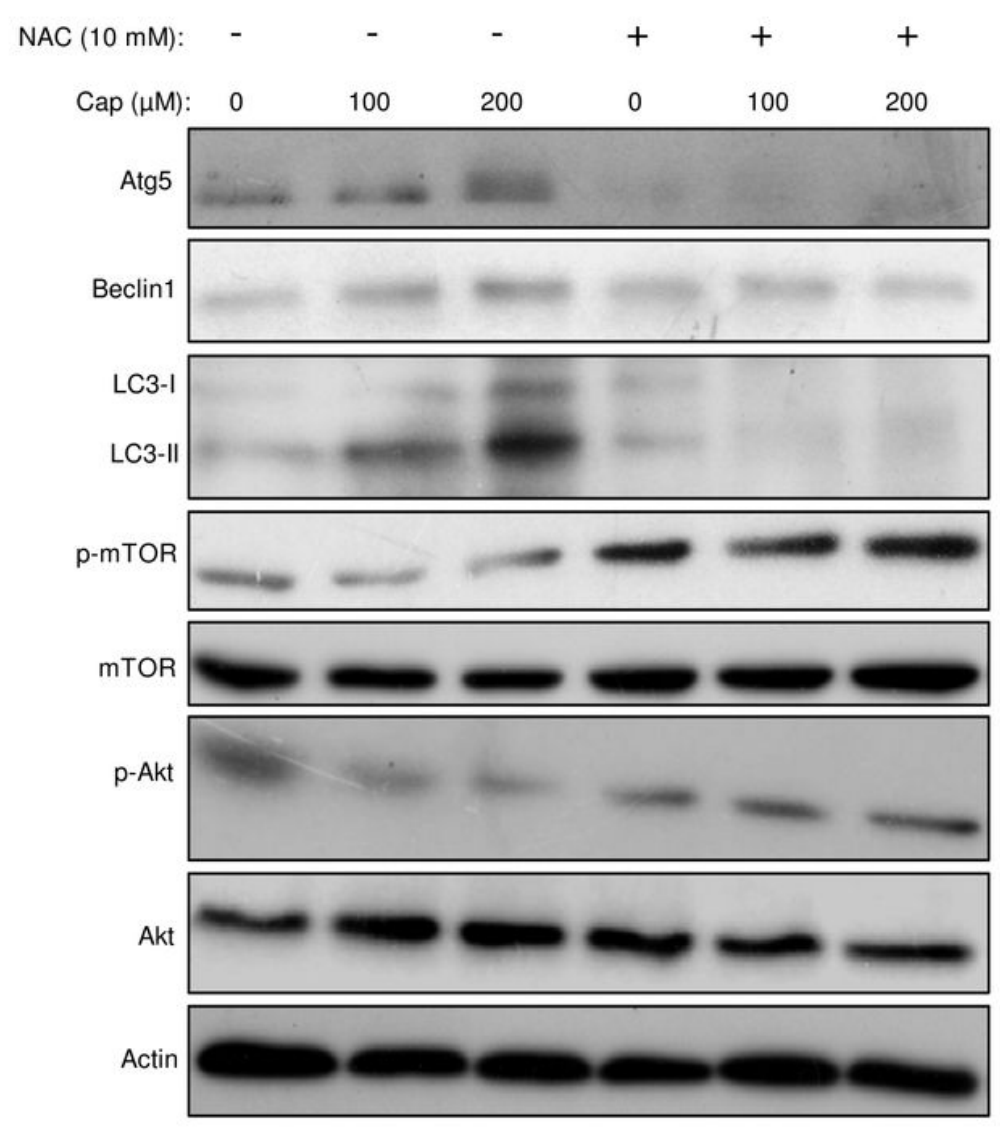

\section{Figure 3}

Capsaicin-induced autophagy is dependent of ROS signaling in A375 cells. (A) The percent change in intracellular ROS generation was measured after cells were exposed to different concentrations of capsaicin for $1 \mathrm{~h}$. Values (means $\pm S D s$ ) are from at least three independent experiments $\left({ }^{*} p<0.05, * \star * p\right.$ $<0.001$ ). (B) Cells were pretreated with or without $10 \mathrm{mM} \mathrm{NAC}$ for $1 \mathrm{~h}$ before exposure to $200 \mu \mathrm{M}$ capsaicin or ethanol for 18 hours. The percentage of autophagic cells was assessed by flow cytometry, and the results are expressed as a percentage of autophagic cells. Values (means \pm SDs) are from at least three independent experiments $(* p<0.05, * \star * p<0.001)$. (C) Cells were pretreated with or without 10 $\mathrm{mM}$ NAC for $1 \mathrm{~h}$ before exposure to capsaicin or ethanol for 24 hours. Aliquots of cell lysates were separated by SDS-PAGE and analyzed for protein expression by Western blotting. 囚-actin was used as an 
internal control to monitor for equal loading. Representative images are shown from at least three independent experiments.
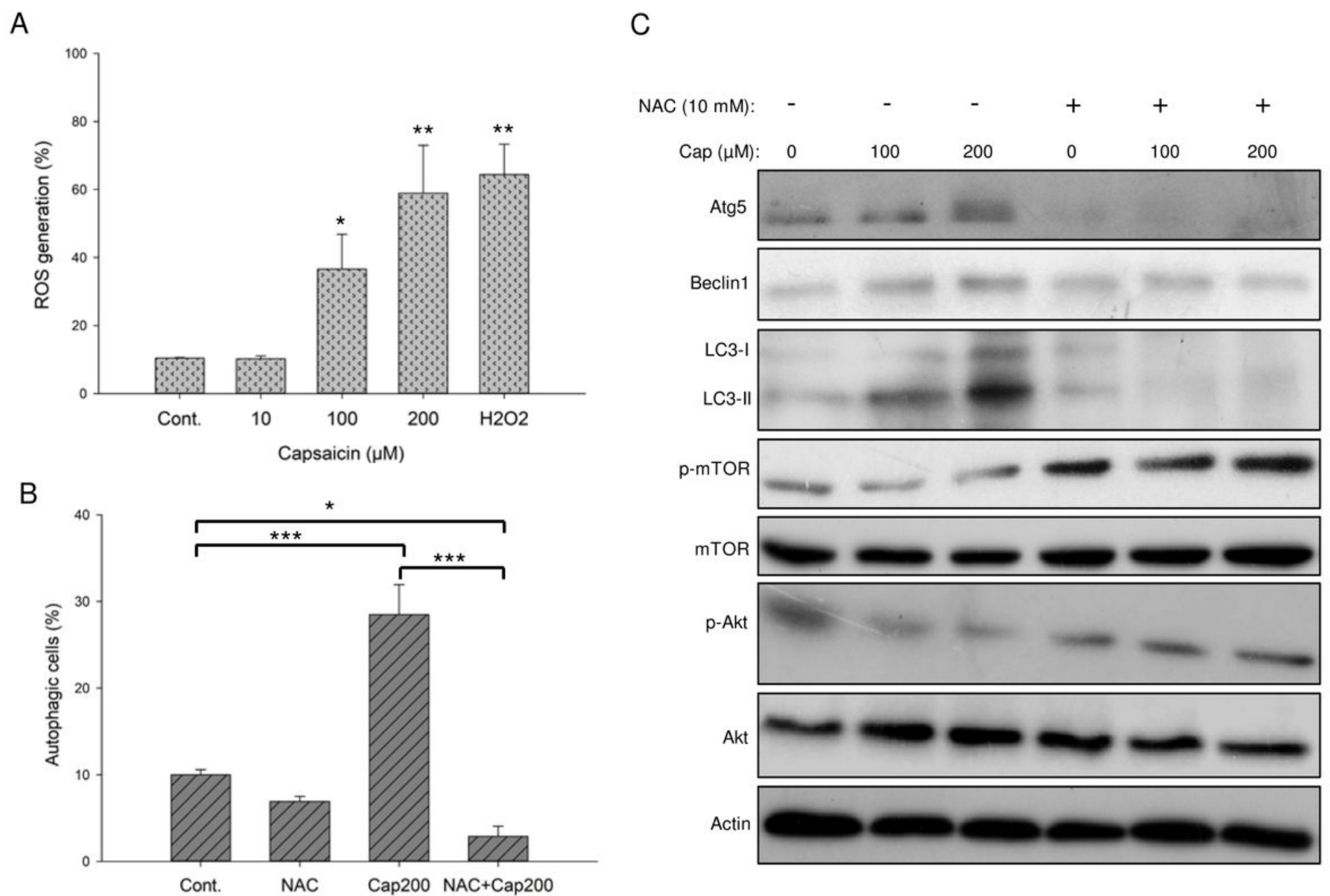

\section{Figure 3}

Capsaicin-induced autophagy is dependent of ROS signaling in A375 cells. (A) The percent change in intracellular ROS generation was measured after cells were exposed to different concentrations of capsaicin for $1 \mathrm{~h}$. Values (means \pm SDs) are from at least three independent experiments $(* p<0.05, \star \star \star ~ p$ $<0.001$ ). (B) Cells were pretreated with or without $10 \mathrm{mM}$ NAC for $1 \mathrm{~h}$ before exposure to $200 \mu \mathrm{M}$ capsaicin or ethanol for 18 hours. The percentage of autophagic cells was assessed by flow cytometry, and the results are expressed as a percentage of autophagic cells. Values (means \pm SDs) are from at least three independent experiments ( $\left.{ }^{*}<<0.05, * \star * p<0.001\right)$. (C) Cells were pretreated with or without 10 mM NAC for $1 \mathrm{~h}$ before exposure to capsaicin or ethanol for 24 hours. Aliquots of cell lysates were separated by SDS-PAGE and analyzed for protein expression by Western blotting. \-actin was used as an internal control to monitor for equal loading. Representative images are shown from at least three independent experiments. 
A

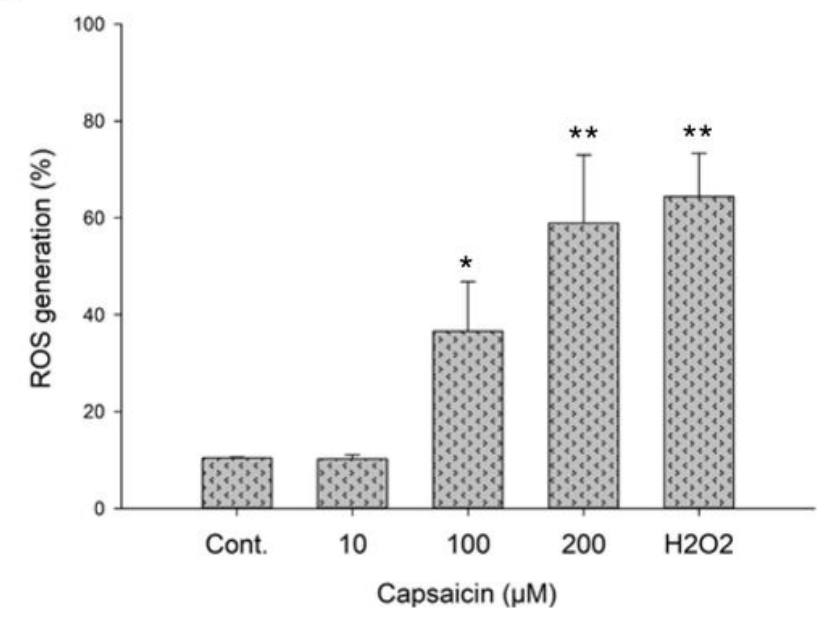

B

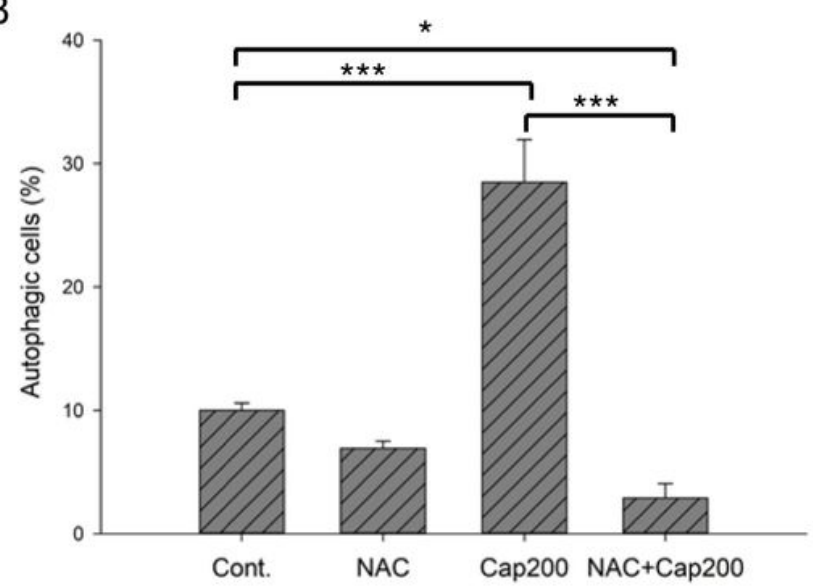

C

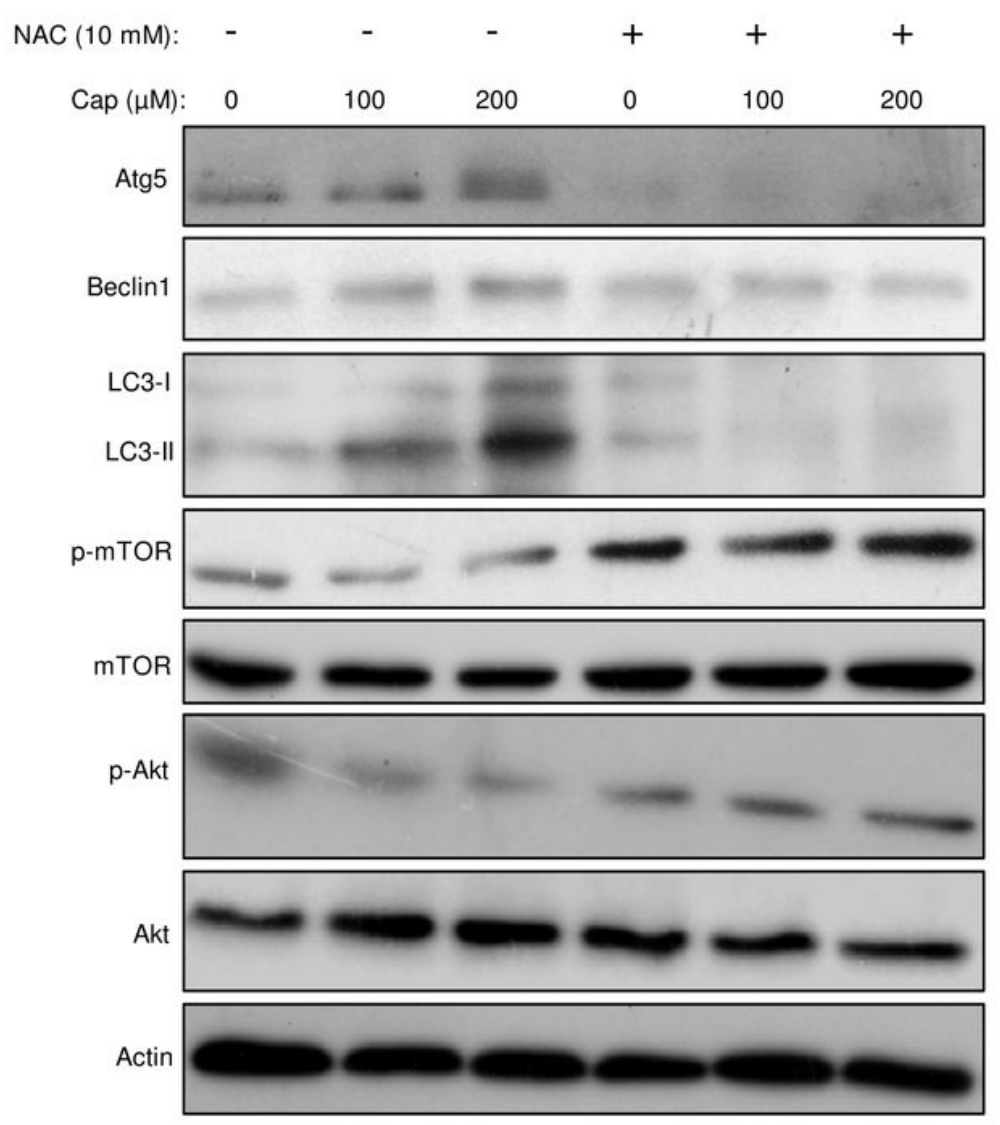

\section{Figure 3}

Capsaicin-induced autophagy is dependent of ROS signaling in A375 cells. (A) The percent change in intracellular ROS generation was measured after cells were exposed to different concentrations of capsaicin for $1 \mathrm{~h}$. Values (means \pm SDs) are from at least three independent experiments $(* p<0.05, * \star \star p$ <0.001). (B) Cells were pretreated with or without $10 \mathrm{mM}$ NAC for $1 \mathrm{~h}$ before exposure to $200 \mu \mathrm{M}$ capsaicin or ethanol for 18 hours. The percentage of autophagic cells was assessed by flow cytometry, and the results are expressed as a percentage of autophagic cells. Values (means \pm SDs) are from at least three independent experiments (* $p<0.05, * \star \star p<0.001)$. (C) Cells were pretreated with or without 10 $\mathrm{mM}$ NAC for $1 \mathrm{~h}$ before exposure to capsaicin or ethanol for 24 hours. Aliquots of cell lysates were separated by SDS-PAGE and analyzed for protein expression by Western blotting. \-actin was used as an internal control to monitor for equal loading. Representative images are shown from at least three independent experiments. 
A

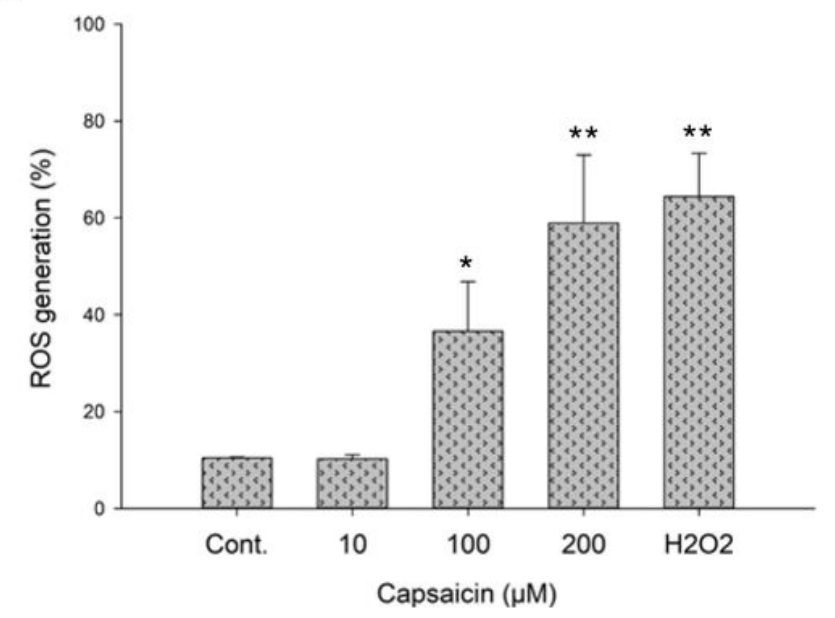

B

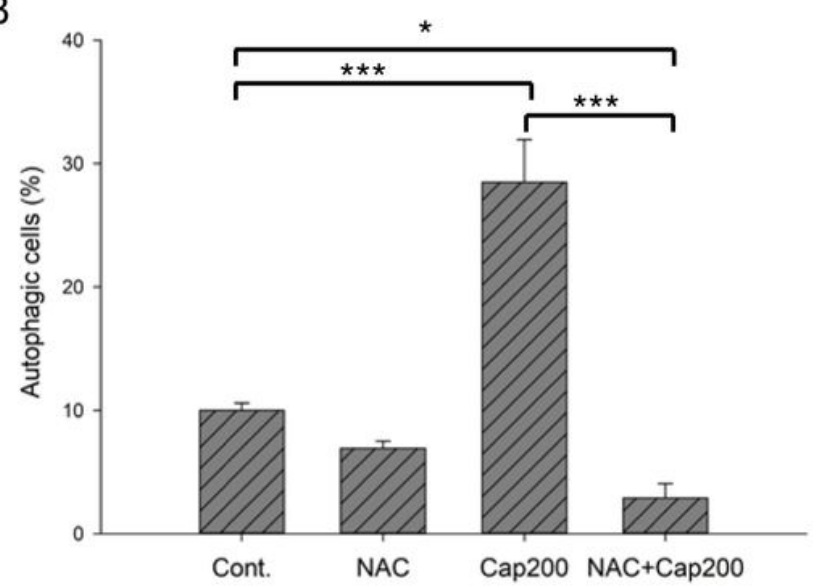

C

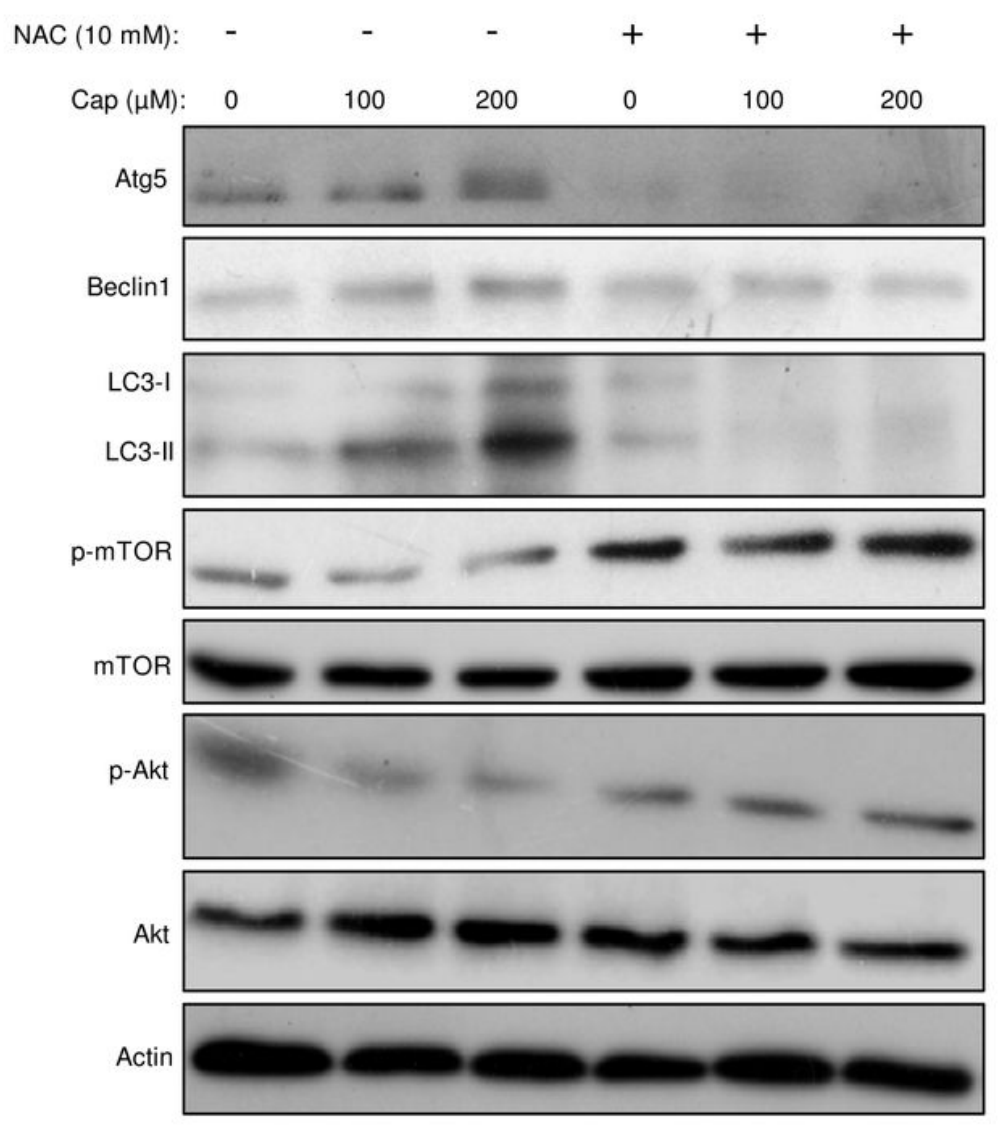

\section{Figure 3}

Capsaicin-induced autophagy is dependent of ROS signaling in A375 cells. (A) The percent change in intracellular ROS generation was measured after cells were exposed to different concentrations of capsaicin for $1 \mathrm{~h}$. Values (means \pm SDs) are from at least three independent experiments $(* p<0.05, * \star \star p$ <0.001). (B) Cells were pretreated with or without $10 \mathrm{mM}$ NAC for $1 \mathrm{~h}$ before exposure to $200 \mu \mathrm{M}$ capsaicin or ethanol for 18 hours. The percentage of autophagic cells was assessed by flow cytometry, and the results are expressed as a percentage of autophagic cells. Values (means \pm SDs) are from at least three independent experiments (* $p<0.05, * \star \star p<0.001)$. (C) Cells were pretreated with or without 10 $\mathrm{mM}$ NAC for $1 \mathrm{~h}$ before exposure to capsaicin or ethanol for 24 hours. Aliquots of cell lysates were separated by SDS-PAGE and analyzed for protein expression by Western blotting. \-actin was used as an internal control to monitor for equal loading. Representative images are shown from at least three independent experiments. 
A

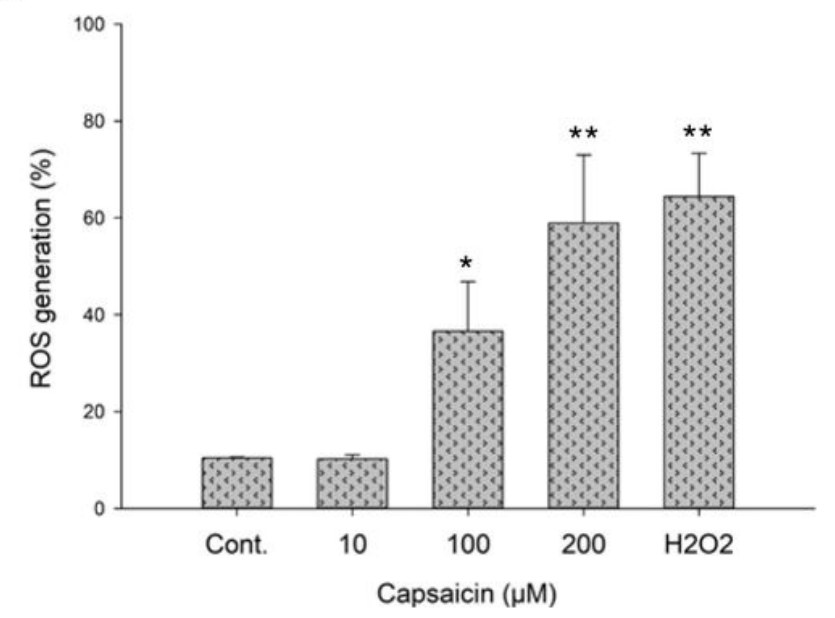

B

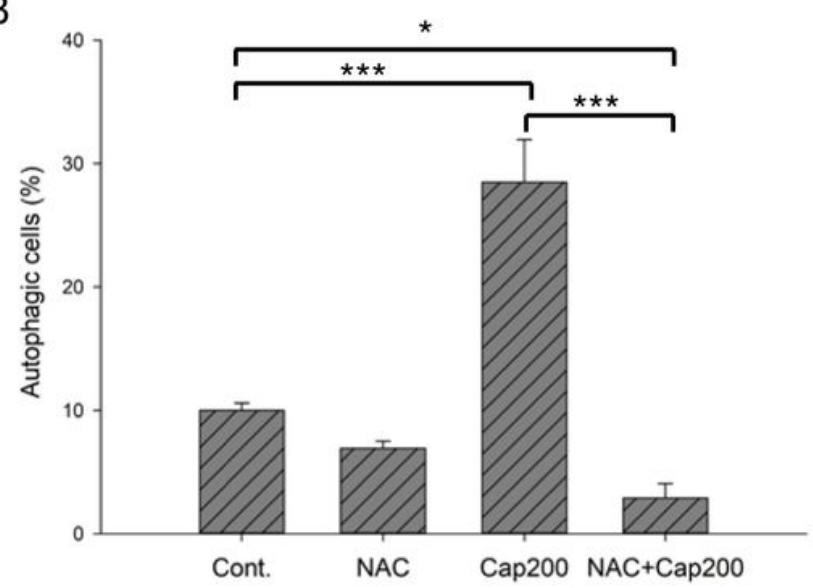

C

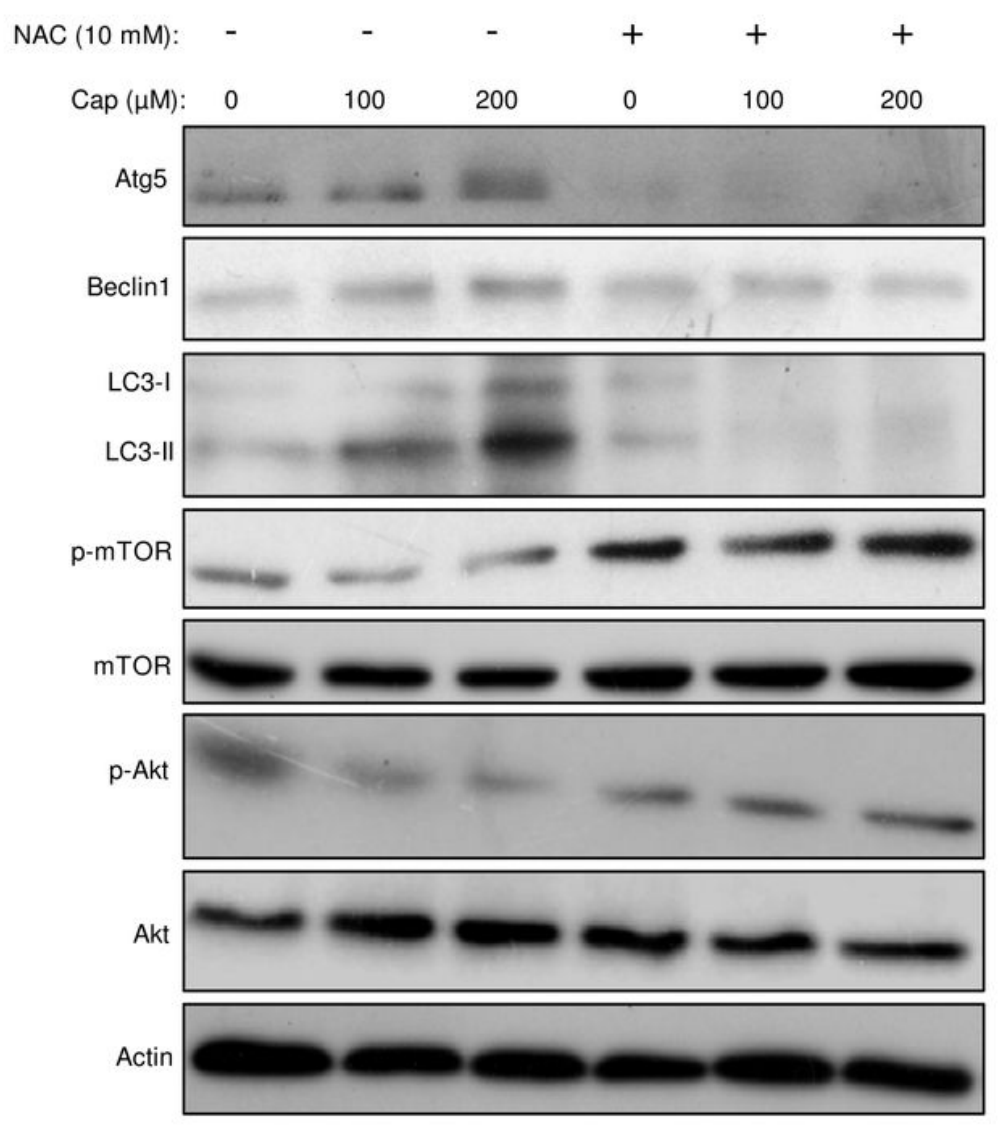

\section{Figure 3}

Capsaicin-induced autophagy is dependent of ROS signaling in A375 cells. (A) The percent change in intracellular ROS generation was measured after cells were exposed to different concentrations of capsaicin for $1 \mathrm{~h}$. Values (means \pm SDs) are from at least three independent experiments $(* p<0.05, * \star \star p$ <0.001). (B) Cells were pretreated with or without $10 \mathrm{mM}$ NAC for $1 \mathrm{~h}$ before exposure to $200 \mu \mathrm{M}$ capsaicin or ethanol for 18 hours. The percentage of autophagic cells was assessed by flow cytometry, and the results are expressed as a percentage of autophagic cells. Values (means \pm SDs) are from at least three independent experiments (* $p<0.05, * \star \star p<0.001)$. (C) Cells were pretreated with or without 10 $\mathrm{mM}$ NAC for $1 \mathrm{~h}$ before exposure to capsaicin or ethanol for 24 hours. Aliquots of cell lysates were separated by SDS-PAGE and analyzed for protein expression by Western blotting. \-actin was used as an internal control to monitor for equal loading. Representative images are shown from at least three independent experiments. 
A

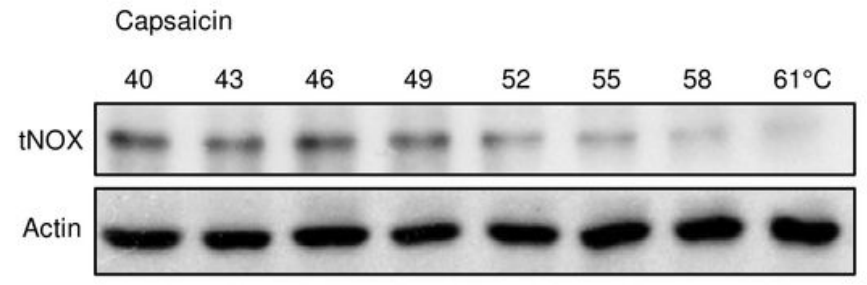

\section{Control}

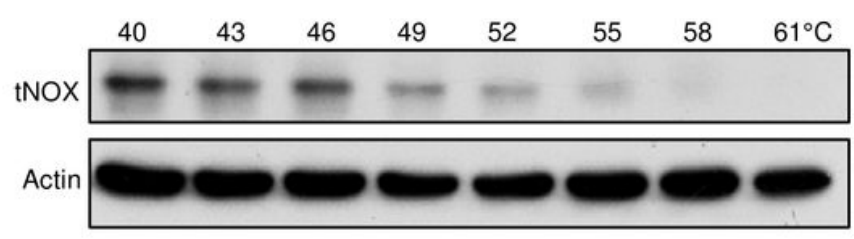

C

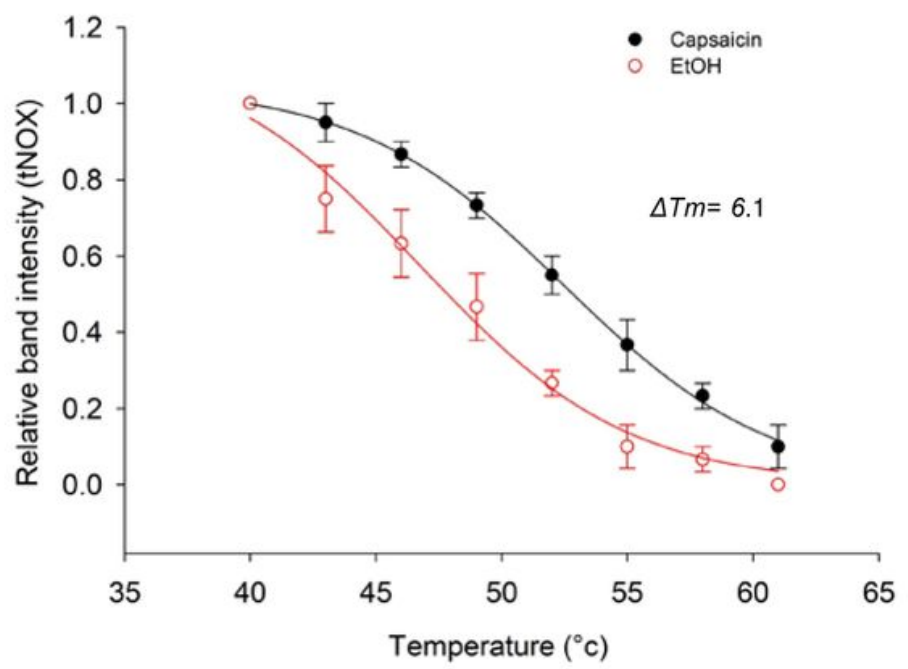

B

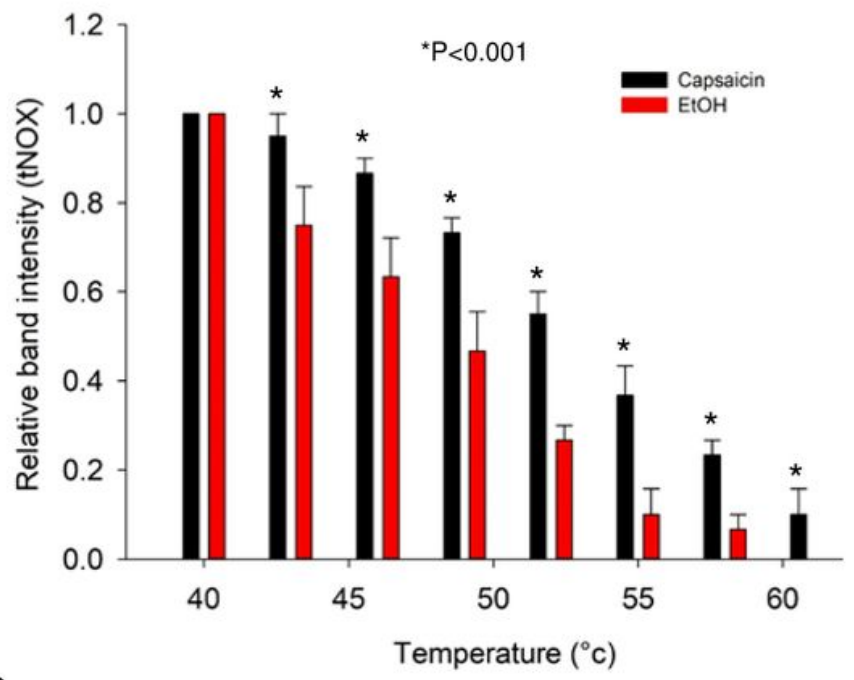

D

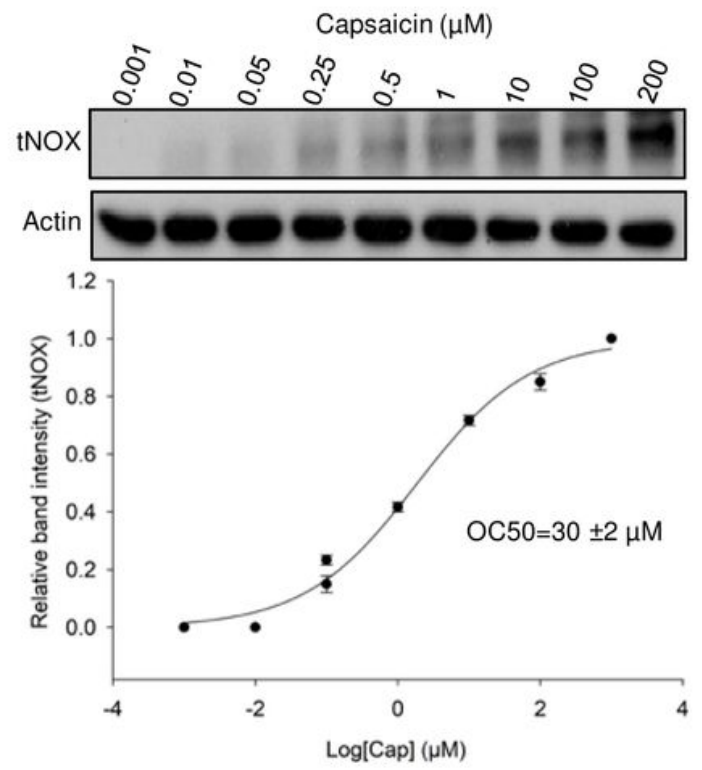

Figure 4

CETSA-based validation of direct binding between capsaicin and tNOX protein. (A) The immunoblot intensity of tNOX in A375 cells in the presence and absence of capsaicin as described in the Material and Methods. Representative images are shown. (B) The quantification of relative intensity of tNOX protein in the presence and absence of capsaicin versus increased temperature from three independent experiments ( ${ }^{*} p 0.05$ ). (C) CETSA-melting curves of tNOX in the presence and absence of capsaicin as described in the Material and Methods in A375 cells. The immunoblot intensity was normalized to the intensity of the $40^{\circ} \mathrm{C}$ sample. (D) A375 cells were incubated with different concentrations of capsaicin at $54^{\circ} \mathrm{C}$ as described in the Material and Methods. Dose-dependent thermal stability change of tNOX upon capsaicin treatment was evaluated after heating samples at $54^{\circ} \mathrm{C}$ for $3 \mathrm{~min}$. The band intensities of tNOX were normalized with respect to the intensity of actin. Representative images are shown. 
A

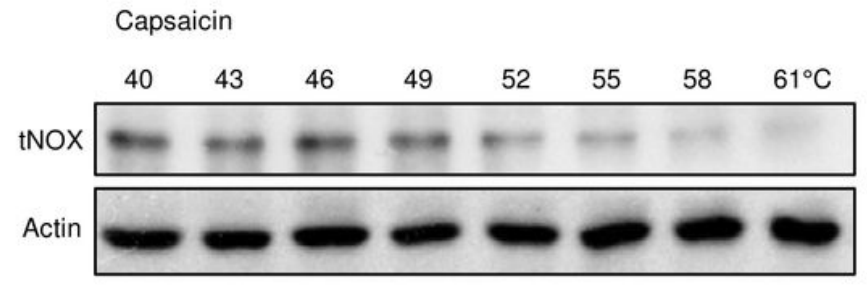

\section{Control}

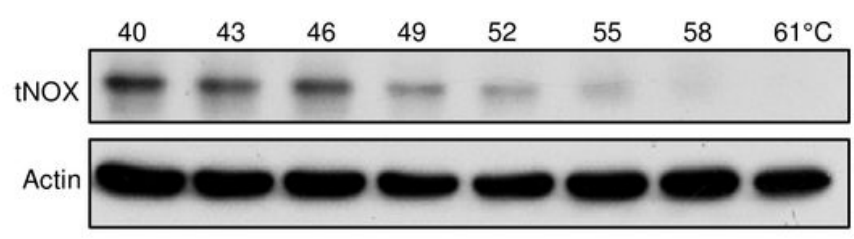

C

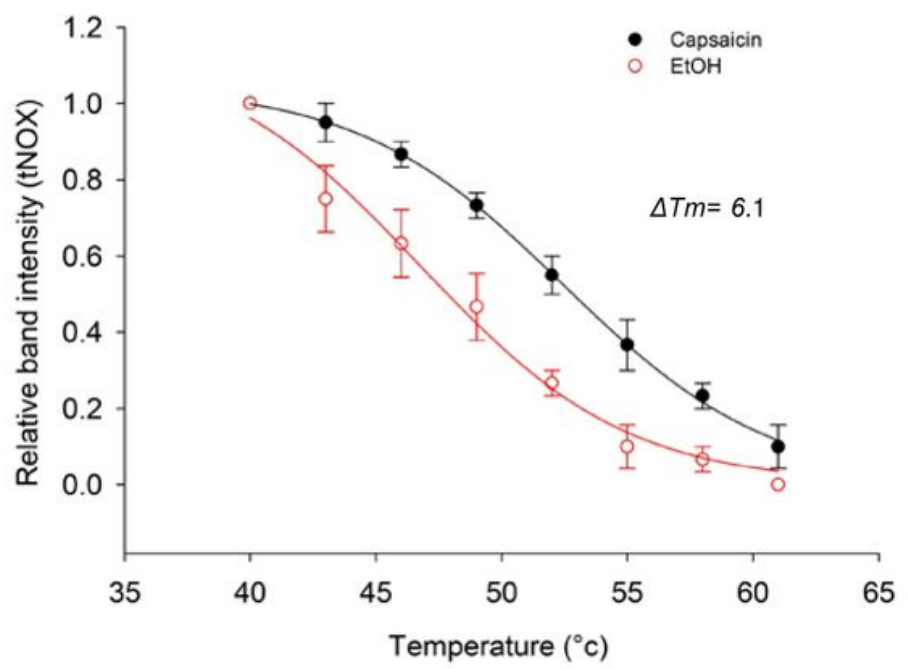

B

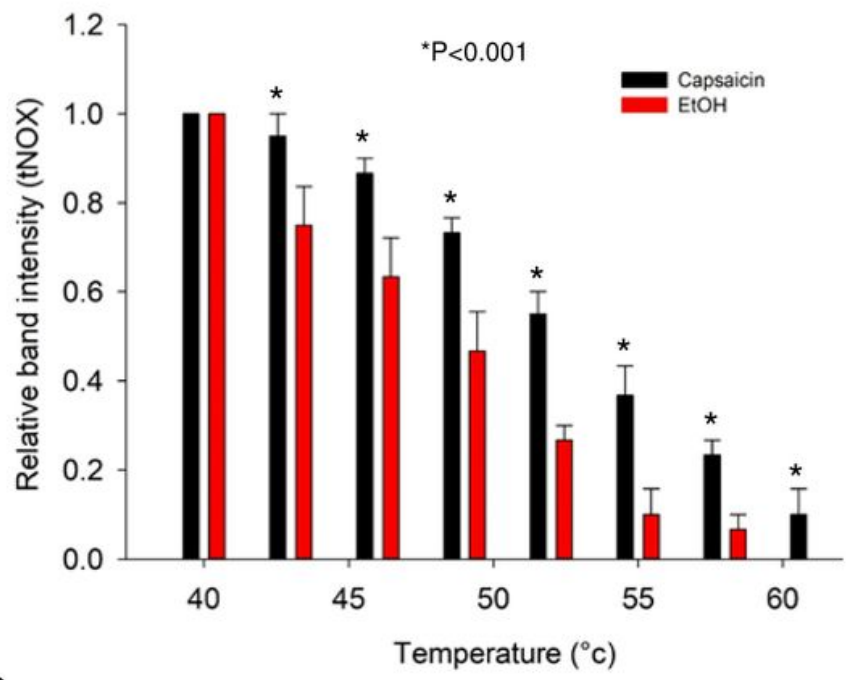

D

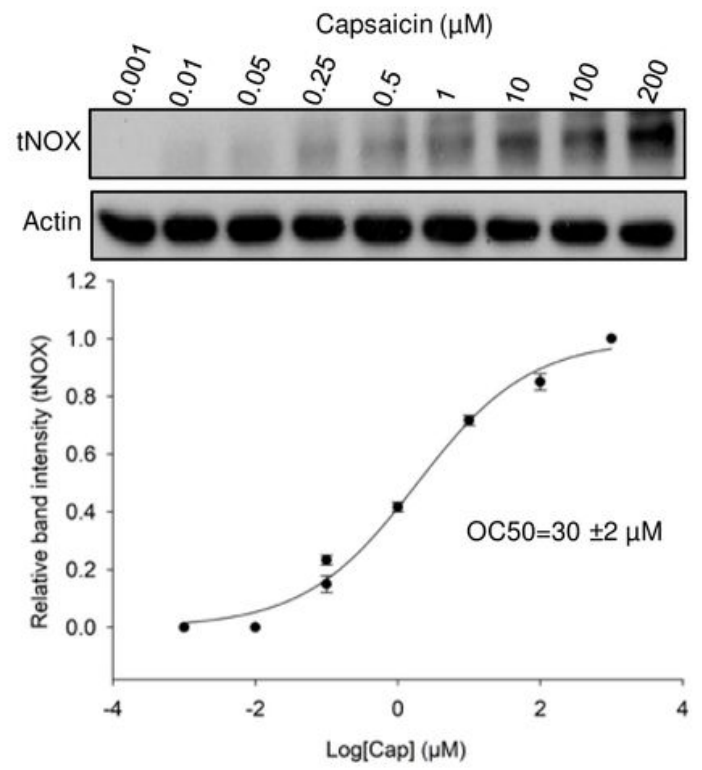

Figure 4

CETSA-based validation of direct binding between capsaicin and tNOX protein. (A) The immunoblot intensity of tNOX in A375 cells in the presence and absence of capsaicin as described in the Material and Methods. Representative images are shown. (B) The quantification of relative intensity of tNOX protein in the presence and absence of capsaicin versus increased temperature from three independent experiments ( ${ }^{*} p 0.05$ ). (C) CETSA-melting curves of tNOX in the presence and absence of capsaicin as described in the Material and Methods in A375 cells. The immunoblot intensity was normalized to the intensity of the $40^{\circ} \mathrm{C}$ sample. (D) A375 cells were incubated with different concentrations of capsaicin at $54^{\circ} \mathrm{C}$ as described in the Material and Methods. Dose-dependent thermal stability change of tNOX upon capsaicin treatment was evaluated after heating samples at $54^{\circ} \mathrm{C}$ for $3 \mathrm{~min}$. The band intensities of tNOX were normalized with respect to the intensity of actin. Representative images are shown. 
A
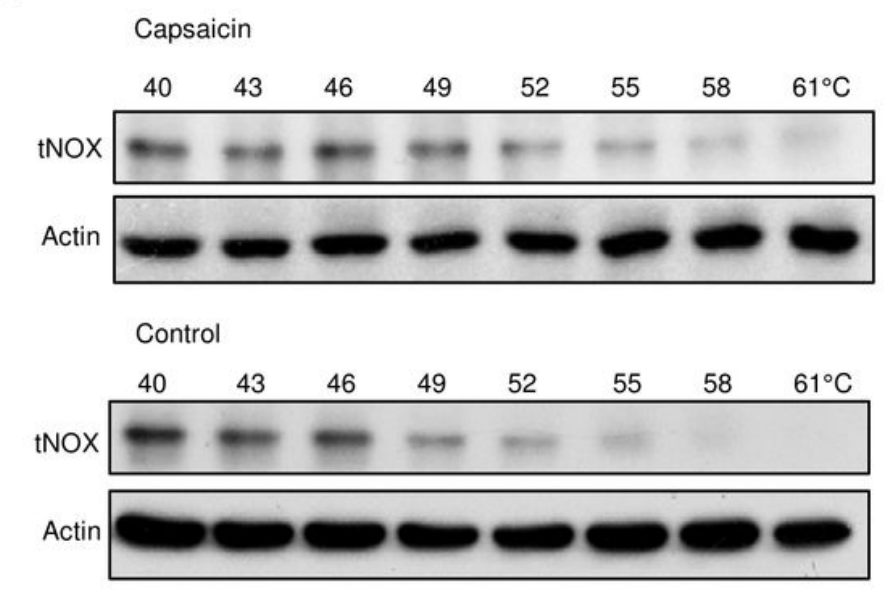

C

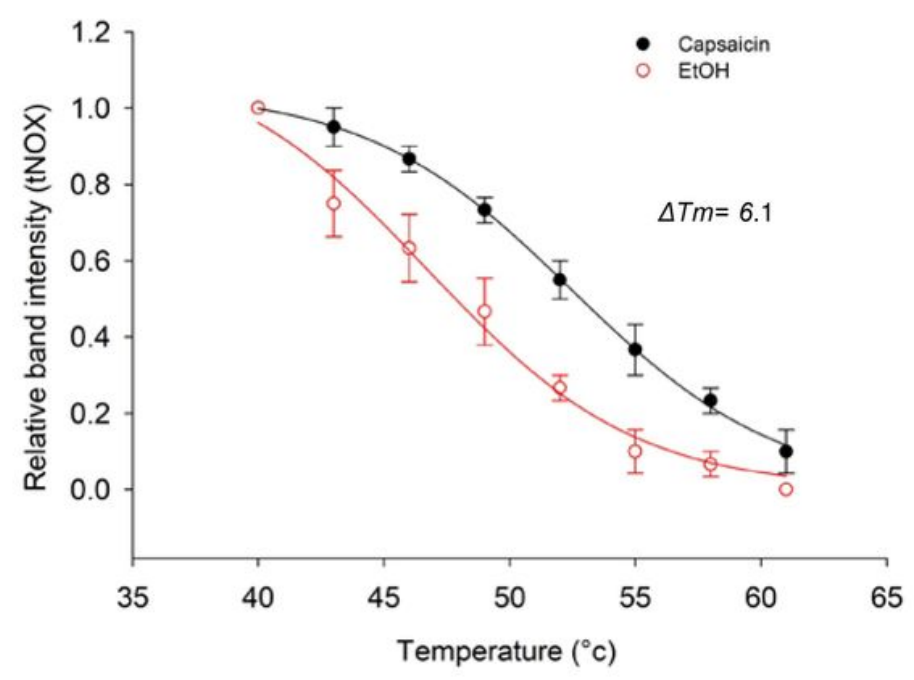

B

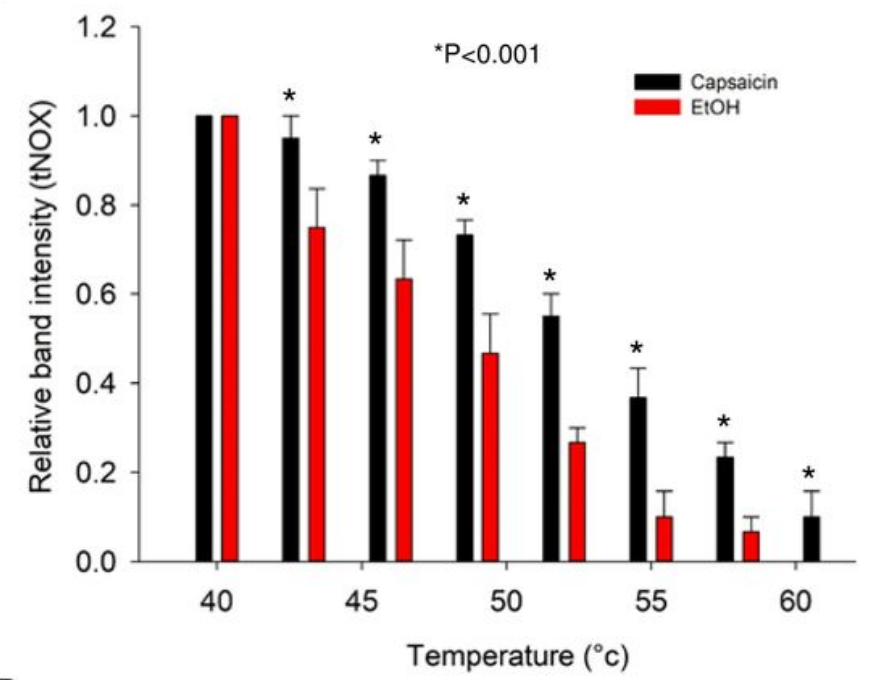

D

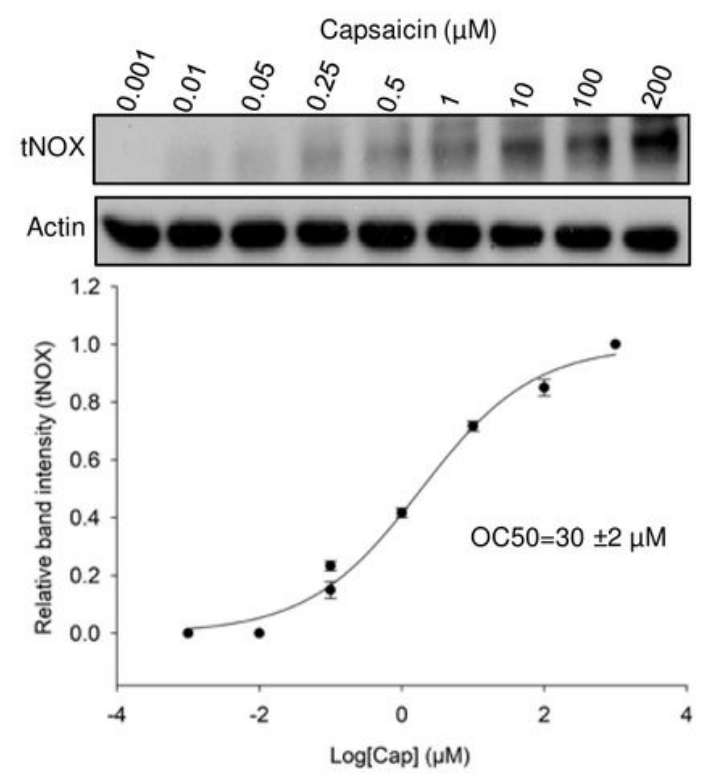

Figure 4

CETSA-based validation of direct binding between capsaicin and tNOX protein. (A) The immunoblot intensity of tNOX in A375 cells in the presence and absence of capsaicin as described in the Material and Methods. Representative images are shown. (B) The quantification of relative intensity of tNOX protein in the presence and absence of capsaicin versus increased temperature from three independent experiments ( $\left.{ }^{*} p<0.05\right)$. (C) CETSA-melting curves of $t N O X$ in the presence and absence of capsaicin as described in the Material and Methods in A375 cells. The immunoblot intensity was normalized to the intensity of the $40^{\circ} \mathrm{C}$ sample. (D) A375 cells were incubated with different concentrations of capsaicin at $54^{\circ} \mathrm{C}$ as described in the Material and Methods. Dose-dependent thermal stability change of tNOX upon capsaicin treatment was evaluated after heating samples at $54^{\circ} \mathrm{C}$ for $3 \mathrm{~min}$. The band intensities of tNOX were normalized with respect to the intensity of actin. Representative images are shown. 
A
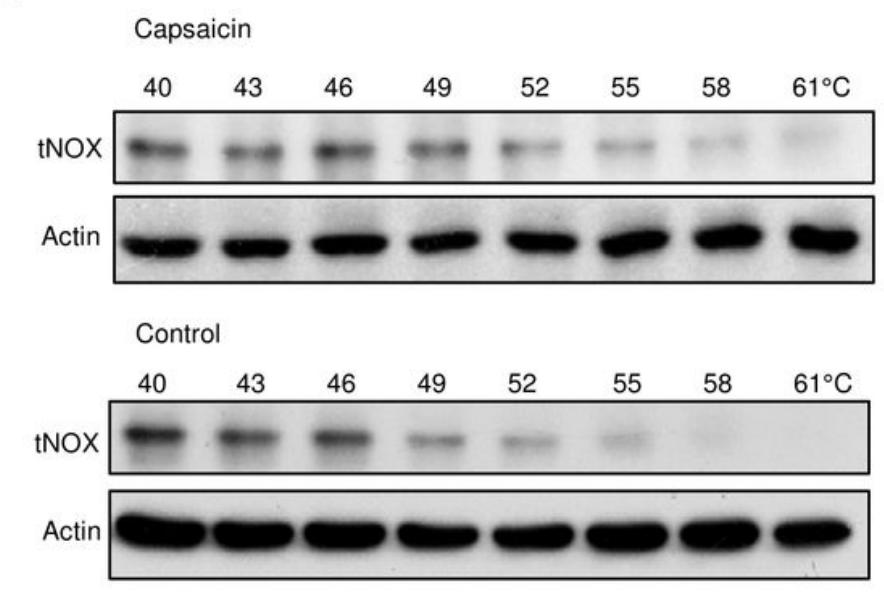

C

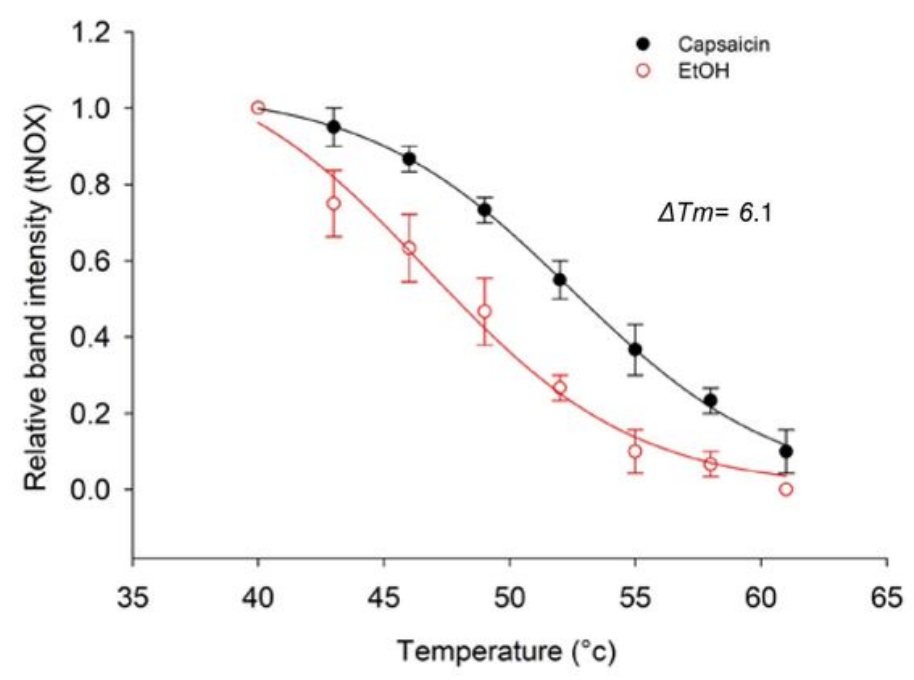

B

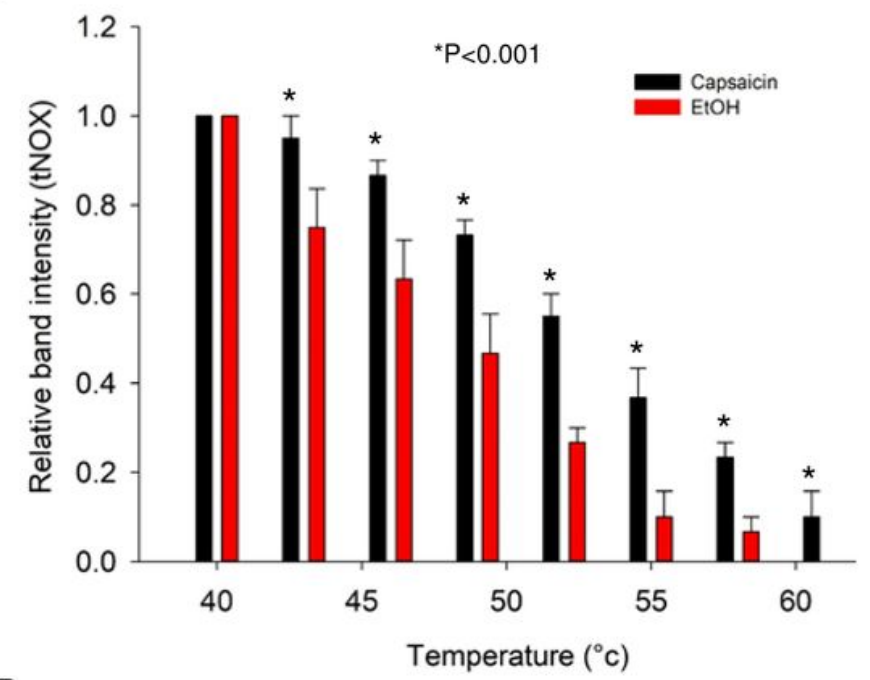

D

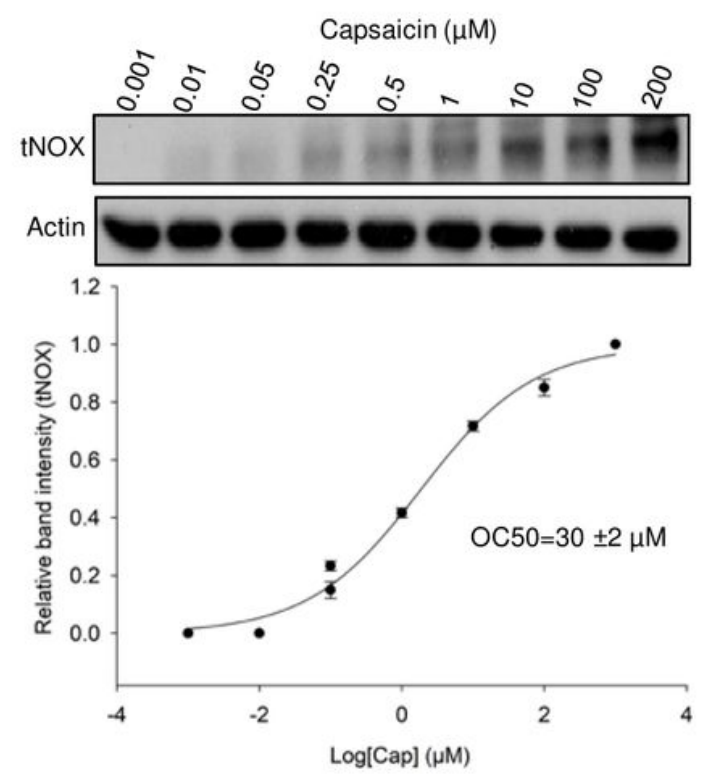

Figure 4

CETSA-based validation of direct binding between capsaicin and tNOX protein. (A) The immunoblot intensity of tNOX in A375 cells in the presence and absence of capsaicin as described in the Material and Methods. Representative images are shown. (B) The quantification of relative intensity of tNOX protein in the presence and absence of capsaicin versus increased temperature from three independent experiments ( $\left.{ }^{*} p<0.05\right)$. (C) CETSA-melting curves of $t N O X$ in the presence and absence of capsaicin as described in the Material and Methods in A375 cells. The immunoblot intensity was normalized to the intensity of the $40^{\circ} \mathrm{C}$ sample. (D) A375 cells were incubated with different concentrations of capsaicin at $54^{\circ} \mathrm{C}$ as described in the Material and Methods. Dose-dependent thermal stability change of tNOX upon capsaicin treatment was evaluated after heating samples at $54^{\circ} \mathrm{C}$ for $3 \mathrm{~min}$. The band intensities of tNOX were normalized with respect to the intensity of actin. Representative images are shown. 
A

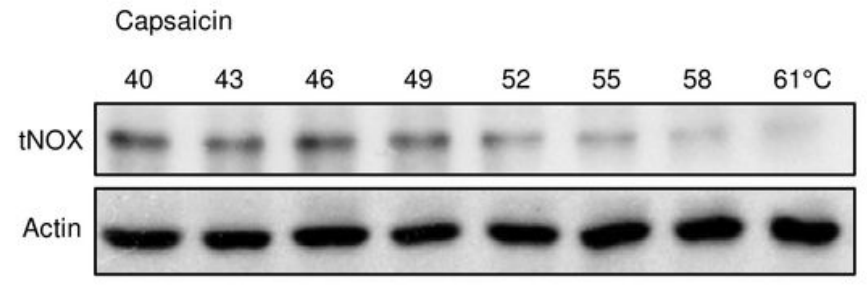

\section{Control}

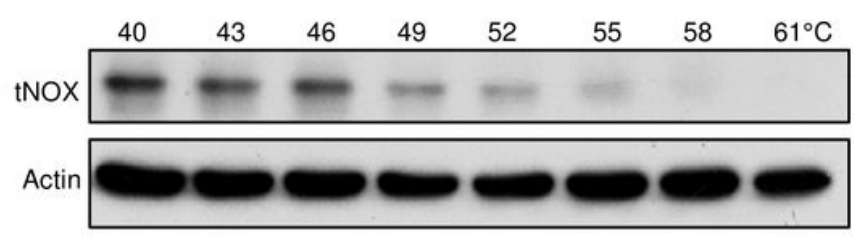

C

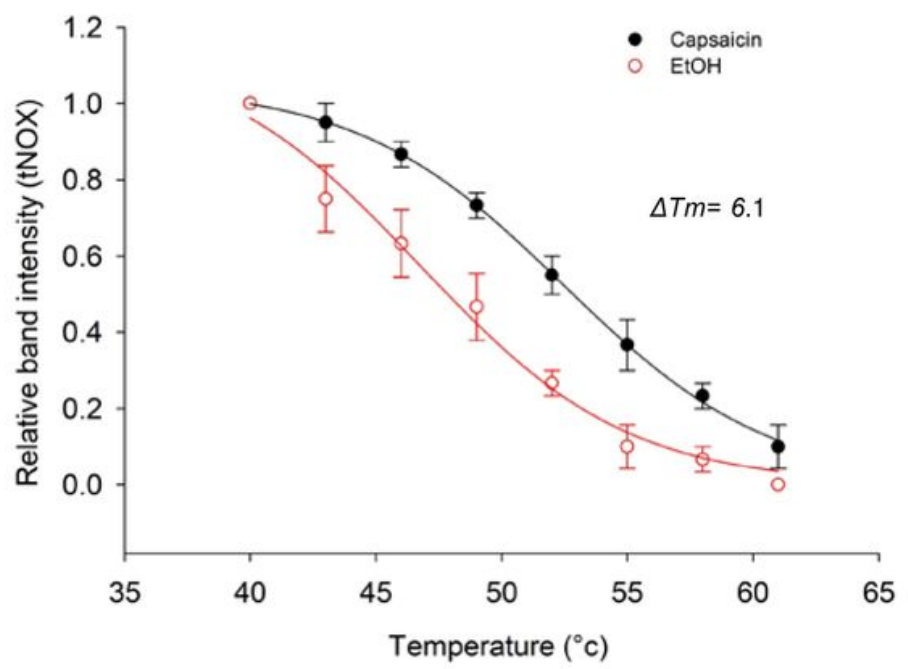

B

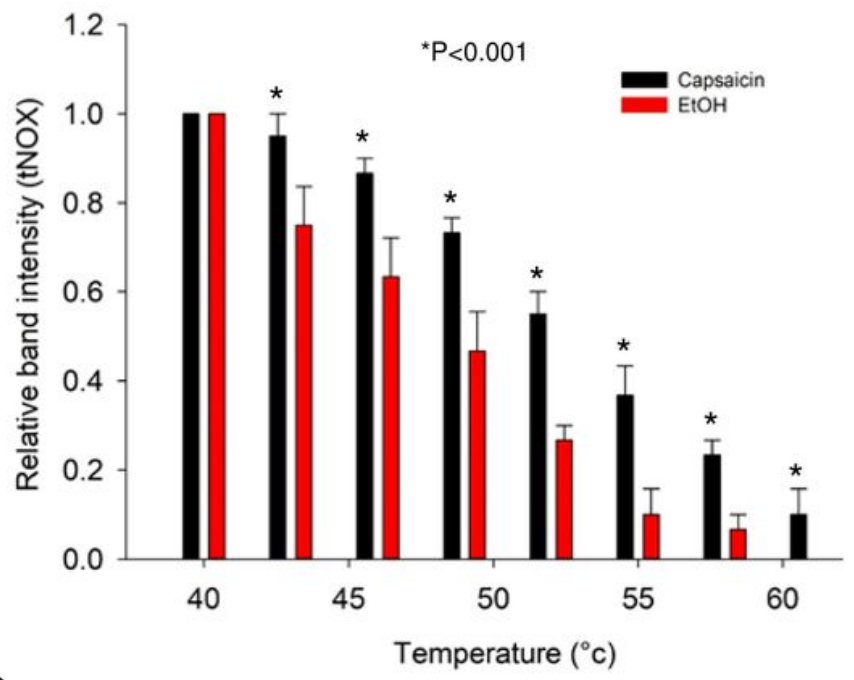

D

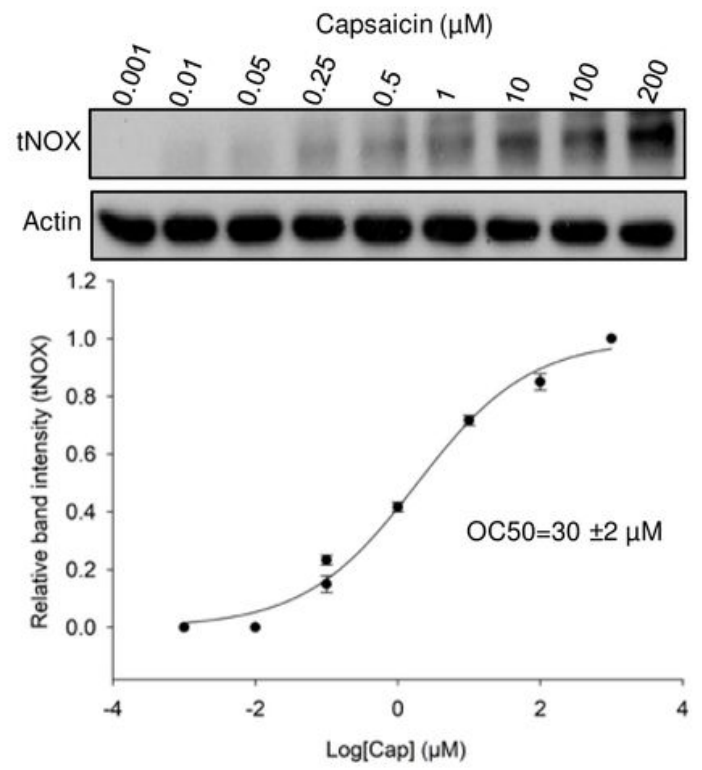

Figure 4

CETSA-based validation of direct binding between capsaicin and tNOX protein. (A) The immunoblot intensity of tNOX in A375 cells in the presence and absence of capsaicin as described in the Material and Methods. Representative images are shown. (B) The quantification of relative intensity of tNOX protein in the presence and absence of capsaicin versus increased temperature from three independent experiments ( ${ }^{*} p 0.05$ ). (C) CETSA-melting curves of tNOX in the presence and absence of capsaicin as described in the Material and Methods in A375 cells. The immunoblot intensity was normalized to the intensity of the $40^{\circ} \mathrm{C}$ sample. (D) A375 cells were incubated with different concentrations of capsaicin at $54^{\circ} \mathrm{C}$ as described in the Material and Methods. Dose-dependent thermal stability change of tNOX upon capsaicin treatment was evaluated after heating samples at $54^{\circ} \mathrm{C}$ for $3 \mathrm{~min}$. The band intensities of tNOX were normalized with respect to the intensity of actin. Representative images are shown. 

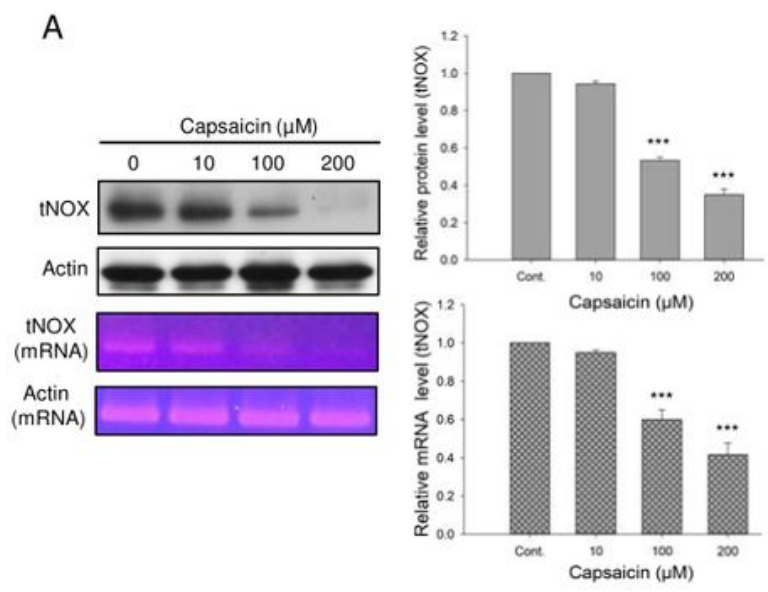

C

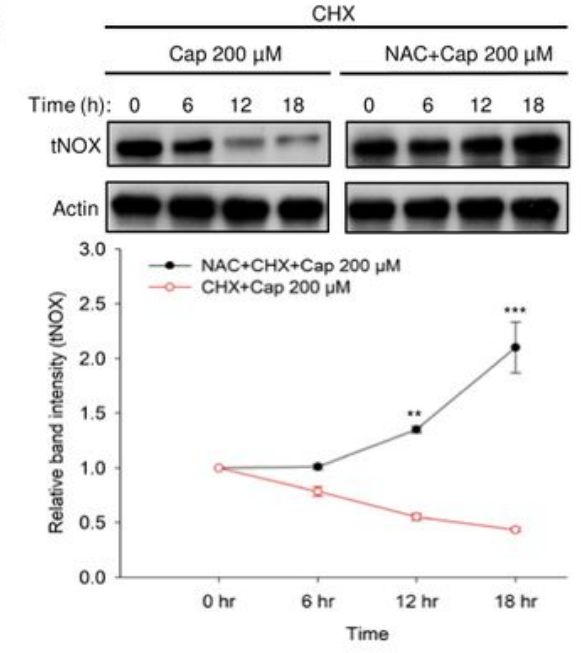

$E$
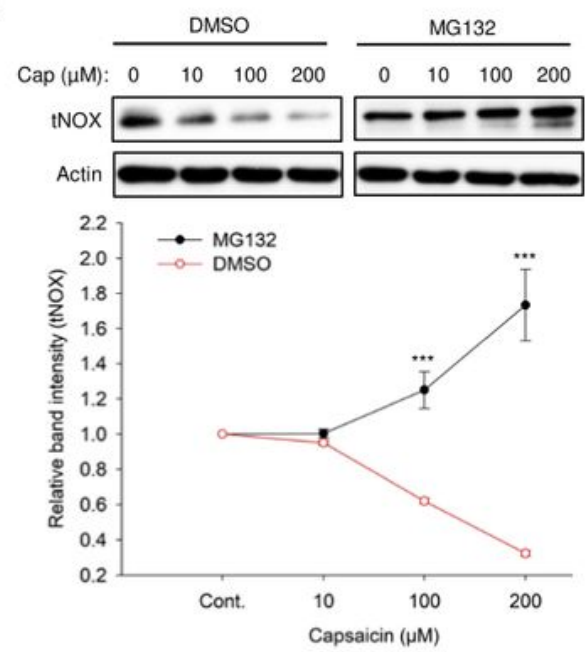

B

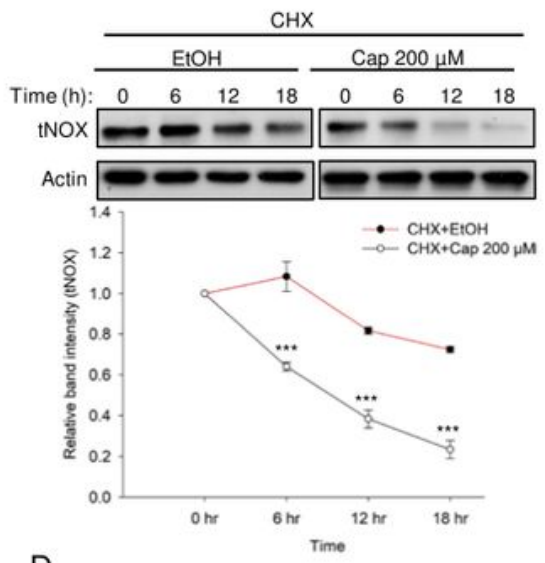

D
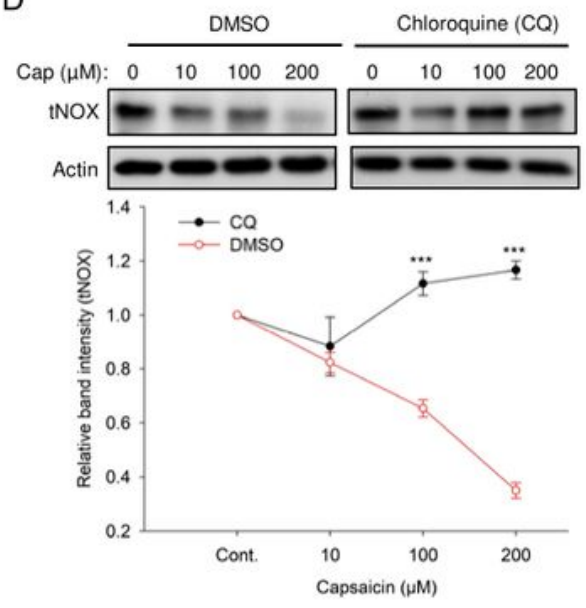

$\mathrm{F}$

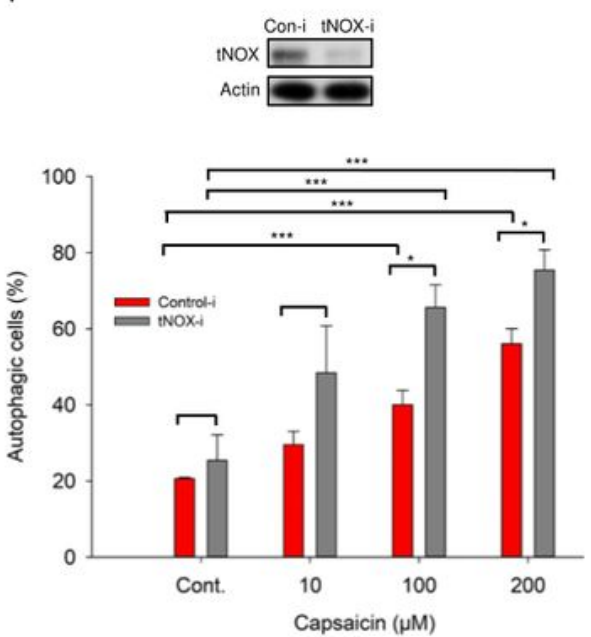

\section{Figure 5}

Capsaicin-induced tNOX downregulation is associated with proteasomal and lysosomal degradation in A375 cells. (A) Capsaicin significantly reduced tNOX expression at translational level analyzed by Western blotting and at transcriptional level determined by RT-PCR. (B) Capsaicin (200 $\mu \mathrm{M})$ decreased tNOX stability determined by a cycloheximide-chase assay in a time-dependent fashion. (C) Capsaicinmediated tNOX downregulation was restored by the ROS scavenger, NAC. (D) Capsaicin-induced tNOX 
downregulation was reverted by chloroquine (CQ), the lysosome inhibitor. (E) Capsaicin-mediated tNOX downregulation was reinstated by the proteasome inhibitor, MG132. Aliquots of cell lysates were separated by SDS-PAGE and analyzed by Western blotting. $\beta$-Actin was detected as an internal control. Representative images are shown. Values (means \pm SDs) are from at least three independent experiments $\left(\star \star p<0.01,{ }^{* \star *} p<0.001\right)$. (F) RNA interference-mediated tNOX depletion was conducted in A375 cells. These cells were exposed to different concentrations of capsaicin or ethanol for $24 \mathrm{~h}$, and the percentage of autophagic cells was determined by flow cytometry. The presented values (mean \pm SDs) represent at least three independent experiments $\left(* p<0.05\right.$ or ${ }^{* \star *} p<0.001$ for tNOX-depleted cells vs. controls or capsaicin-treated vs. controls). 

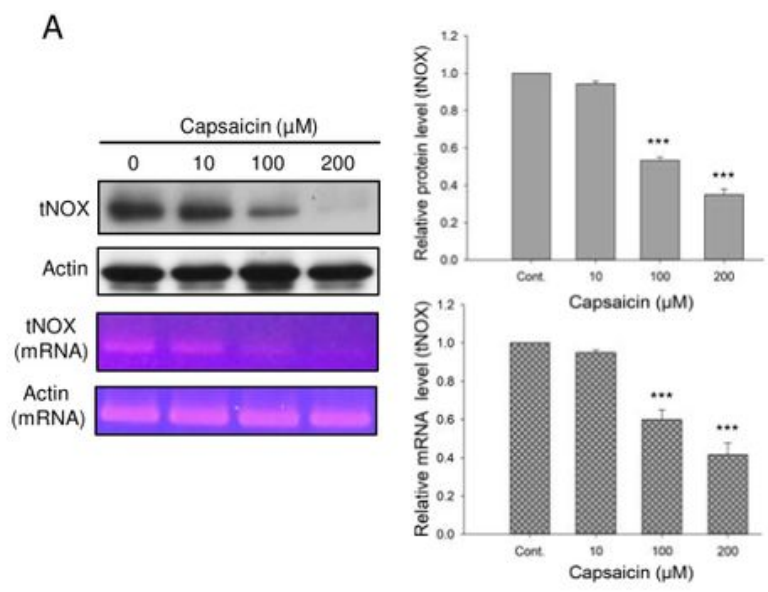

C

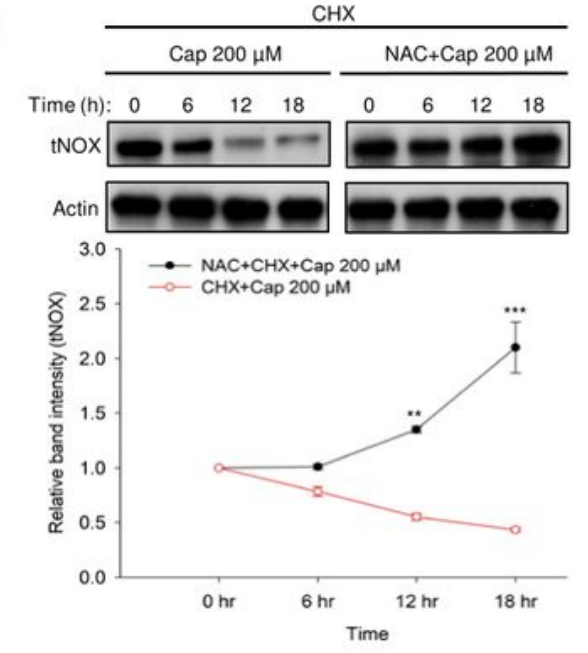

$E$
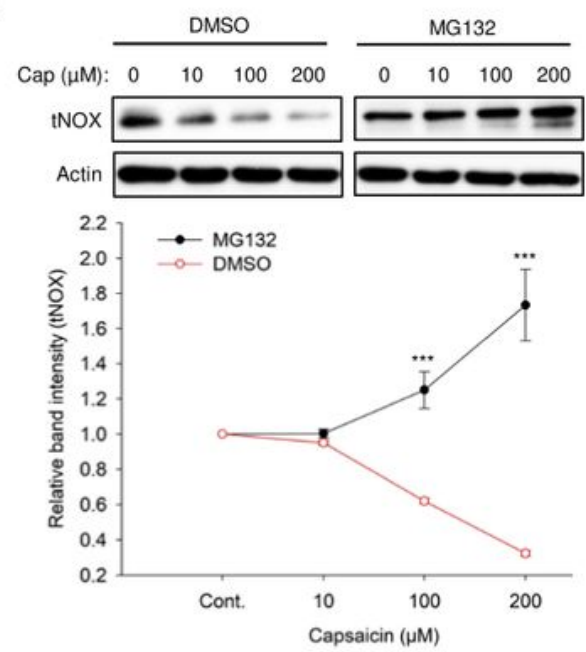

B

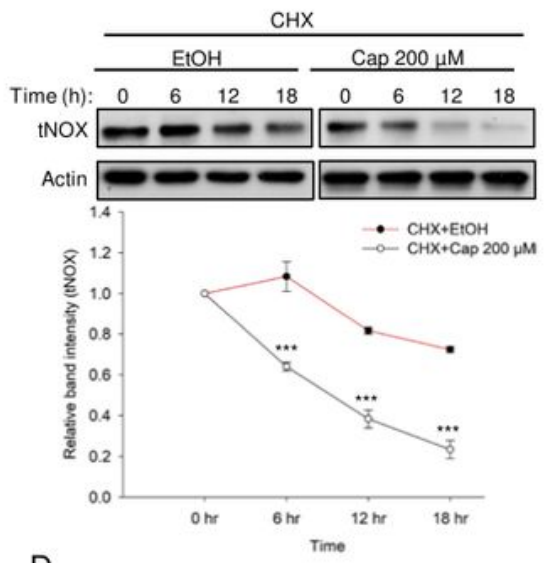

D
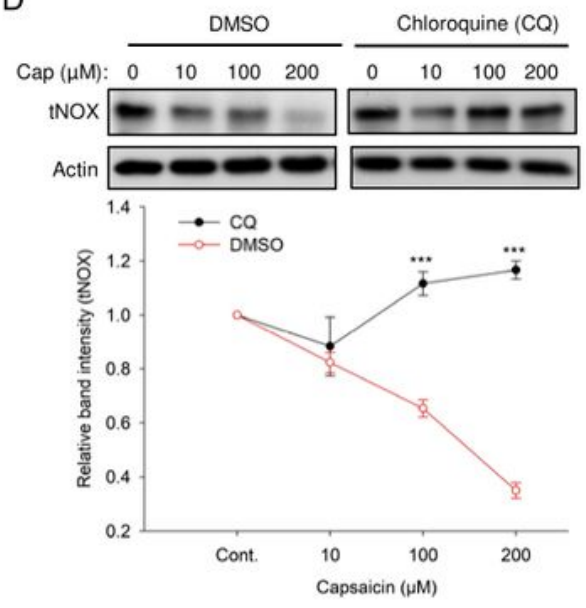

$\mathrm{F}$

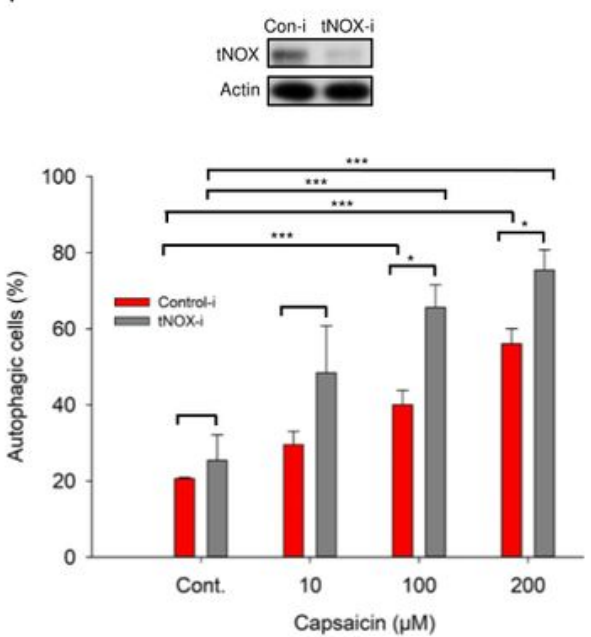

\section{Figure 5}

Capsaicin-induced tNOX downregulation is associated with proteasomal and lysosomal degradation in A375 cells. (A) Capsaicin significantly reduced tNOX expression at translational level analyzed by Western blotting and at transcriptional level determined by RT-PCR. (B) Capsaicin (200 $\mu \mathrm{M})$ decreased tNOX stability determined by a cycloheximide-chase assay in a time-dependent fashion. (C) Capsaicinmediated tNOX downregulation was restored by the ROS scavenger, NAC. (D) Capsaicin-induced tNOX 
downregulation was reverted by chloroquine (CQ), the lysosome inhibitor. (E) Capsaicin-mediated tNOX downregulation was reinstated by the proteasome inhibitor, MG132. Aliquots of cell lysates were separated by SDS-PAGE and analyzed by Western blotting. $\beta$-Actin was detected as an internal control. Representative images are shown. Values (means \pm SDs) are from at least three independent experiments $\left(\star \star p<0.01,{ }^{* \star *} p<0.001\right)$. (F) RNA interference-mediated tNOX depletion was conducted in A375 cells. These cells were exposed to different concentrations of capsaicin or ethanol for $24 \mathrm{~h}$, and the percentage of autophagic cells was determined by flow cytometry. The presented values (mean \pm SDs) represent at least three independent experiments $\left(* p<0.05\right.$ or ${ }^{* \star *} p<0.001$ for tNOX-depleted cells vs. controls or capsaicin-treated vs. controls). 

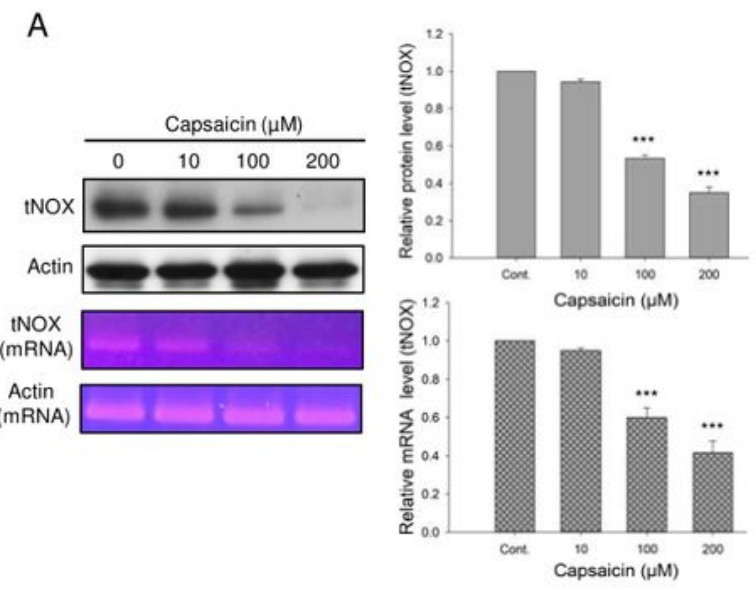

B
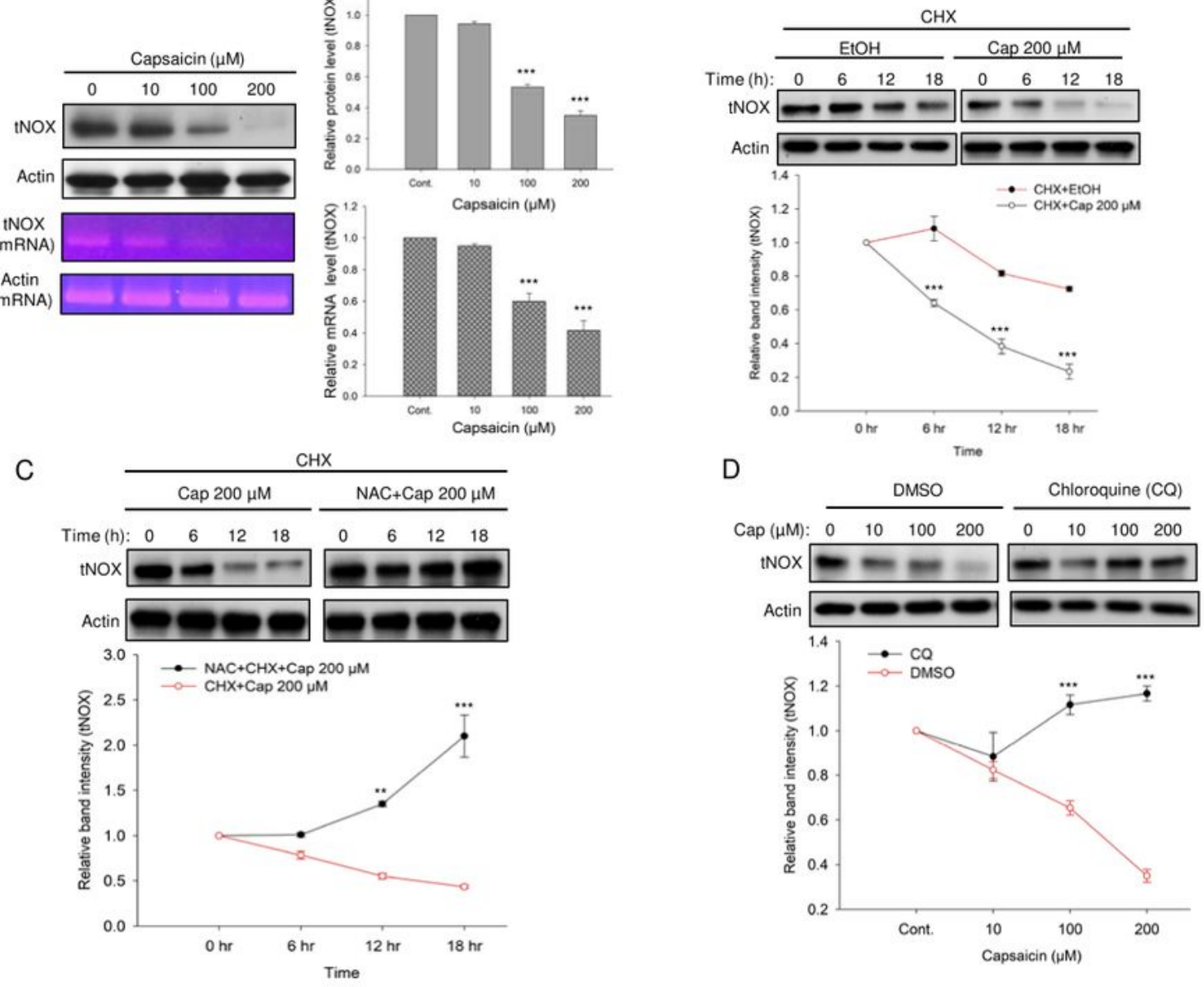

E
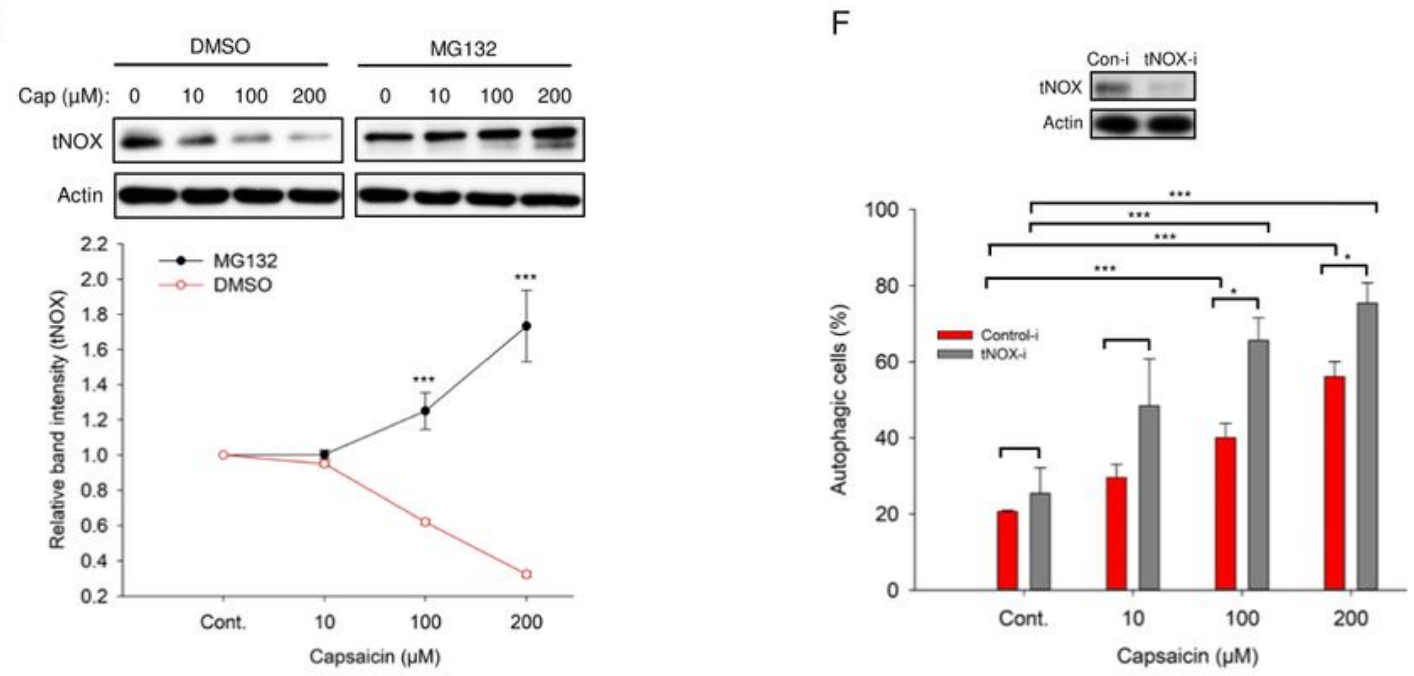

\section{Figure 5}

Capsaicin-induced tNOX downregulation is associated with proteasomal and lysosomal degradation in A375 cells. (A) Capsaicin significantly reduced tNOX expression at translational level analyzed by Western blotting and at transcriptional level determined by RT-PCR. (B) Capsaicin (200 $\mu \mathrm{M})$ decreased tNOX stability determined by a cycloheximide-chase assay in a time-dependent fashion. (C) Capsaicinmediated tNOX downregulation was restored by the ROS scavenger, NAC. (D) Capsaicin-induced tNOX 
downregulation was reverted by chloroquine (CQ), the lysosome inhibitor. (E) Capsaicin-mediated tNOX downregulation was reinstated by the proteasome inhibitor, MG132. Aliquots of cell lysates were separated by SDS-PAGE and analyzed by Western blotting. $\beta$-Actin was detected as an internal control. Representative images are shown. Values (means \pm SDs) are from at least three independent experiments $\left(\star \star p<0.01,{ }^{* \star *} p<0.001\right)$. (F) RNA interference-mediated tNOX depletion was conducted in A375 cells. These cells were exposed to different concentrations of capsaicin or ethanol for $24 \mathrm{~h}$, and the percentage of autophagic cells was determined by flow cytometry. The presented values (mean \pm SDs) represent at least three independent experiments $\left(* p<0.05\right.$ or ${ }^{* \star *} p<0.001$ for tNOX-depleted cells vs. controls or capsaicin-treated vs. controls). 

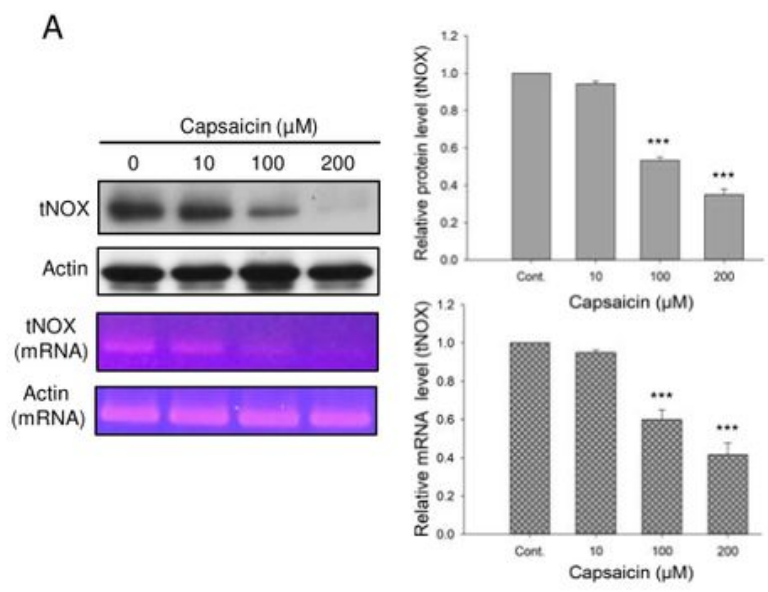

C

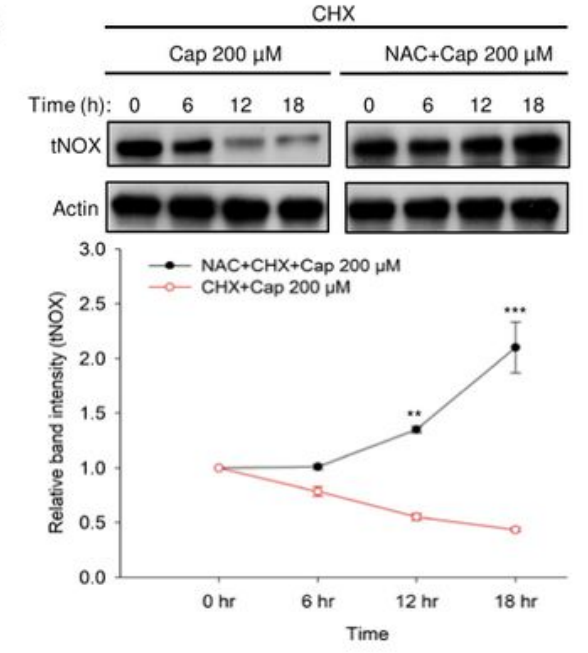

$E$
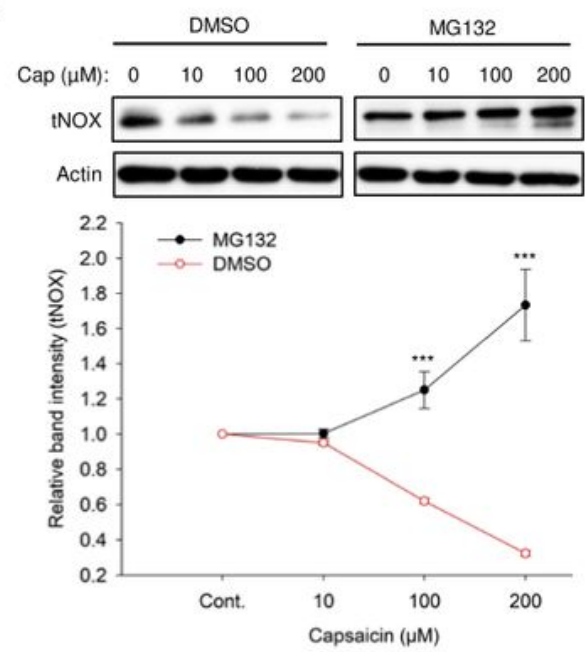

B

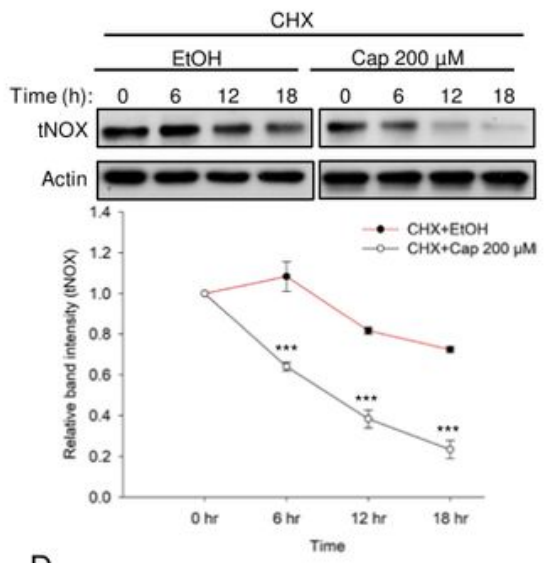

D
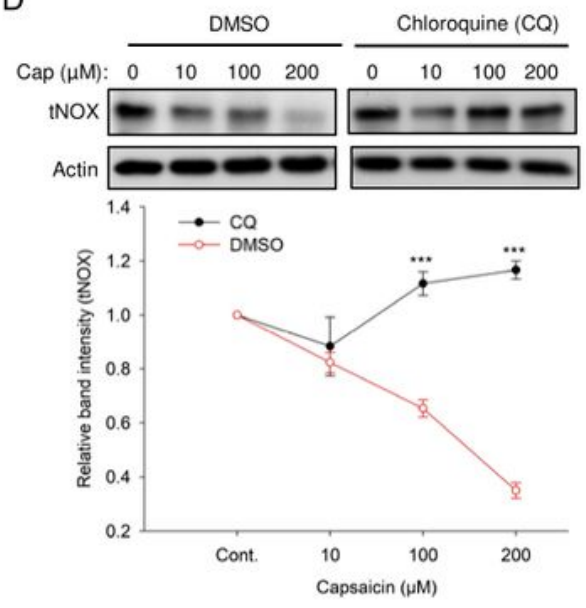

$\mathrm{F}$

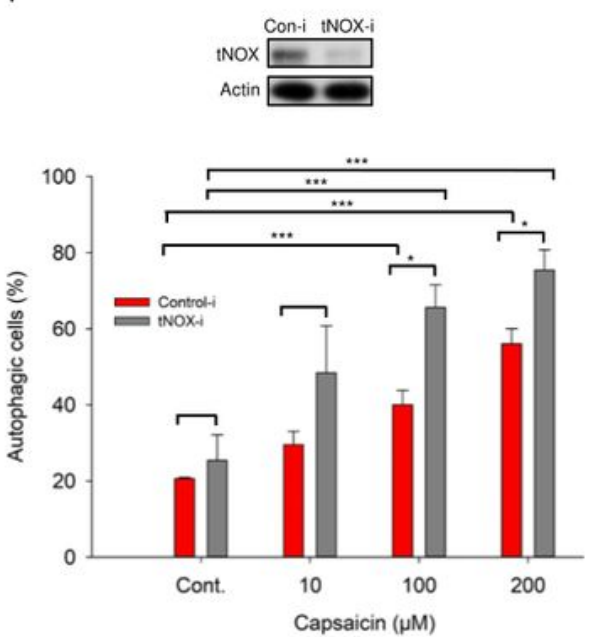

\section{Figure 5}

Capsaicin-induced tNOX downregulation is associated with proteasomal and lysosomal degradation in A375 cells. (A) Capsaicin significantly reduced tNOX expression at translational level analyzed by Western blotting and at transcriptional level determined by RT-PCR. (B) Capsaicin (200 $\mu \mathrm{M})$ decreased tNOX stability determined by a cycloheximide-chase assay in a time-dependent fashion. (C) Capsaicinmediated tNOX downregulation was restored by the ROS scavenger, NAC. (D) Capsaicin-induced tNOX 
downregulation was reverted by chloroquine (CQ), the lysosome inhibitor. (E) Capsaicin-mediated tNOX downregulation was reinstated by the proteasome inhibitor, MG132. Aliquots of cell lysates were separated by SDS-PAGE and analyzed by Western blotting. $\beta$-Actin was detected as an internal control. Representative images are shown. Values (means \pm SDs) are from at least three independent experiments $\left(\star \star p<0.01,{ }^{* \star *} p<0.001\right)$. (F) RNA interference-mediated tNOX depletion was conducted in A375 cells. These cells were exposed to different concentrations of capsaicin or ethanol for $24 \mathrm{~h}$, and the percentage of autophagic cells was determined by flow cytometry. The presented values (mean \pm SDs) represent at least three independent experiments $\left(* p<0.05\right.$ or ${ }^{* \star *} p<0.001$ for tNOX-depleted cells vs. controls or capsaicin-treated vs. controls). 

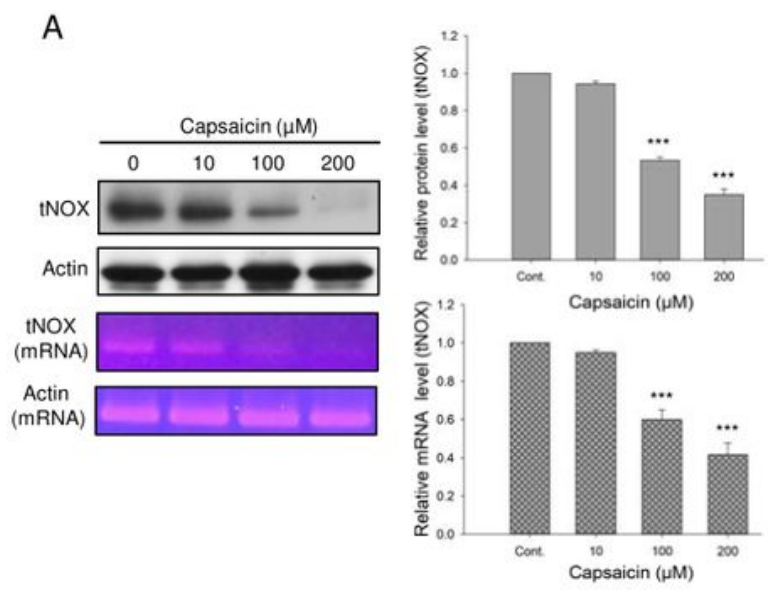

C

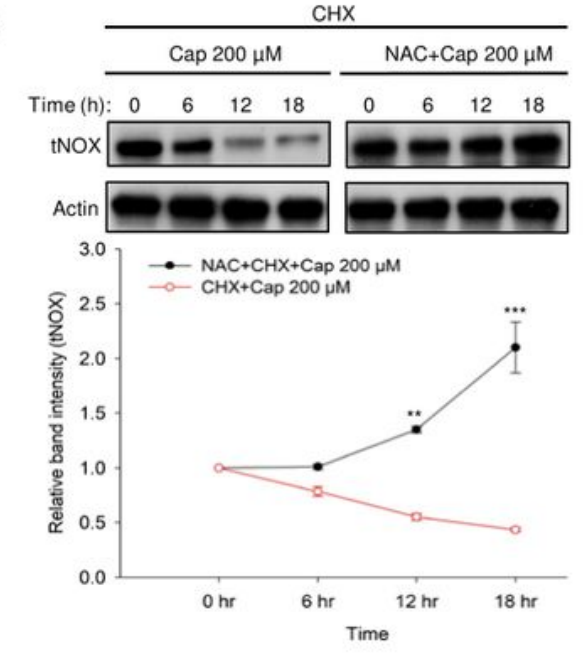

$E$
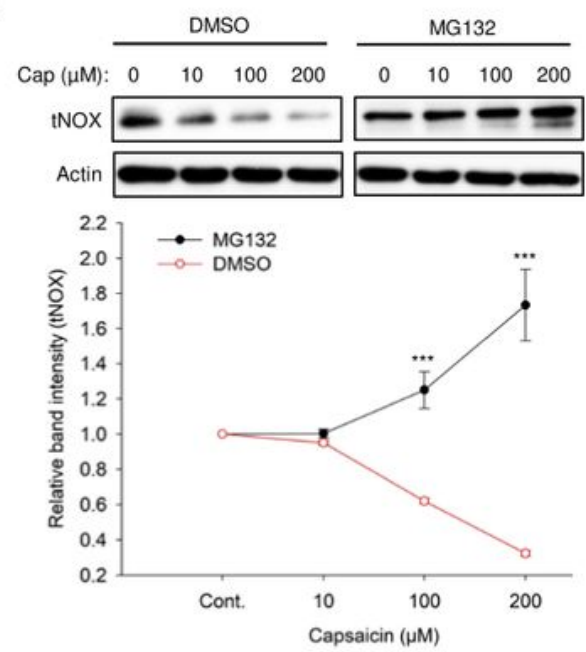

B

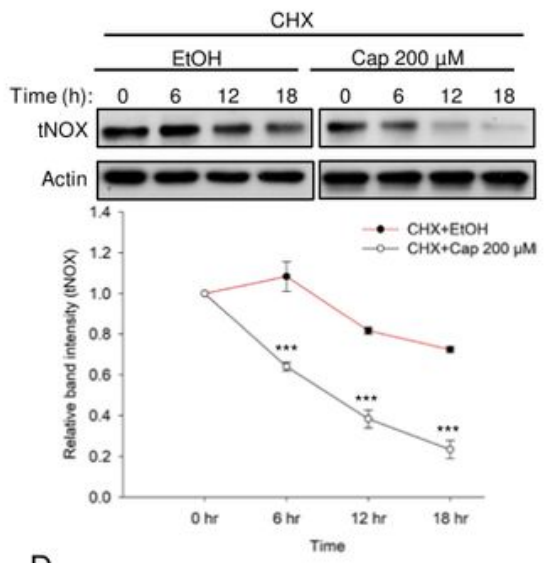

D
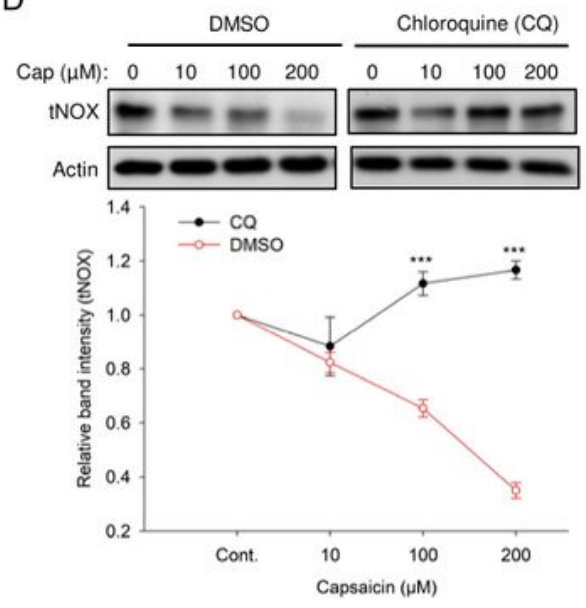

$\mathrm{F}$

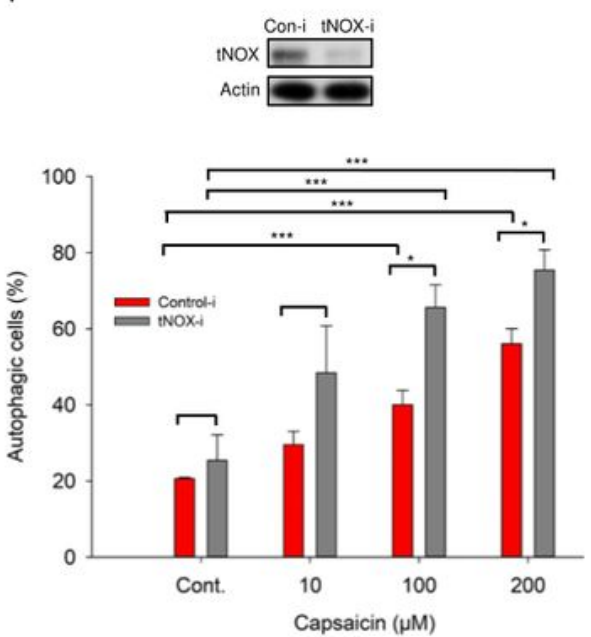

\section{Figure 5}

Capsaicin-induced tNOX downregulation is associated with proteasomal and lysosomal degradation in A375 cells. (A) Capsaicin significantly reduced tNOX expression at translational level analyzed by Western blotting and at transcriptional level determined by RT-PCR. (B) Capsaicin (200 $\mu \mathrm{M})$ decreased tNOX stability determined by a cycloheximide-chase assay in a time-dependent fashion. (C) Capsaicinmediated tNOX downregulation was restored by the ROS scavenger, NAC. (D) Capsaicin-induced tNOX 
downregulation was reverted by chloroquine (CQ), the lysosome inhibitor. (E) Capsaicin-mediated tNOX downregulation was reinstated by the proteasome inhibitor, MG132. Aliquots of cell lysates were separated by SDS-PAGE and analyzed by Western blotting. $\beta$-Actin was detected as an internal control. Representative images are shown. Values (means \pm SDs) are from at least three independent experiments $(* * p<0.01, * \star * p<0.001)$. (F) RNA interference-mediated tNOX depletion was conducted in A375 cells. These cells were exposed to different concentrations of capsaicin or ethanol for $24 \mathrm{~h}$, and the percentage of autophagic cells was determined by flow cytometry. The presented values (mean \pm SDs) represent at least three independent experiments ( $p<0.05$ or ${ }^{\star * *} p<0.001$ for tNOX-depleted cells vs. controls or capsaicin-treated vs. controls).

A

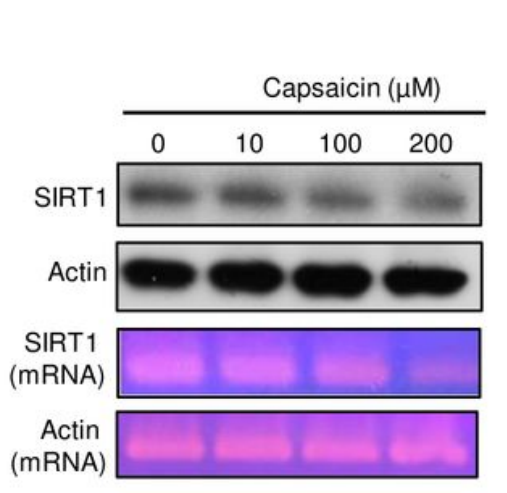

C

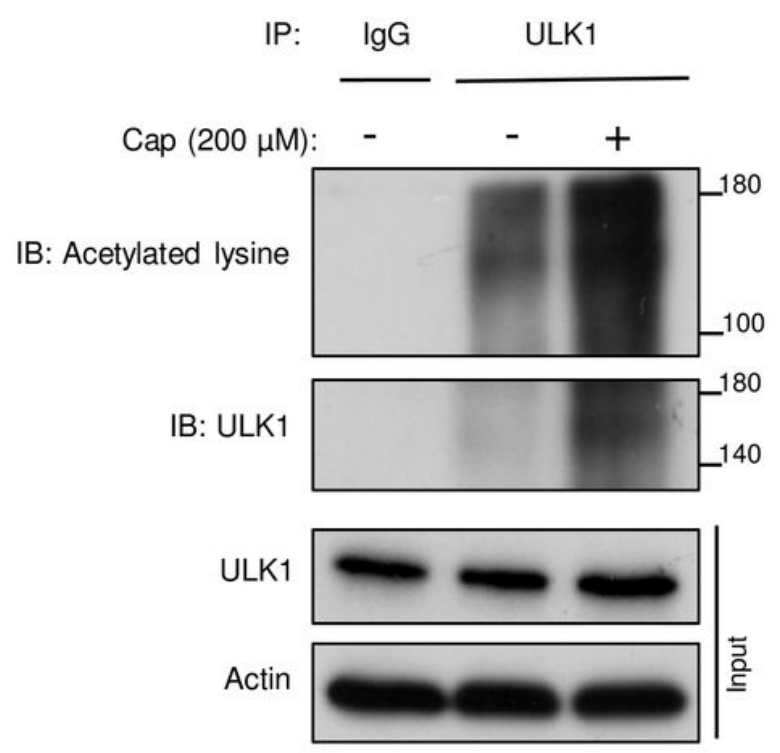

B
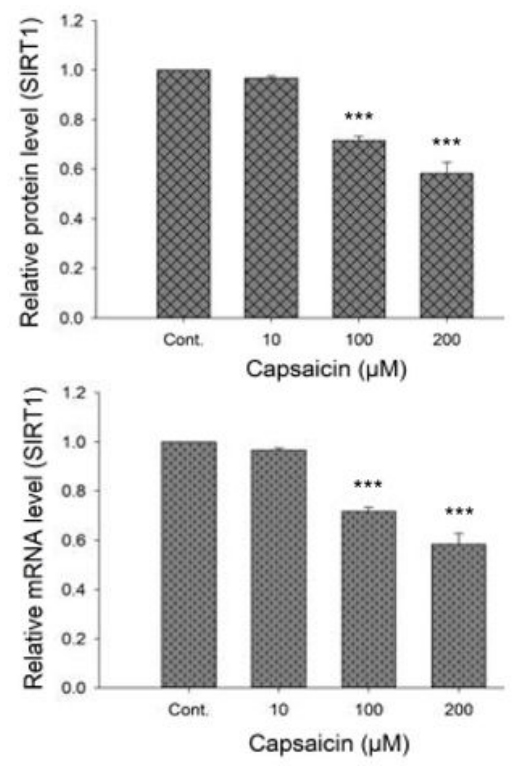

D

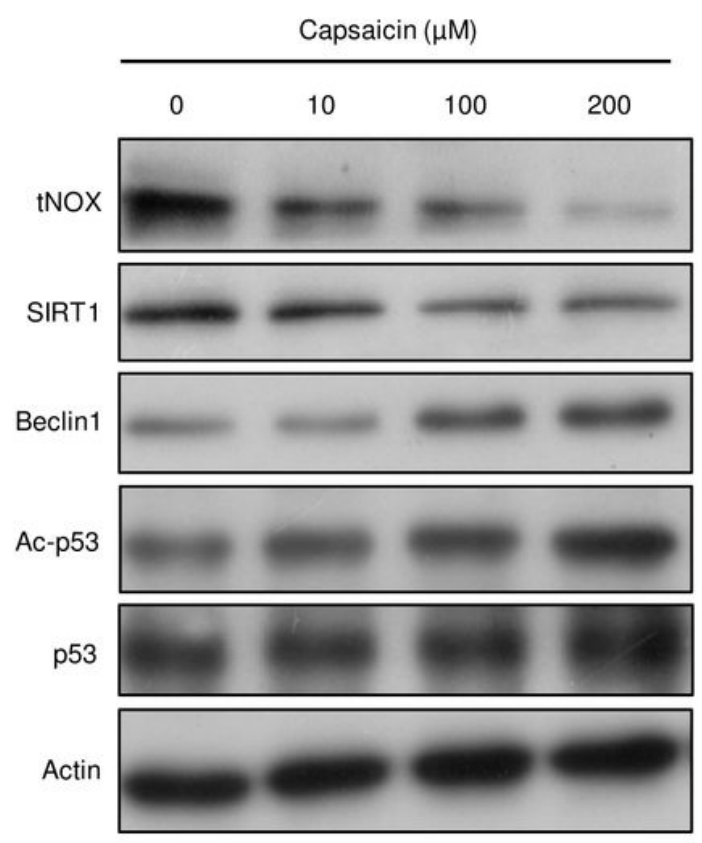

Figure 6 
Capsaicin inhibits SIRT1 expression and enzymatic activity in A375 cells. (A) Capsaicin significantly induced SIRT1 downregulation at the translational level analyzed by Western blotting and at the transcriptional level determined by RT-PCR. (B) Capsaicin suppressed cellular SIRT1 activity analyzed by a SIRT1 Activity Assay Kit (Fluorometric) with control or capsaicin-exposed A375 cell lysates. Values (mean \pm SDs) are from three independent experiments $(* \star \star p<0.001)$. (C) The lysates of A375 cells were immunoprecipitated with nonimmune $\lg G$ or an antibody against ULK1, and the bound proteins were detected by Western blotting with pan-acetylated lysine or ULK1 antibodies. (D) A375 cells were exposed to different concentrations of capsaicin or ethanol for 24 hours. Aliquots of cell lysates were separated by SDS-PAGE and analyzed for protein expression by Western blotting. $\beta$-actin was used as an internal control to monitor for equal loading. Representative images are shown from at least three independent experiments.

A

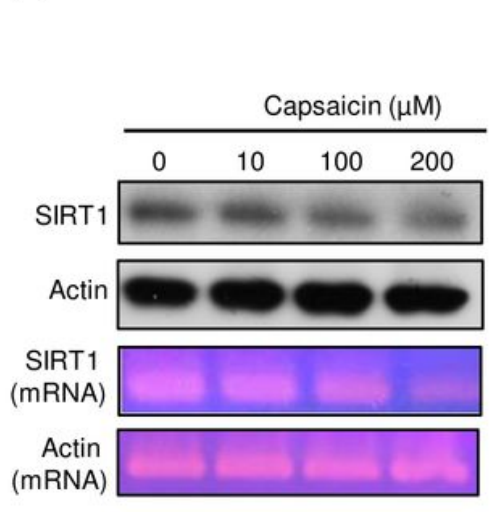

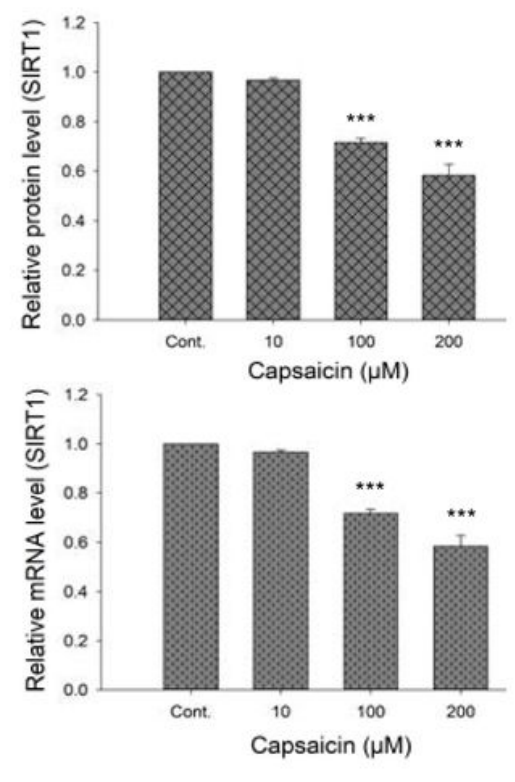

C
B

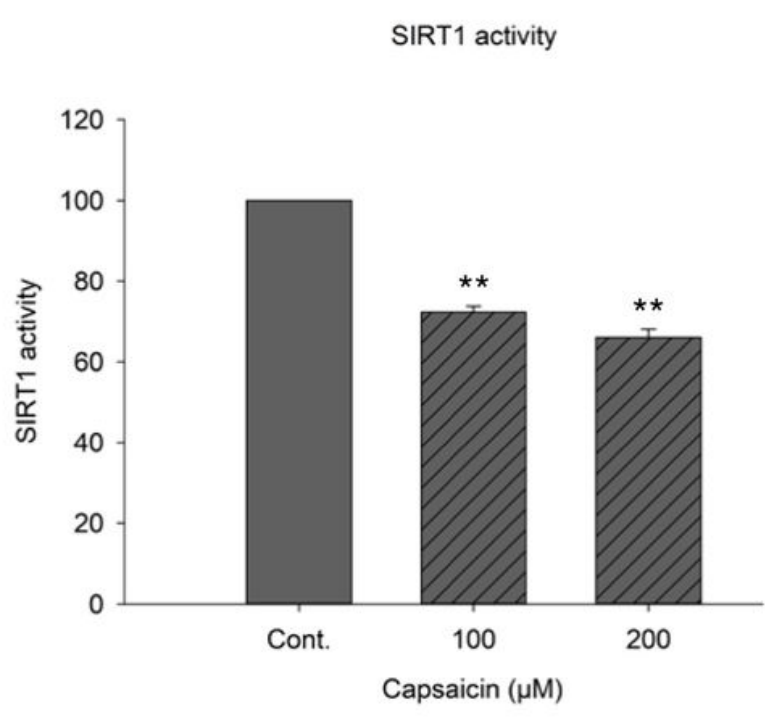

D

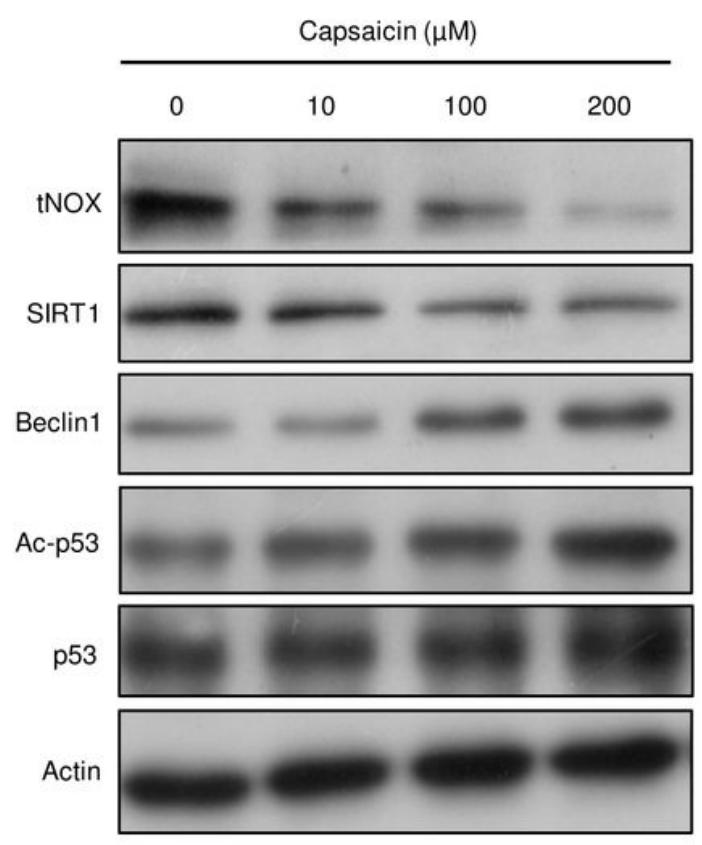




\section{Figure 6}

Capsaicin inhibits SIRT1 expression and enzymatic activity in A375 cells. (A) Capsaicin significantly induced SIRT1 downregulation at the translational level analyzed by Western blotting and the transcriptional level determined by RT-PCR. (B) Capsaicin suppressed cellular SIRT1 activity analyzed by a SIRT1 Activity Assay Kit (Fluorometric) with control or capsaicin-exposed A375 cell lysates. Values (mean \pm SDs) are from three independent experiments ( $* \star * p<0.001)$. (C) The lysates of A375 cells were immunoprecipitated with nonimmune IgG or an antibody against ULK1, and the bound proteins were detected by Western blotting with pan-acetylated lysine or ULK1 antibodies. (D) A375 cells were exposed to different concentrations of capsaicin or ethanol for 24 hours. Aliquots of cell lysates were separated by SDS-PAGE and analyzed for protein expression by Western blotting. $\beta$-actin was used as an internal control to monitor for equal loading. Representative images are shown from at least three independent experiments. 
A

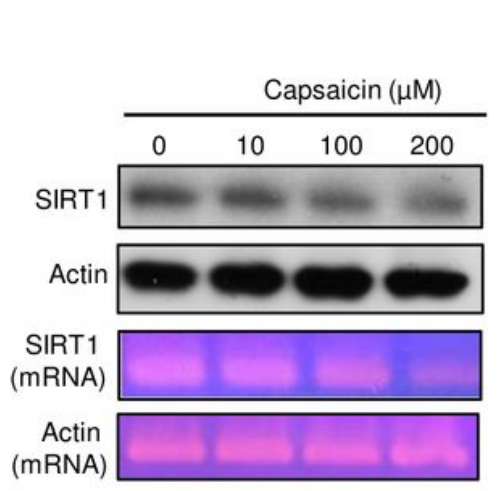

$\mathrm{C}$

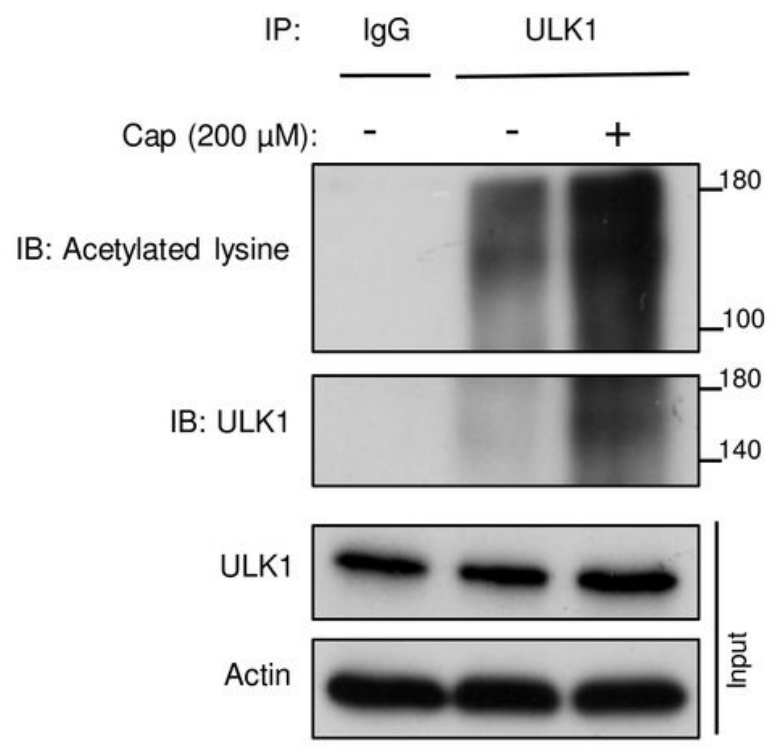

B
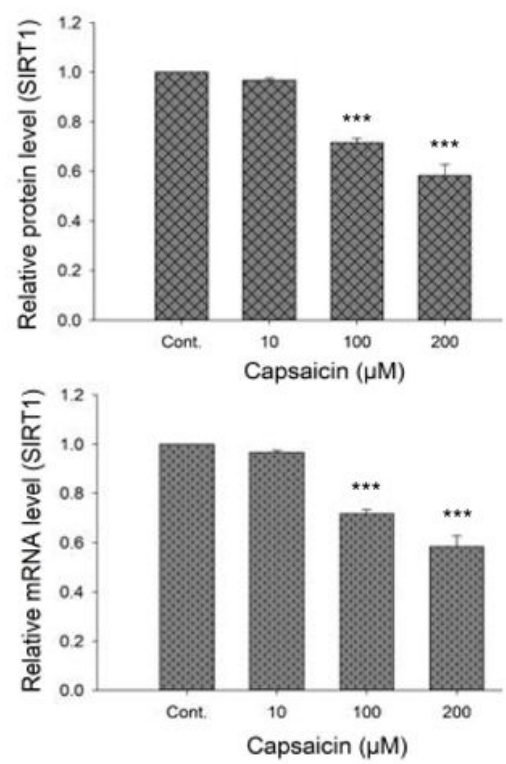

D

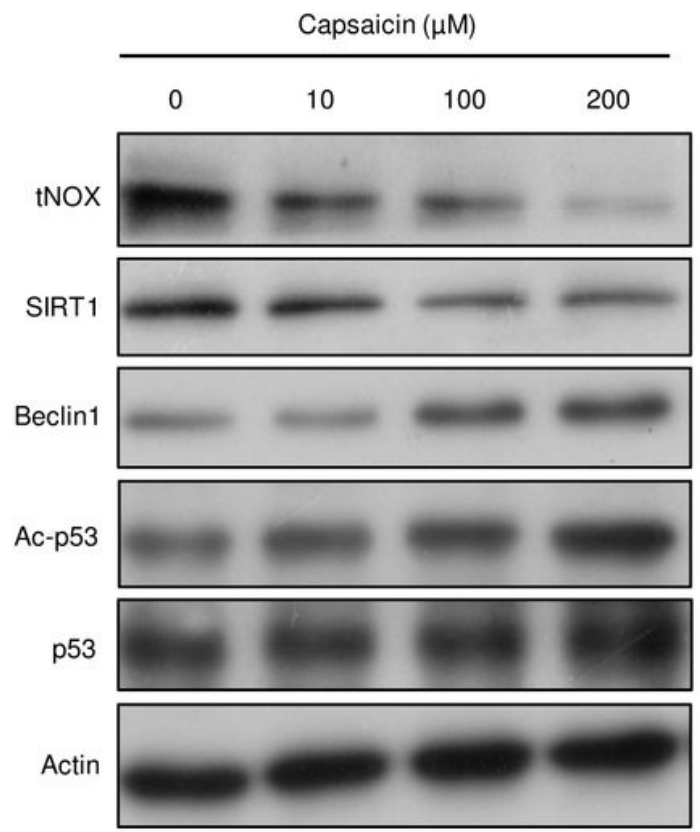

\section{Figure 6}

Capsaicin inhibits SIRT1 expression and enzymatic activity in A375 cells. (A) Capsaicin significantly induced SIRT1 downregulation at the translational level analyzed by Western blotting and at the transcriptional level determined by RT-PCR. (B) Capsaicin suppressed cellular SIRT1 activity analyzed by a SIRT1 Activity Assay Kit (Fluorometric) with control or capsaicin-exposed A375 cell lysates. Values (mean \pm SDs) are from three independent experiments ( $* \star * p<0.001)$. (C) The lysates of A375 cells were immunoprecipitated with nonimmune $\lg \mathrm{G}$ or an antibody against ULK1, and the bound proteins were detected by Western blotting with pan-acetylated lysine or ULK1 antibodies. (D) A375 cells were exposed to different concentrations of capsaicin or ethanol for 24 hours. Aliquots of cell lysates were separated by 
SDS-PAGE and analyzed for protein expression by Western blotting. $\beta$-actin was used as an internal control to monitor for equal loading. Representative images are shown from at least three independent experiments.

A

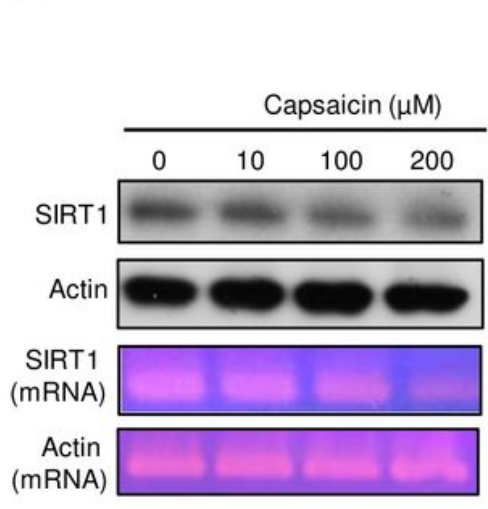

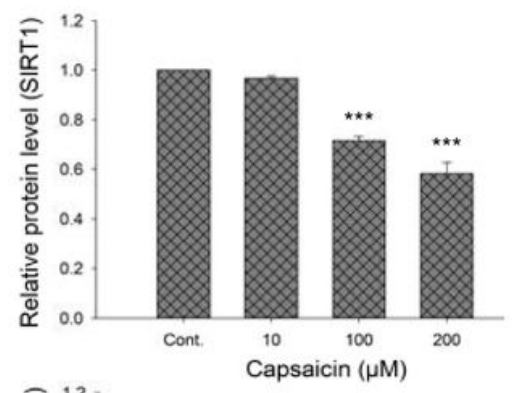

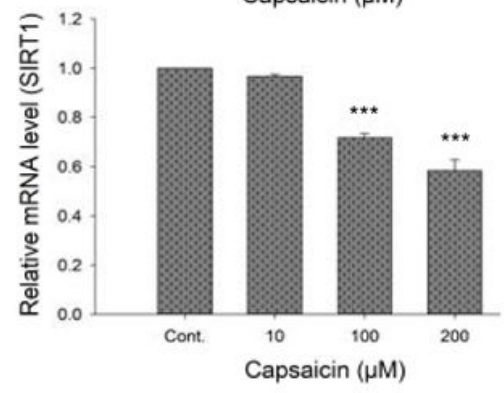

C

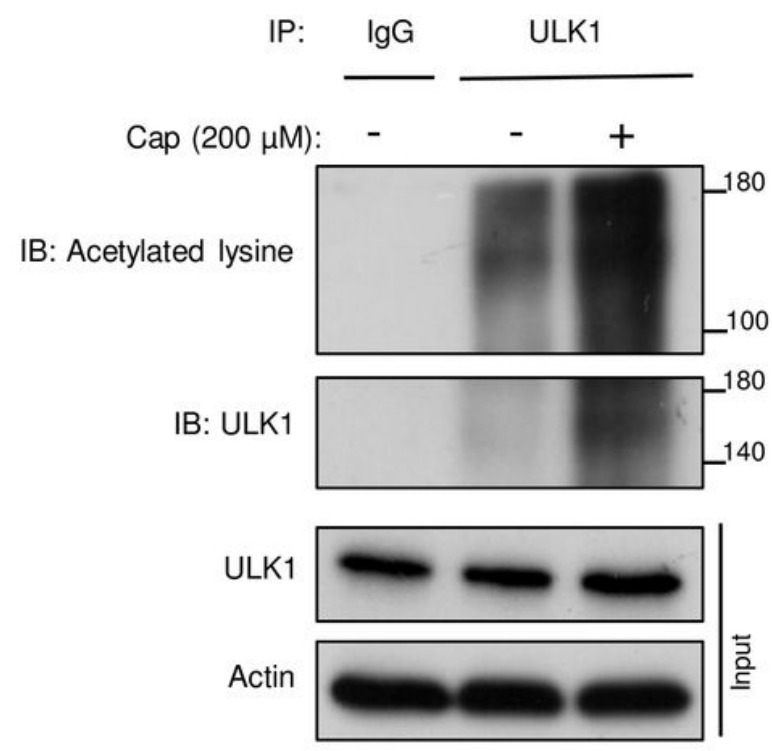

B

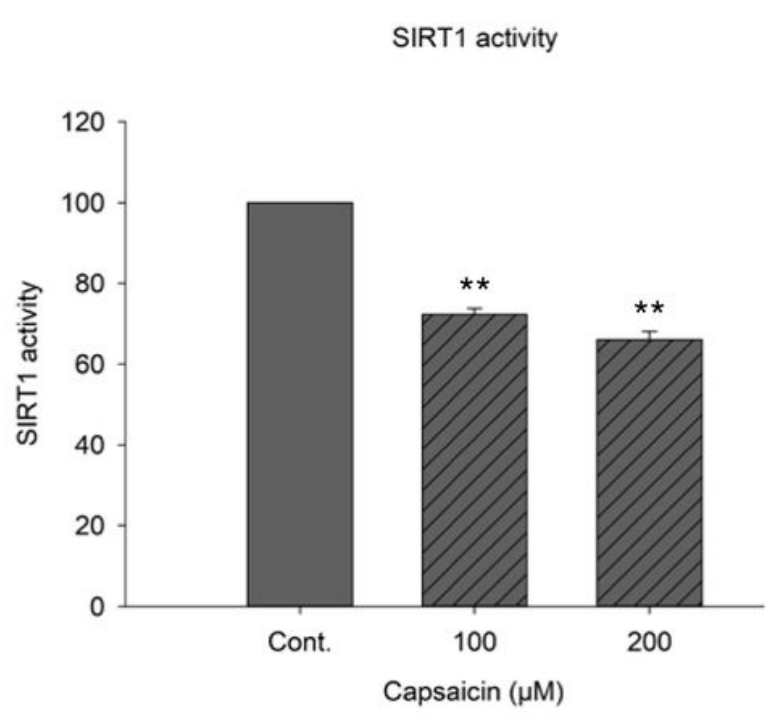

D

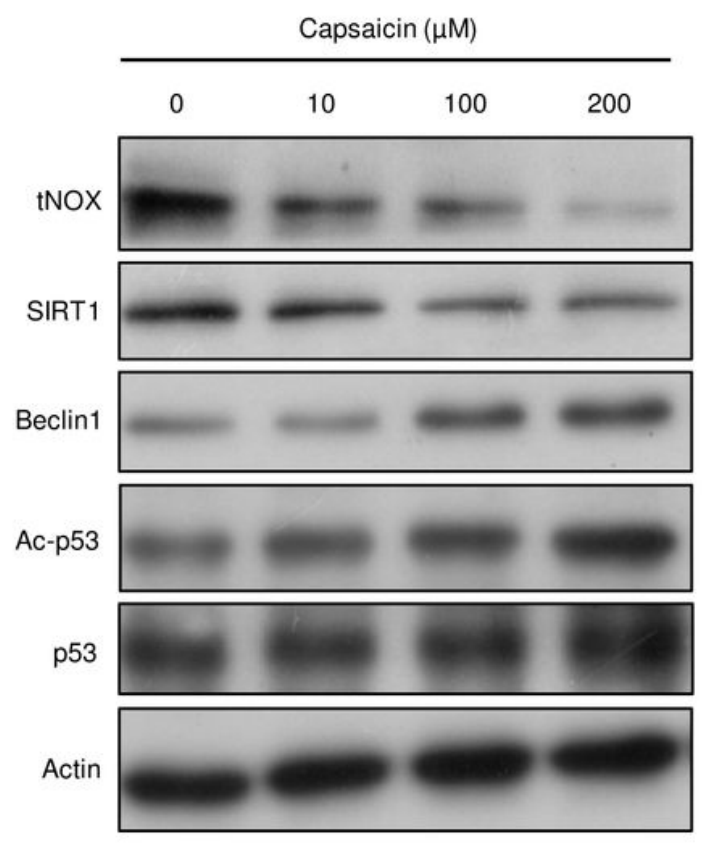

\section{Figure 6}

Capsaicin inhibits SIRT1 expression and enzymatic activity in A375 cells. (A) Capsaicin significantly induced SIRT1 downregulation at the translational level analyzed by Western blotting and at the transcriptional level determined by RT-PCR. (B) Capsaicin suppressed cellular SIRT1 activity analyzed by a SIRT1 Activity Assay Kit (Fluorometric) with control or capsaicin-exposed A375 cell lysates. Values (mean \pm SDs) are from three independent experiments ( $\left.{ }^{\star \star \star} p<0.001\right)$. (C) The lysates of A375 cells were 
immunoprecipitated with nonimmune IgG or an antibody against ULK1, and the bound proteins were detected by Western blotting with pan-acetylated lysine or ULK1 antibodies. (D) A375 cells were exposed to different concentrations of capsaicin or ethanol for 24 hours. Aliquots of cell lysates were separated by SDS-PAGE and analyzed for protein expression by Western blotting. $\beta$-actin was used as an internal control to monitor for equal loading. Representative images are shown from at least three independent experiments.

A

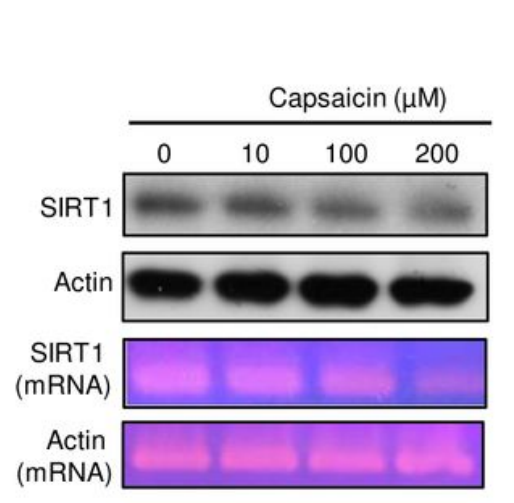

C

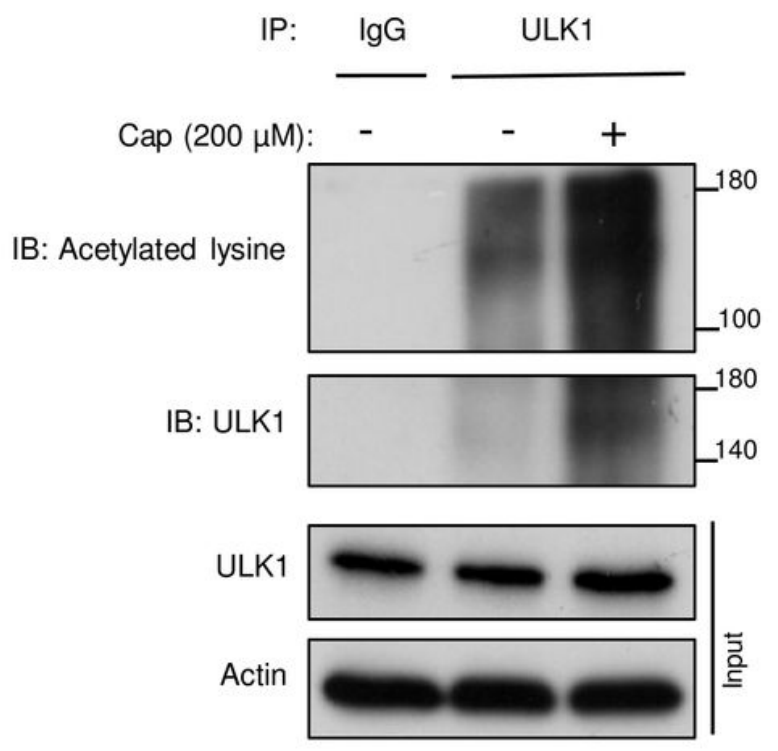

B
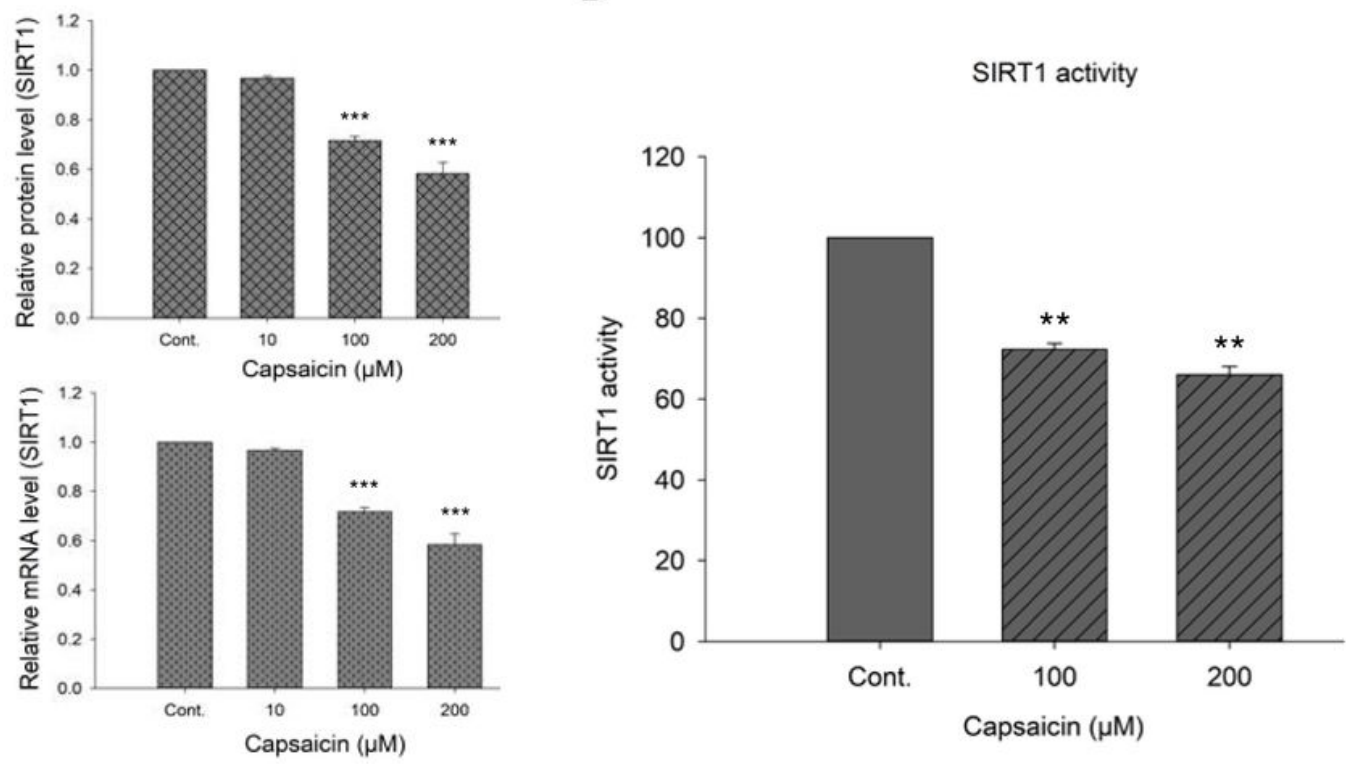

D

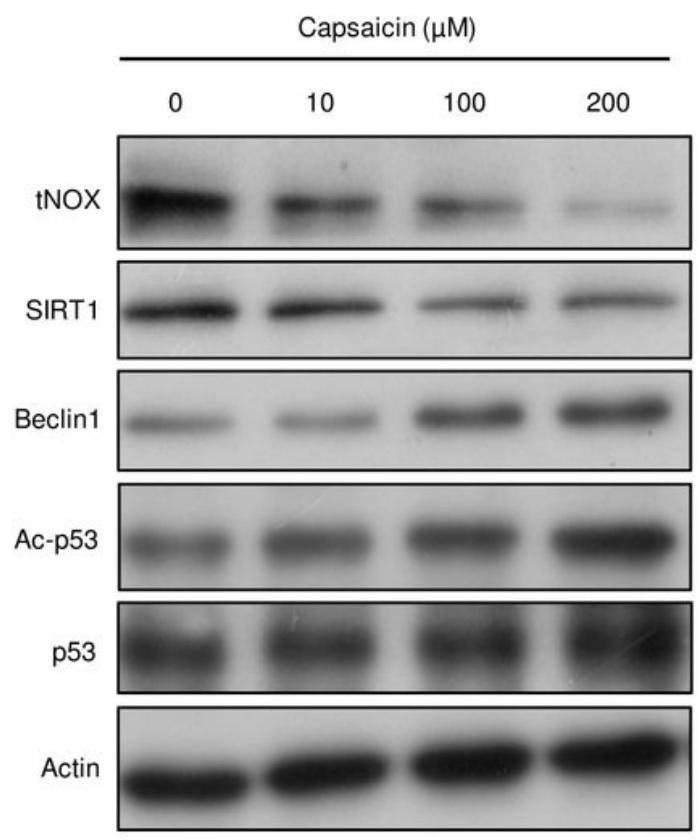

Figure 6

Capsaicin inhibits SIRT1 expression and enzymatic activity in A375 cells. (A) Capsaicin significantly induced SIRT1 downregulation at the translational level analyzed by Western blotting and at the 
transcriptional level determined by RT-PCR. (B) Capsaicin suppressed cellular SIRT1 activity analyzed by a SIRT1 Activity Assay Kit (Fluorometric) with control or capsaicin-exposed A375 cell lysates. Values (mean \pm SDs) are from three independent experiments (*** $p<0.001)$. (C) The lysates of A375 cells were immunoprecipitated with nonimmune lgG or an antibody against ULK1, and the bound proteins were detected by Western blotting with pan-acetylated lysine or ULK1 antibodies. (D) A375 cells were exposed to different concentrations of capsaicin or ethanol for 24 hours. Aliquots of cell lysates were separated by SDS-PAGE and analyzed for protein expression by Western blotting. $\beta$-actin was used as an internal control to monitor for equal loading. Representative images are shown from at least three independent experiments.

A

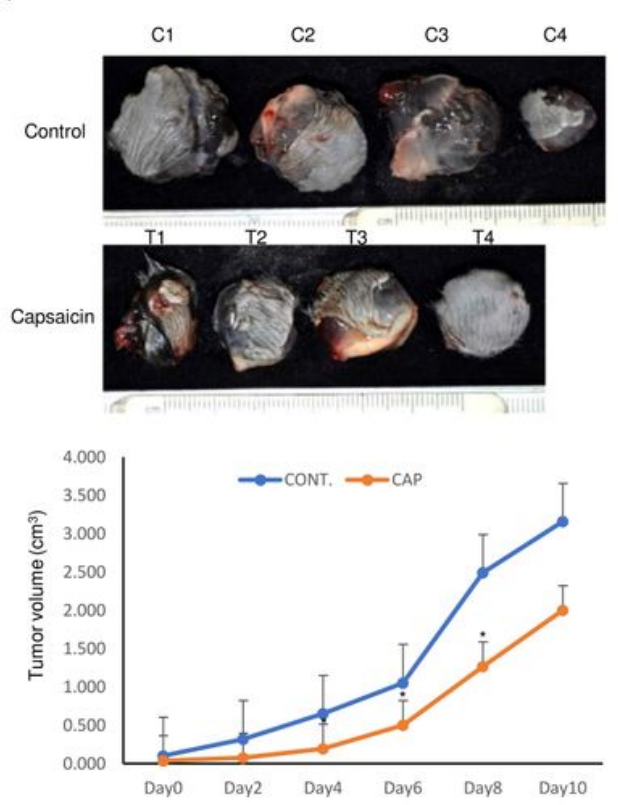

B

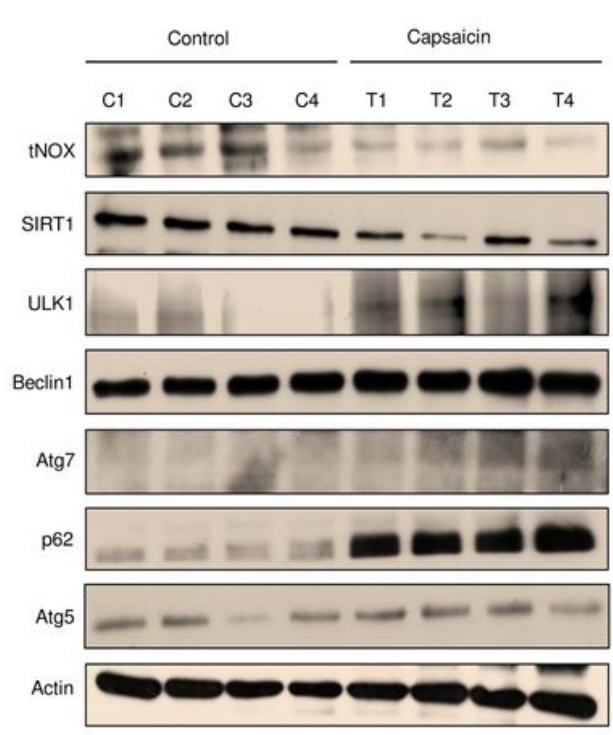

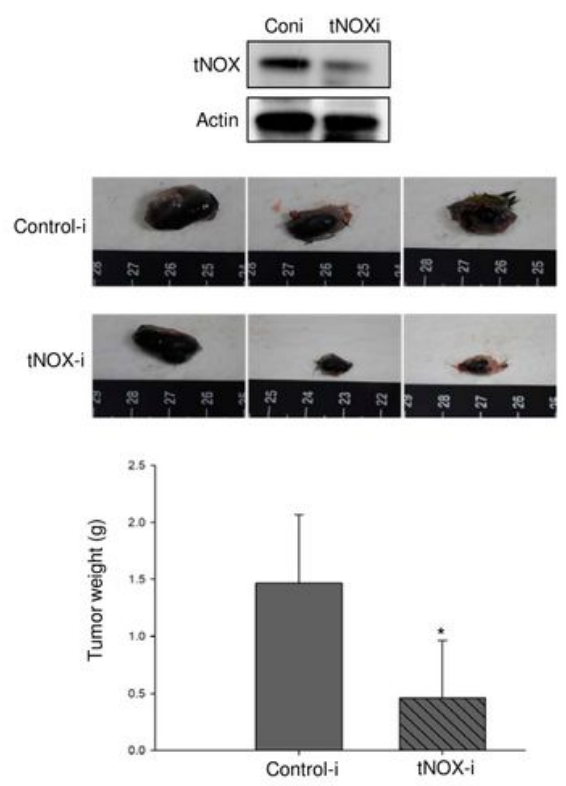

Figure 7

In vivo verification for capsaicin-reduced tNOX and tNOX-depletion suppresses melanoma tumor growth. (A) In a tumor-bearing mouse xenograft model, control mice were intratumorally injected with vehicle buffer and treatment group mice were intratumorally treated with $200 \mu \mathrm{g}$ capsaicin as described in Materials and Methods. The morphology of the tumor tissues excised from tumor-bearing mice (top panel) and quantitative analysis of xenografted tumor volume during the treatment period (bottom panel) are shown. (B) Tissues from two sets of tumor-bearing mice were grounded and prepared for Western blotting analysis. $\beta$-actin was used as an internal control to monitor for equal loading. (C) In another mouse xenograft model, B16F10 cells transfected with either scramble (control-i) or tNOX (tNOX-i) shRNA were subcutaneously injected into mice. The morphology of the tumor tissues excised from tumorbearing mice (top panel) and quantitative analysis of xenografted tumor weights from two sets of mice are shown. 
A
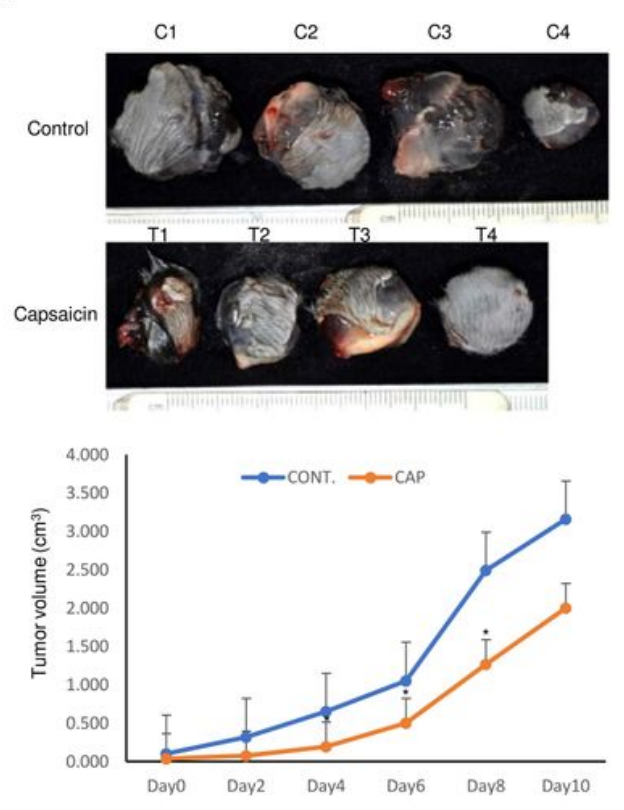

B

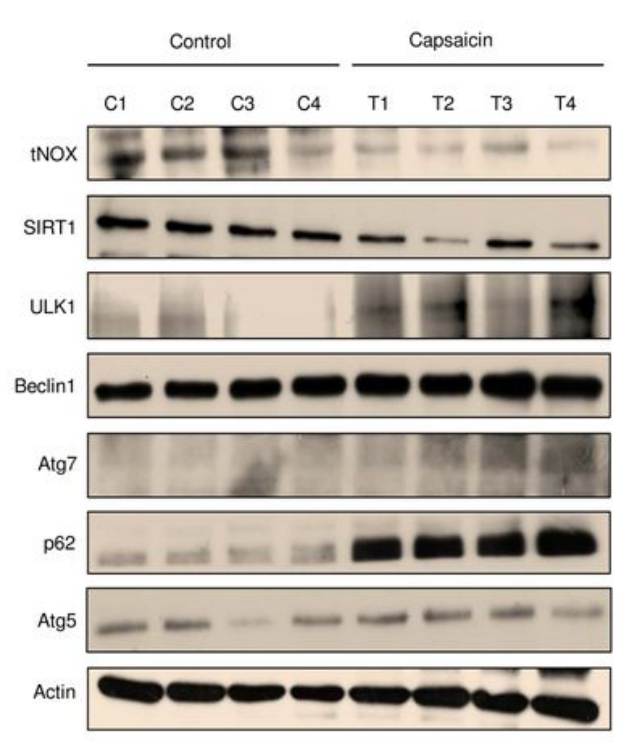

C

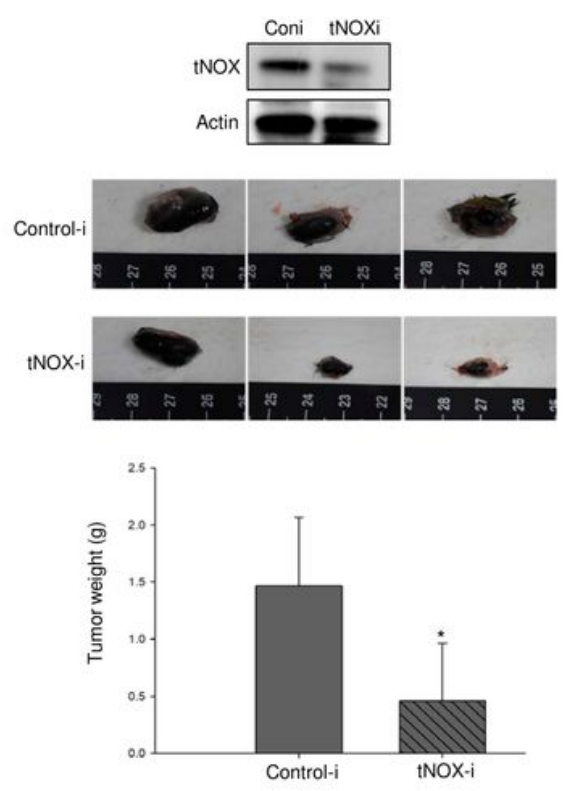

Figure 7

In vivo verification for capsaicin-reduced tNOX and tNOX-depletion suppresses melanoma tumor growth. (A) In a tumor-bearing mouse xenograft model, control mice were intratumorally injected with vehicle buffer and treatment group mice were intratumorally treated with $200 \mu \mathrm{g}$ capsaicin as described in Materials and Methods. The morphology of the tumor tissues excised from tumor-bearing mice (top panel) and quantitative analysis of xenografted tumor volume during the treatment period (bottom panel) are shown. (B) Tissues from two sets of tumor-bearing mice were grounded and prepared for Western blotting analysis. $\beta$-actin was used as an internal control to monitor for equal loading. (C) In another mouse xenograft model, B16F10 cells transfected with either scramble (control-i) or tNOX (tNOX-i) shRNA were subcutaneously injected into mice. The morphology of the tumor tissues excised from tumorbearing mice (top panel) and quantitative analysis of xenografted tumor weights from two sets of mice are shown. 
A
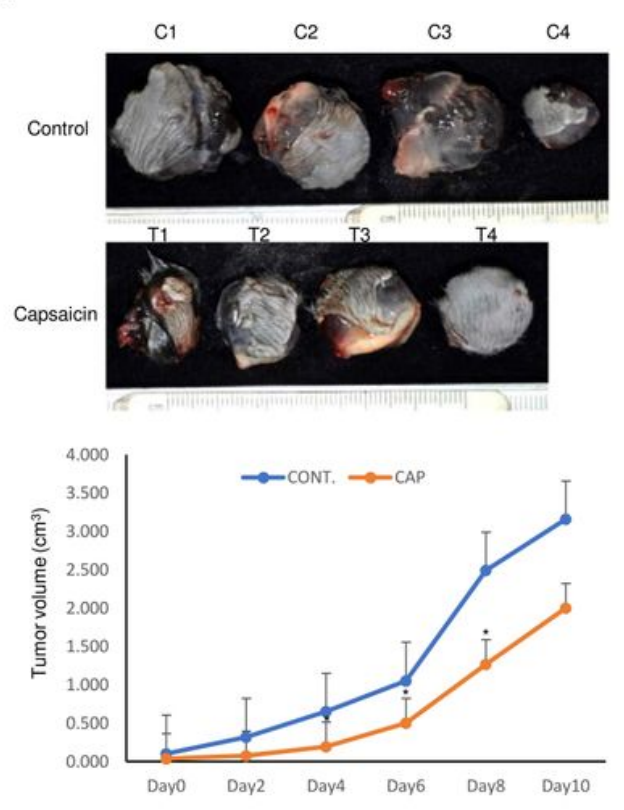

B

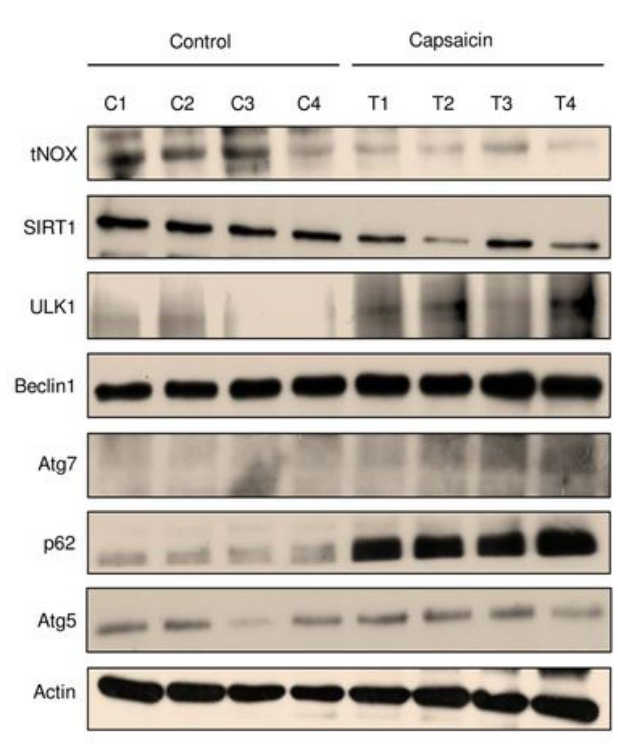

C

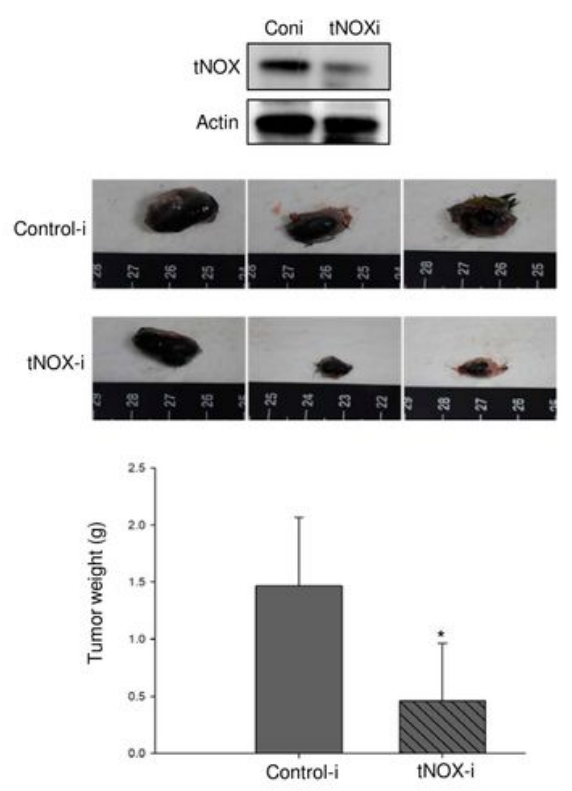

Figure 7

In vivo verification for capsaicin-reduced tNOX and tNOX-depletion suppresses melanoma tumor growth. (A) In a tumor-bearing mouse xenograft model, control mice were intratumorally injected with vehicle buffer and treatment group mice were intratumorally treated with $200 \mu \mathrm{g}$ capsaicin as described in Materials and Methods. The morphology of the tumor tissues excised from tumor-bearing mice (top panel) and quantitative analysis of xenografted tumor volume during the treatment period (bottom panel) are shown. (B) Tissues from two sets of tumor-bearing mice were grounded and prepared for Western blotting analysis. $\beta$-actin was used as an internal control to monitor for equal loading. (C) In another mouse xenograft model, B16F10 cells transfected with either scramble (control-i) or tNOX (tNOX-i) shRNA were subcutaneously injected into mice. The morphology of the tumor tissues excised from tumorbearing mice (top panel) and quantitative analysis of xenografted tumor weights from two sets of mice are shown. 
A
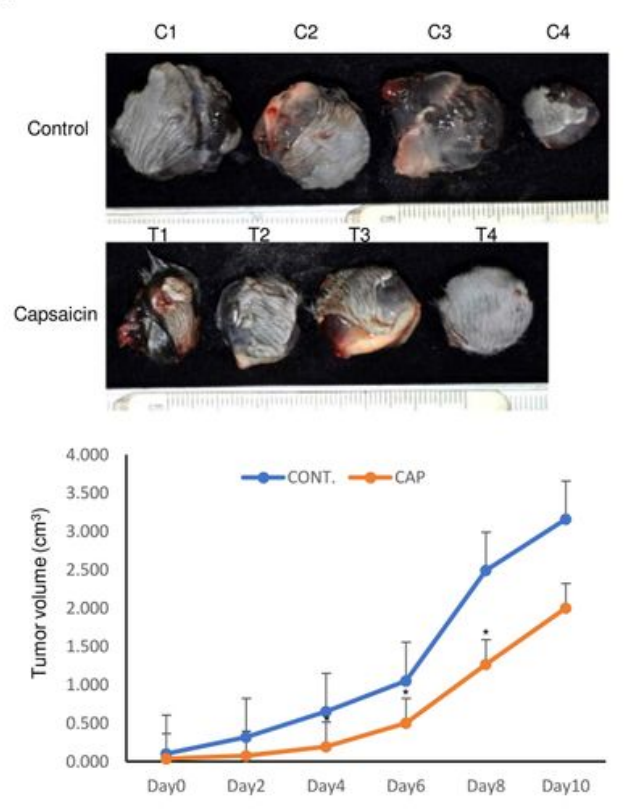

B

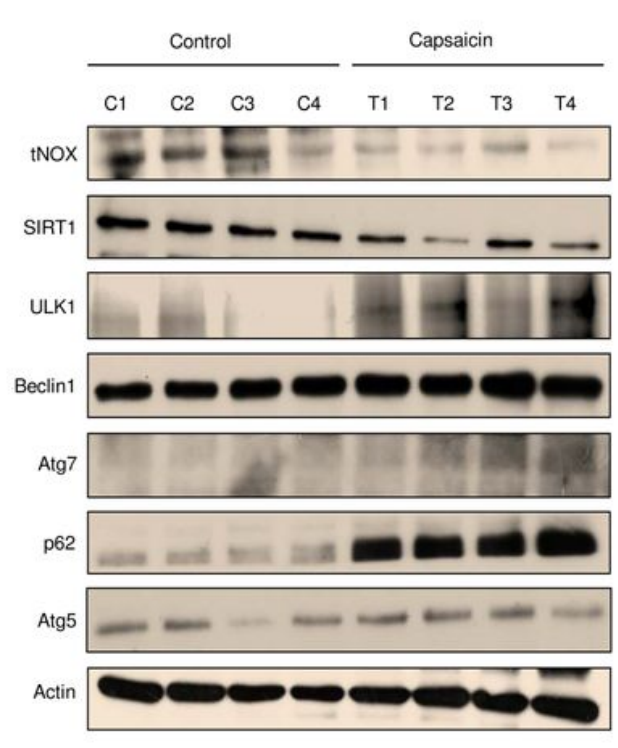

C

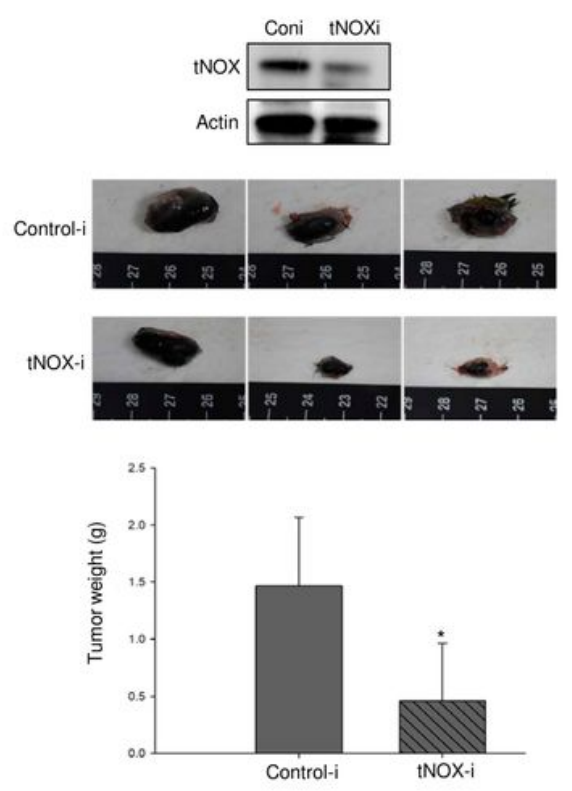

Figure 7

In vivo verification for capsaicin-reduced tNOX and tNOX-depletion suppresses melanoma tumor growth. (A) In a tumor-bearing mouse xenograft model, control mice were intratumorally injected with vehicle buffer and treatment group mice were intratumorally treated with $200 \mu \mathrm{g}$ capsaicin as described in Materials and Methods. The morphology of the tumor tissues excised from tumor-bearing mice (top panel) and quantitative analysis of xenografted tumor volume during the treatment period (bottom panel) are shown. (B) Tissues from two sets of tumor-bearing mice were grounded and prepared for Western blotting analysis. $\beta$-actin was used as an internal control to monitor for equal loading. (C) In another mouse xenograft model, B16F10 cells transfected with either scramble (control-i) or tNOX (tNOX-i) shRNA were subcutaneously injected into mice. The morphology of the tumor tissues excised from tumorbearing mice (top panel) and quantitative analysis of xenografted tumor weights from two sets of mice are shown. 
A
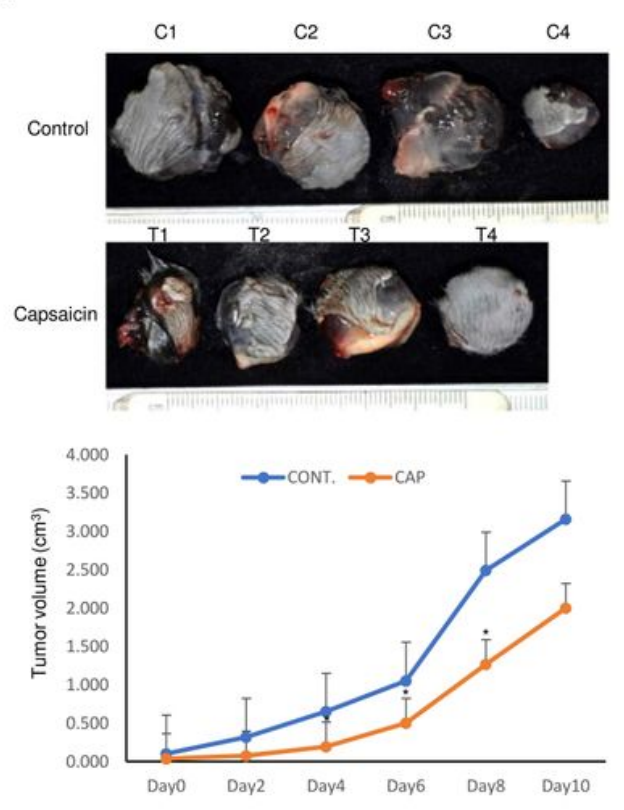

B

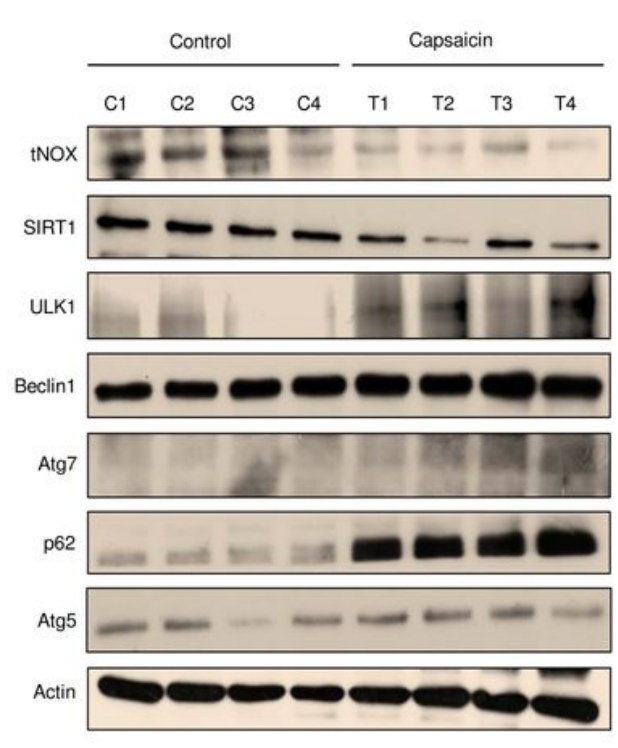

C

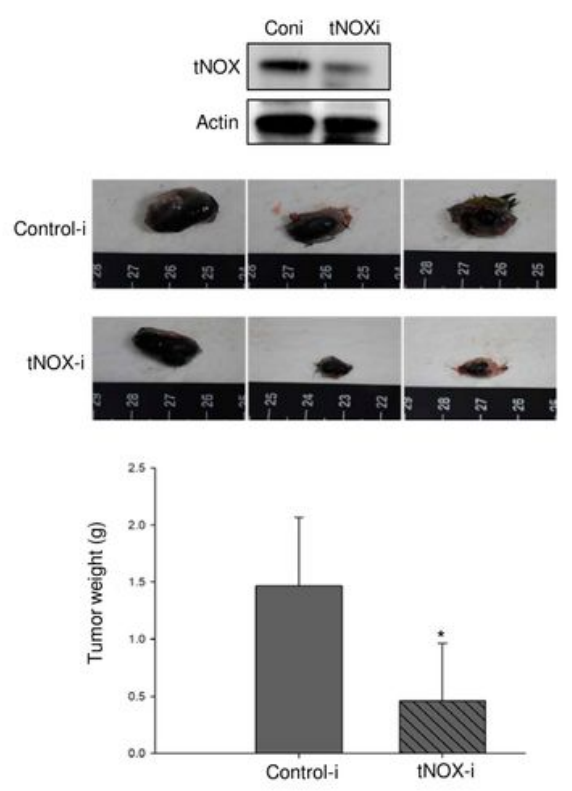

Figure 7

In vivo verification for capsaicin-reduced tNOX and tNOX-depletion suppresses melanoma tumor growth. (A) In a tumor-bearing mouse xenograft model, control mice were intratumorally injected with vehicle buffer and treatment group mice were intratumorally treated with $200 \mu \mathrm{g}$ capsaicin as described in Materials and Methods. The morphology of the tumor tissues excised from tumor-bearing mice (top panel) and quantitative analysis of xenografted tumor volume during the treatment period (bottom panel) are shown. (B) Tissues from two sets of tumor-bearing mice were grounded and prepared for Western blotting analysis. $\beta$-actin was used as an internal control to monitor for equal loading. (C) In another mouse xenograft model, B16F10 cells transfected with either scramble (control-i) or tNOX (tNOX-i) shRNA were subcutaneously injected into mice. The morphology of the tumor tissues excised from tumorbearing mice (top panel) and quantitative analysis of xenografted tumor weights from two sets of mice are shown. 